NBER WORKING PAPER SERIES

\title{
THE UNDER-REPORTING OF TRANSFERS IN HOUSEHOLD SURVEYS: ITS NATURE AND CONSEQUENCES
}

\author{
Bruce D. Meyer \\ Wallace K. C. Mok \\ James X. Sullivan \\ Working Paper 15181 \\ http://www.nber.org/papers/w15181
}

\author{
NATIONAL BUREAU OF ECONOMIC RESEARCH \\ 1050 Massachusetts Avenue \\ Cambridge, MA 02138 \\ July 2009
}

This research was supported in part by the U.S. Social Security Administration through grant \#10-M-98363 -1-01 to the National Bureau of Economic Research as part of the SSA Retirement Research Consortium and by the Economic Research Service of the USDA through Cooperative Research Agreement 58-50006-0106. The findings and conclusions expressed are solely those of the authors and do not represent the views of the SSA, the ERS or any agency of the Federal Government, or the NBER. We thank participants at the Princeton Data Improvement Initiative Conference, the American Economic Association Annual Meetings, the Washington Statistical Society, seminars at the Economic Research Service, the Institute for Social Research and the University of Chicago for their comments, and Stephen Issacson, Karen Peko and the staff at the Food and Nutrition Service, Kevin Stapleton at the Department of Labor, and Steve Heeringa at the PSID Statistical Design Group for help with data. We also thank Richard Bavier, Charles Pierret, Kalman Rupp, Robert Schoeni, and Frank Stafford for their helpful suggestions. The views expressed herein are those of the author(s) and do not necessarily reflect the views of the National Bureau of Economic Research.

NBER working papers are circulated for discussion and comment purposes. They have not been peerreviewed or been subject to the review by the NBER Board of Directors that accompanies official NBER publications.

(C) 2009 by Bruce D. Meyer, Wallace K. C. Mok, and James X. Sullivan. All rights reserved. Short sections of text, not to exceed two paragraphs, may be quoted without explicit permission provided that full credit, including $\odot$ notice, is given to the source. 
The Under-Reporting of Transfers in Household Surveys: Its Nature and Consequences

Bruce D. Meyer, Wallace K. C. Mok, and James X. Sullivan

NBER Working Paper No. 15181

July 2009

JEL No. C42,H53,H55

\begin{abstract}
$\underline{\text { ABSTRACT }}$
High rates of understatement are found for many government transfer programs and in many datasets. This understatement has major implications for our understanding of economic well-being and the effects of transfer programs. We provide estimates of the extent of under-reporting for ten transfer programs in five major nationally representative surveys by comparing reported weighted totals for these programs with totals obtained from government agencies. We also examine imputation procedures and rates. We find increasing under-reporting and imputation over time and sharp differences across programs and surveys. We explore reasons for under-reporting and how under-reporting biases existing studies and suggest corrections.
\end{abstract}

\author{
Bruce D. Meyer \\ Harris School of Public Policy \\ University of Chicago \\ 1155 E. 60th Street \\ Chicago, IL 60637 \\ and NBER \\ bdmeyer@uchicago.edu \\ Wallace K. C. Mok \\ Department of Economics \\ Northwestern University \\ Evanston, IL 60208 \\ k-mok@northwestern.edu
}

\author{
James X. Sullivan \\ Department of Economics \\ and Econometrics \\ 447 Flanner Hall \\ University of Notre Dame \\ Notre Dame, IN 46556 \\ James.X.Sullivan.197@nd.edu
}




\section{Introduction}

Under-reporting of benefit receipt (or misreporting in general) has important consequences for many types of analyses. ${ }^{1}$ First, under-reporting of benefits leads analyses to overstate the dispersion of the income distribution of the entire population or various demographic groups, such as the aged. For example, the official income and poverty report for the U.S. (U.S. Census Bureau 2008) provides such statistics. Second, under-reporting of benefits leads to an understatement of the effect of income transfer programs or taxes on this distribution. ${ }^{2}$ Third, estimates of program takeup — the fraction of those eligible for a program who participate - are biased downward. ${ }^{3}$

This paper provides information on the quality of individual reports of receipt of program benefits for ten large transfer programs in five key household surveys. We calculate the reporting rate - the ratio of weighted survey reports of benefits received to administrative totals for benefits paid out - for a wide range of programs, datasets and years. These reporting rates (when subtracted from one) generally provide a lower bound on the extent of under-reporting. We relate the degree of under-reporting to survey and program characteristics, such as form of interview, type of questionnaire, or potential for stigma. This information is informative for both survey designers and data users. We consider ways our results can be used to correct different types of data analyses. For example, the reporting rates we calculate, under certain circumstances, can be used to make under-reporting adjustments to survey estimates of benefit takeup rates.

The reporting rates that we discuss in this paper count imputed values as reported numbers. The reporting rates would be much lower in many cases if these imputed values were

\footnotetext{
${ }^{1}$ We refer to the subject of the paper as under-reporting rather than measurement error because the main pattern appears to be under-statement of benefits, rather than unbiased but potentially erroneous reporting. We should emphasize that we think of under-reporting as a synonym for under-statement or under-recording, since it is likely due to errors by both interviewers and interviewees.

${ }^{2}$ For example, Jolliffe et al. (2005) examines the effects of the Food Stamp Program on poverty. Engelhardt and Gruber (2006) analyze the effects of social security on poverty and the income distribution. Meyer (2007), U.S. Census (2007) and Scholz, Moffitt and Cowan (2008) analyze the mechanical effects of a wide variety of programs and taxes on features of the income distribution.

${ }^{3}$ For example, Blank and Ruggles (1996) examine the takeup of Aid to Families with Dependent Children (AFDC) and Food Stamps, while McGarry (2002) analyzes the takeup rate for Supplemental Security Income (SSI). A few takeup studies have corrected for under-reporting, such as Bitler, Currie and Scholz (2003) who examine the Women, Infants and Children (WIC) program. Some other studies use administrative data numerators that do not suffer from under-reporting. For surveys of research on takeup, see Remler and Glied (2003) and Currie (2006).
} 
ignored. As a consequence, we also examine imputation rates and procedures, as they are both needed to interpret reporting rates and are an independent measure of data quality. Our results provide an important measure of data quality, but are only part of the picture. ${ }^{4}$

The programs we examine are Unemployment Insurance (UI), Workers' Compensation (WC), Social Security Retirement and Survivors Insurance (OASI) and Social Security Disability Insurance (SSDI), Supplemental Security Income (SSI), the Food Stamp Program (FSP), the Earned Income Tax Credit (EITC), Aid to Families with Dependent Children/Temporary Assistance for Needy Families (AFDC/TANF), the Special Supplemental Nutrition Program for Women, Infants and Children (WIC) program and the National School Lunch Program (NSLP). We calculate reporting rates in five large household surveys that are approximately random samples of the entire civilian non-institutionalized U.S. population. ${ }^{5}$ The surveys are the Current Population Survey - Annual Demographic File/Annual Social and Economic Supplement (CPS), the Survey of Income and Program Participation (SIPP), the Panel Study of Income Dynamics (PSID), the American Community Survey (ACS), and the Consumer Expenditure Interview Survey (CE Survey). We calculate reporting rates and imputation rates for as many years as is feasible. We account for definition and universe differences as well as other data issues.

The datasets that we analyze are among the most important for social science research and government policy. Income numbers from the CPS are the source of the official U.S. poverty rate and income distribution statistics. The SIPP was specifically designed to determine eligibility and receipt of government transfers. The PSID is the main source for information on changes in income and poverty over a lifetime and for changes in income and inequality across generations. ${ }^{6}$ The ACS is the replacement for the Census Long Form data and is the household survey with the largest sample. The CE Survey is the main source of consumption information in the U.S. These datasets are among our most important for analyzing income and its distribution as well as transfer receipt. Thus, the understatement of transfers in these data has major implications for our understanding of the economic circumstances of the population and the effects of government programs.

\footnotetext{
${ }^{4}$ Excellent summaries of data reporting issues in surveys include Moore, Stinson and Welniak (2000), Bound, Brown and Mathiowetz (2001), and Hotz and Scholz (2002).

${ }^{5}$ We only consider surveys that cover the entire U.S. population to facilitate accurate comparisons since administrative data are often not available for all age groups and other characteristics that define certain surveys.

${ }^{6}$ The PSID is also the only survey dataset that allows the longitudinal analysis of the income and consumption of a random sample of the disabled (Stephens 2001; Charles 2003; and Meyer and Mok 2008).
} 
In the next section we begin by describing the various methods that can be used to examine under-reporting. We then describe our methods in detail as well as the statistical framework to interpret how the reported estimates related to underlying true mean values. In Section 3 we describe our main results on dollar and month reporting and provide some comparisons to earlier studies. Section 4 describes imputation methods and the rates at which transfers are imputed. Section 5 discusses caveats to our main results and potential biases. Section 6 discusses characteristics of programs and surveys that may lead to under-reporting and possible lessons from our results. Section 7 describes adjustment methods and examples of how the estimates in the paper may be used. Section 8 concludes. A detailed data appendix provides sufficient information to reproduce our results.

\section{Research Design and Methods}

Past work on the extent of transfer under-reporting has used two approaches. The first approach is the one taken here, the comparison of weighted microdata to administrative aggregates. A second approach compares individual microdata to administrative microdata. ${ }^{7}$ Neither approach has been used on a broad scale. Comparisons to administrative aggregates have been used more widely, but results are only available for a few years, for a few transfer programs and for some of the key datasets. Important papers include Duncan and Hill (1989), Coder and Scoon-Rogers (1996), and Roemer (2000). These papers tend to find substantial under-reporting that varies across programs. Comparisons to administrative microdata are even more limited in the literature. This approach has often been restricted to a single state, year, program and dataset (Taeuber et al. 2004). Examples of studies that examine more than one program (but still a single dataset) include Moore, Marquis and Bogen (1996), Sears and Rupp (2003) and Huynh et al. (2002). ${ }^{8}$

A third way to examine under-reporting is to compare the characteristics of program recipients in administrative and survey data. This approach has been applied to under-reporting in the Food Stamp Program (Meyer and Sullivan 2007a). Intuitively, the differences between the

\footnotetext{
${ }^{7}$ Bound et al. (2001, p. 3741) divide micro level comparisons into several types. We use a simpler categorization here and focus on their "complete record check study" category.

${ }^{8}$ In related work, Card, Hildreth and Shore-Sheppard (2001) examine Medicaid reporting in the SIPP in California for several years.
} 
characteristics of recipients in the two data sources can be used to determine how those characteristics affect reporting. This approach can be used for many datasets and programs and many years, but relies on the survey data and the administrative data representing the same population. Biases in the estimated determinants of reporting could come from imputations, inaccurate weights and false positive reporting (i.e. non-recipients who report receipt) in the survey data.

Our analyses focus on how under-reporting has changed over time and how it differs across programs and datasets. We compare weighted survey data to administrative aggregates because this approach can be used for the widest range of transfer programs, the longest time period and many datasets. We would also like to know how reporting varies with individual characteristics, but matches to microdata have been quite limited in their scope. Furthermore, the use of information from microdata matches is likely to be combined with the aggregate data described here to adjust for changes over time or differences across datasets. This combination of data could be used to extrapolate results from a one-year microdata match to other years.

\section{A. Calculating Reporting Rates}

A dollar reporting rate $\left(\mathrm{RR}_{\mathrm{D}}\right)$ can be defined as the following ratio

$\mathrm{RR}_{\mathrm{D}}=$ dollars reported as received in a survey weighted to predict population totals dollars paid out as reported in an administrative data source

Similarly, one can define a month reporting rate $\left(R_{M}\right)$ as

$\mathrm{RR}_{\mathrm{M}}=\underline{\text { months reported as received in a survey weighted to predict population totals }}$ months paid out as reported in an administrative data source.

The weaknesses of this approach are that it relies on the accuracy of weights and the comparability of sample universes. The approach may understate non-reporting by true recipients because of false positive reporting by non-recipients. We provide some estimates of false positive reporting rates in Section 5. We calculate dollar and month reporting rates for our ten programs for as many individual years as are available for the 
CPS, the SIPP, the ACS, the CE Survey and the PSID. ${ }^{9}$ The benefit programs available by year and respondent type are reported in Appendix Tables 1 and 2 in summary form for the PSID and the CPS, respectively. The remaining datasets are less complicated, but descriptions of the data sources can be found in the Data Appendix. We should note that our approach of examining reporting rates by calendar year will at times mask differences in reporting rates across SIPP survey panels and over time within panels, especially when data from multiple panels are available for the same calendar year.

\section{B. Making the Numerator and Denominator Comparable}

We make a number of adjustments in order to make the administrative and survey data totals comparable. ${ }^{10}$ All of our household surveys include only individuals living in the 50 states and the District of Columbia. Consequently, to maintain comparability, for most programs in most years, we are able to exclude from the administrative totals payments to those in U.S. territories and those outside the U.S. In other cases, we subtract estimates of the share of such payments obtained from years when this information is available. Specifically, we use the dollars paid to those in the U.S. territories (and outside the U.S. in the case of OASI and SSDI) for AFDC/TANF, FS, OASI, SSDI, SSI and UI reported in U.S. Social Security Administration (various years), U.S. Department of Health and Human Services (2008) and U.S Department of Labor (various years). ${ }^{11}$ We also adjust the administrative monthly counts using these data because we do not have other alternatives. For most programs these adjustments are typically small, ranging from $0.02 \%$ (SSI) to about 3\% (SSDI). The notable exception is the Food Stamps Program, where dollars paid to U.S. territories constituted about $10 \%$ of the total prior to $1982 .{ }^{12}$

For some programs (SSI, SSDI, OASI), the institutionalized can receive benefits but such individuals are excluded from all of our survey datasets. ${ }^{13}$ To adjust for this, we rely on data

\footnotetext{
${ }^{9}$ We should emphasize that in some cases one can calculate dollar and month reporting rates for sub-groups using administrative totals for geographic areas or demographic groups defined by characteristics such as age and gender. ${ }^{10}$ A full description of the data sources and methods can be found in the Data Appendix.

${ }^{11}$ Currently, we make no adjustments to the data for WIC, WC, and EITC payments to those in U.S. Territories and outside the U.S.

${ }^{12}$ About $97 \%$ of the U.S. territory payments went to Puerto Rico. Payments to those in Puerto Rico under the Food Stamp Program were replaced in 1982 by a block grant program called the Nutrition Assistance Program.

${ }^{13}$ The institutionalized are included in the 2006 ACS. However, we exclude these individuals from our survey estimates to maintain consistency with the other estimates.
} 
from the Decennial Censuses (which include the institutionalized) and the 2006 ACS to determine the share of dollars that are likely missed in the five surveys. We simply reduce the administrative data totals by the share of Census/ACS dollars that are received by the institutionalized. $^{14}$ Some programs, such as AFDC/TANF cannot be received while institutionalized, but it is possible that some individuals are not institutionalized and receive benefits during the survey's reference period, but then become institutionalized during the survey's sampling period. Currently, we ignore this possibility because we expect it to be infrequent.

Another comparability issue is the possibility that recipients of transfers in the previous year could subsequently die before being interviewed the next year. This is a potential concern because all of the surveys (except for the SIPP) ask about income during the previous year. ${ }^{15}$ Previous studies have adjusted for decedents by applying age, gender and race specific death rates to the data (Roemer 2000). However, if survey weights have previously been calculated to match survey weighted population totals with universe population estimates by age, gender and race then such an adjustment is unwarranted. A case could be made for adjusting the data if these characteristics are nonstationary (but such an adjustment is likely to be small), or if the adjustments were based on additional individual characteristics which are not used to determine weights but are related to death, such as receipt of SSDI or SSI or other programs. Because we do not have this information, we do not adjust for decedents. Consequently, SSDI and SSI reporting ratios are likely to be biased downward somewhat, since recipients likely have a higher mortality rate than the average person of their age, gender and race, and consequently are more likely to miss the interview the following year. ${ }^{16}$

A significant difficulty in several of the datasets is that there are at least some cases where Social Security Disability benefits are combined with Social Security Retirement and Survivors benefits. In these circumstances, we will use the data published in the various issues of the Annual Statistical Supplement to the Social Security Bulletin (U.S. Social Security Administration, various years) to calculate for each year, age, in school status, and gender cell, the proportions of total social security dollars that are paid to OASI and SSDI recipients. We use

\footnotetext{
${ }^{14}$ In 2000 , the share of dollars received by the institutionalized reaches 3.4 percent for OASI and 4.5 percent for SSI.

${ }^{15}$ The CPS and PSID ask about the previous calendar year, while the ACS and CE Survey ask about the previous 12 months.

${ }^{16}$ It might be possible to correct for this potential source of bias with administrative data or data from the PSID.
} 
these proportions to allocate combined SSDI and OASI benefits to the separate programs whenever we have incomplete information about which program was received and whenever a combined amount was reported for the programs. This allocation procedure is used for all OASDI dollars and months in the CPS, ACS, and the CE Survey, and most years in the PSID. ${ }^{17}$ For the SIPP and the PSID (during 1983-1992 and 2003), it applies to a small share of dollars as indicated in section 4 of the Data Appendix.

The PSID sample weights are not appropriate for weighting to the universe in some years. We adjust them in a manner suggested by the PSID staff (see the Data Appendix for more details). Also in the PSID, benefit receipt by family members besides the head and spouse is not recorded in some years. We account for these other family members using estimates of their share from the years when their benefit receipt is available. Finally, we convert fiscal year administrative data to a calendar basis by appropriately weighting the fiscal years.

\section{C. Statistical Framework}

Program reporting can be separated out into a possibly mismeasured binary random variable $R_{i}$ for receipt and a nonnegative random variable for dollars $D_{i}$, or the length of period received, such as months, $\mathrm{M}_{\mathrm{i}}$ conditional on recorded recipiency (these last two variables are taken to be zero when receipt is not recorded). Denote the corresponding correctly measured, but unobserved, random variables $\mathrm{R}_{\mathrm{i}}^{*}, \mathrm{D}_{\mathrm{i}}^{*}$ and $\mathrm{M}_{\mathrm{i}}{ }^{*}$. Recorded dollars and months are $\mathrm{R}_{\mathrm{i}} \mathrm{D}_{\mathrm{i}}$ and $\mathrm{R}_{\mathrm{i}} \mathrm{M}_{\mathrm{i}}$. The expected values of the dollar and month reporting rates can then be written as $E\left[R_{D}\right]=E[R D] / E[R * D *]$, while $E\left[R R_{M}\right]=E[R M] / E[R * M *]$. In the case where a receipt response is available for each month (as is typically true in the SIPP) $E\left[R R_{M}\right]$ has the simpler form $E[R] / E\left[R^{*}\right]$.

In general, we can write

$$
\begin{aligned}
E\left[R R_{D}\right] & =\frac{E[R D]}{E\left[R^{*} D^{*}\right]} \\
& =\frac{\pi\left(1-\pi_{01}\right) E\left[D \mid R=1, R^{*}=1\right]+(1-\pi) \pi_{10} E\left[D \mid R=1, R^{*}=0\right]}{\pi E\left[D^{*} \mid R^{*}=1\right]}
\end{aligned}
$$

\footnotetext{
${ }^{17}$ The procedure is also used in the SIPP when we cannot unequivocally differentiate between SSDI or OASI (e.g. when an individual reports receipt of both).
} 
and

$$
\begin{aligned}
E\left[R R_{M}\right] & =\frac{E[R M]}{E\left[R^{*} M^{*}\right]} \\
& =\frac{\pi\left(1-\pi_{01}\right) E\left[M \mid R=1, R^{*}=1\right]+(1-\pi) \pi_{10} E\left[M \mid R=1, R^{*}=0\right]}{\pi E\left[M^{*} \mid R^{*}=1\right]}
\end{aligned}
$$

where $\pi=\mathrm{E}\left[\mathrm{R}^{*}\right]$ is the probability of true receipt, $\pi_{01}=\mathrm{P}\left[\mathrm{R}=0 \mid \mathrm{R}^{*}=1\right]$ is the probability of not reporting given true receipt (the false negative rate), and $\pi_{10}=\mathrm{P}[\mathrm{R}=1 \mid \mathrm{R} *=0]$ is the probability of reporting receipt given true non-receipt (the false positive rate).

The reporting rates are informative about the false negative rate in several cases that are worth considering. Let $\mathrm{D}_{11}=\left[\mathrm{D} \mid \mathrm{R}=1, \mathrm{R}^{*}=1\right], \mathrm{D}_{10}=\left[\mathrm{D} \mid \mathrm{R}=1, \mathrm{R}^{*}=0\right], \mathrm{M}_{11}=\left[\mathrm{M} \mid \mathrm{R}=1, \mathrm{R}^{*}=1\right]$, and $\mathrm{M}_{10}=\left[\mathrm{M} \mid \mathrm{R}=1, \mathrm{R}^{*}=0\right]$. Suppose there are no false positives $\left(\pi_{10}=0\right)$, and the observed value of $\mathrm{D}$ conditional on recorded receipt is unbiased, i.e. the expected value of $\mathrm{D}$ given $\mathrm{R}=1$ is the true mean (given true receipt), i.e. $\mathrm{D}_{11}=\mathrm{E}\left[\mathrm{D} \mid \mathrm{R}=1, \mathrm{R}^{*}=1\right]=\mathrm{E}\left[\mathrm{D} * \mathrm{R}^{*}=1\right]$. Then, the dollar reporting ratio is an unbiased estimate of $1-\pi_{01}$, i.e. $E\left[R R_{D}\right]=1-\pi_{01}=E\left[R \mid R^{*}=1\right]$. The analogous result for months of receipt is that if $\pi_{10}=0$ and the observed value of $\mathrm{M}$ conditional on recorded receipt is unbiased, then $E\left[R R_{M}\right]=1-\pi_{01}=E\left[R \mid R^{*}=1\right]$. Thus, in this case either $R R_{D}$ or $R R_{M}$ can be used to obtain an unbiased estimate of the probability of not reporting given true receipt. If $\pi_{10}$ does not equal zero (but the other conditions hold), then $R_{D}$ and $R R_{M}$ provide upper bound estimates of the probability of reporting receipt given true receipt, i.e. $E\left[1-R R_{D}\right]>\pi_{01}$ and $E\left[1-R R_{M}\right]>\pi_{01}$. More generally, if $E\left[D \mid R=1, R^{*}=1\right]=E\left[D * \mid R^{*}=1\right]$, we have

$$
\mathrm{E}\left[\mathrm{RR}_{\mathrm{D}}\right]=1-\pi_{01}+\pi_{10}(1-\pi) \mathrm{D}_{10} / \mathrm{E}\left[\mathrm{D} * \mathrm{R}^{*}=1\right] \pi
$$

An analogous formula can be calculated for $E\left[R_{M}\right]$ under similar assumptions. These relationships indicate that we expect that $1-R R_{D}$ will be an underestimate of the probability of not reporting receipt $\pi_{01}$, except if $E\left[D \mid R=1, R^{*}=1\right]<E\left[D^{*} \mid R^{*}=1\right]$ and the difference is sufficient to outweigh the last term on the right hand side of (3). A analogous result applies to $E\left[R R_{M}\right]$.

These equations are also informative regarding the interpretation of the relationship between $R R_{D}$ and $R R_{M}$. In many cases, we will find that the two reporting rates are not that different, so it is useful to consider what might lead to this result. Suppose there are no false positives $\left(\pi_{10}=0\right), \mathrm{D}_{11}=\mathrm{E}[\mathrm{D} * \mid \mathrm{R} *=1]$, and $\mathrm{M}_{11}=\mathrm{E}\left[\mathrm{M} * \mathrm{R}^{*}=1\right]$, then the dollar and month reporting rates will be the same in expectation. More generally, even if dollar and month reporting 
conditional on reported receipt are biased, but biased by the same amount, then dollar and month reporting rates will be equal in expectation. Another important case to consider is one where month reporting is based on a yes or no question (as in the SIPP), so that trivially $\mathrm{M}_{11}=\mathrm{M}_{10}=$ $\left[M^{*} \mid R^{*}=1\right]$. If $R R_{D}$ and $R R_{M}$ are equal, and we are willing to assume $D_{11}=D_{10}$, then we know $\mathrm{D}_{11}=\mathrm{D}_{10}=\mathrm{E}\left[\mathrm{D}^{*} \mid \mathrm{R}^{*}=1\right]$, i.e. dollar amounts are reported correctly on average. Finally, in the case when months come from a question regarding the number of months received, if the two reporting rates are equal and we are willing to assume $\mathrm{D}_{11}=\mathrm{D}_{10}$ and $\mathrm{M}_{11}=\mathrm{M}_{10}$, then either we are estimating dollars and month on average right or we are understating both dollars and months by the same ratio.

\section{Reporting Rate Results}

Table 1 indicates the years and programs available for each dataset when a reporting rate can be calculated. Information on dollars received generally begins in the 1970s on programs in the PSID, CPS and CE Survey. SIPP program information begins generally in 1983, while the ACS is more recent, beginning in 1999. We examine dollar reporting rates for eight programs in the CPS, seven programs in the SIPP, PSID, and CE Survey and five programs in the ACS. Information on monthly participation is more limited. We can calculate reporting rates for seven programs in the PSID, the SIPP and the CPS, and three in the ACS. We could calculate participation for several programs in the CE Survey, but have not done so. In Tables 2 through 10, we report dollar reporting rates for all of the programs except the NSLP. As noted above, it is often hard to separate out OASI and SSDI reporting. We therefore include a table for the combination (Table 4) as well as tables for the separate programs. Each table reports the dollar reporting rates by calendar year. At the bottom, a simple average over all years available is reported for each dataset. Note that the years this average covers differs across surveys.

\section{A. Dollar Reporting Rates}

Table 2 illustrates the AFDC/TANF reporting rates. The results indicate that since 2003, the PSID, CPS and CE Survey have all had years when less than half of 
TANF dollars were recorded. ${ }^{18}$ In the SIPP under sixty percent of dollars have been recorded in several recent years, while over eighty percent of TANF dollars have been captured by the ACS. Reporting rates have fallen over time. The CPS provides perhaps the clearest case. The dollar reporting rate never falls below 0.69 between 1975 and 1990, but it has not exceeded 0.54 since 2000. It should be noted that in the ACS and the CE Survey, the questionnaire asks for "Public Assistance" (or cash assistance) rather than just AFDC/TANF. Respondents may therefore report other non-AFDC/TANF benefits. Most of these other cash benefits are small except for General Assistance (GA). Therefore in the last two columns of Table 2 we also provide ACS and CE Survey reporting rates when we compare the survey reports with the sum of AFDC/TANF and GA administrative totals. When GA is included, the CE Survey accounts for over half of the dollars until 1996, after which the drop in reporting becomes considerably more pronounced. ${ }^{19}$ By 2004, only about a quarter of the dollars are reported in the CE Survey.

Table 3 provides information on Food Stamp Program dollar reporting. In the PSID and the SIPP, approximately eighty percent of Food Stamp dollars are reported, while in the remaining surveys it is closer to 60 percent. There is a noticeable decline in reporting rates in the CPS and the CE Survey. In the case of the PSID, there is a low rate during much of the 1990s, but a recent improvement.

Tables 4 through 6 provide information on OASDI reporting, with the latter two tables dividing this total into disability and retirement benefits. We provide the combined table first, since some imputation is often required to divide benefits into the two programs. The combined numbers in Table 4 indicate that Social Security benefits are recorded well in the surveys, with average reporting rates near ninety percent in all cases. There is also no apparent decline over time in reporting. Retirement benefits in Table 5 are reported well in all datasets. Only about ten percent of benefit dollars seem to be missed. Table 6 indicates that SSDI is particularly well reported in the PSID and the CPS. There appears to be some over-reporting in the PSID, with reporting rates over one

\footnotetext{
${ }^{18}$ The surveys worked to lessen any confusion that occurred with welfare reform. For example, the CPS had interviewers in a given state ask about TANF using the state specific name for the program.

${ }^{19}$ As explained in section $4 \mathrm{~B}$, one reason the reporting rates are lower in the CE Survey and the PSID in some years is that these surveys do not impute income in some years.
} 
for much of the 1970s through 1990s. This over-reporting does not seem to be due to the allocation of OASDI between OASI and SSDI as the rates are similar during the period when the type of benefits was directly recorded (1983-1992). For example, in the years of allocation 1980-1982 the dollar reporting averaged 1.09, while it was 1.03 during the direct report years 1983-1985 that followed. Similarly it was 1.13 in 1990-1992, the last three direct report years, followed by 1.12 over 1993-1995, the first three years after the return to allocation. In the ACS, reporting of SSDI is not quite as good as the other sources, with almost thirty percent of benefits not recorded.

Table 7 provides information on SSI dollar reporting. SSI is reported at a higher rate than AFDC/TANF or FSP, but one-third of dollars are missing in the PSID and onequarter in the CPS. There is little pattern of decline in reporting over time, except in the PSID.

Unemployment insurance dollars, reported in Table 8, indicate somewhat better reporting than for AFDC/TANF, and less evidence of a decline over time, though a fall is still clear in the CPS and the CE Survey. Over seventy percent of dollars are on average reported in the PSID, the SIPP and the CPS, while just over half are reported in the CE Survey. The ACS does not have specific questions about unemployment insurance (it is combined with Veterans' payments, child support and alimony). ${ }^{20}$

Under-reporting is particularly severe for Workers' Compensation, as shown in Table 9. Typically less than half of all WC dollars are recorded in the surveys (again the ACS does not ask specifically about WC). A decline in reporting over time is less evident, except for in the CE Survey and in the PSID after 2000. We should note that, we have included lump sum payments in the administrative totals (see appendix). It has been argued elsewhere that the CPS and the SIPP intend to exclude lump sum payments. It is difficult to see what wording in the questionnaires would lead to this exclusion, and past authors have suggested that lump sums may not be consistently excluded (see Coder and Scoon-Rogers 1996, pp. 15-16, Roemer 2000, pp. 33-34).

\footnotetext{
${ }^{20}$ The PSID UI reporting rate in 2003 is very low, possibly due to the information being collected in the 2005 survey. Individuals may have more difficulty recalling receipt two years ago than one year ago.
} 
Table 10 reports Earned Income Tax Credit payments in the CPS. ${ }^{21}$ CPS reporting rates for the EITC have a different interpretation than those for the other programs. All EITC payments are imputed based on family status, earnings, and income. Therefore under-reporting comes from errors in one of these variables, the imputation process, or noncompliance as discussed in Section 6. The implicit assumption is that all eligible individuals receive the credit, which should lead the approach to overstate receipt. The numbers in Table 10 indicate a reporting rate of about seventy percent overall, and eighty percent in recent years. This result suggests that the types of errors suggested above are quite frequent.

\section{B. Month Reporting Rates}

Tables 11 through 17 report average monthly participation reporting rates for seven programs (FSP, AFDC/TANF, SSI, OASI, SSDI, WIC, and NSLP). Tables 11 and 12, for AFDC/TANF and FSP, respectively, indicate monthly participation reporting rates that are very similar to the corresponding dollar reporting rates in Tables 2 and 3, respectively. In the case of AFDC/TANF the three datasets with both months and dollars indicate reporting rates of 0.53 (months) and 0.44 (dollars) for the PSID, 0.77 (months) and 0.71 (dollars) for the SIPP and 0.65 (months) and 0.62 (dollars) for the CPS. In the case of FSP, the reporting rates are even more similar, with the two types of reporting rates never differing by more than 0.028 for the three datasets. In the case of AFDC/TANF and the FSP, month reporting comes from a mix of direction questions about each month (the SIPP) and questions about the number of months received (the CPS and the PSID). In the case of the SIPP, assuming that the reported monthly benefit of those who are true recipients and those who are not is similar $\left(\mathrm{D}_{11}\right.$ approximately equals $\mathrm{D}_{10}$ ), this result suggests that individuals report about the right amount on average, conditional on reporting. Or, put another way, most of under-reporting consists of not reporting at all, rather than reporting too little conditional on reporting. The dollar reporting rates are slightly lower than the month reporting rates, suggesting that there is a

\footnotetext{
${ }^{21}$ We considered including EITC reporting rates for the SIPP. However, most respondents to the topical module that asks about EITC receipt and amounts refuse to answer the questions, don't answer, or don't know (see Lerman and Mikelson 2004).
} 
small amount of under-reporting dollars conditional on receipt, nevertheless. In the case of the CPS and the PSID, the evidence suggests that total dollars and months are understated by similar amounts, again suggesting that monthly benefits are reported about right on average.

For the programs in Tables 13 through 15 and 17 (OASI, SSDI, SSI and WIC) reporting rates for monthly receipt are similar to dollar reporting rates, but the similarity is not as close as it was for AFDC/TANF and FSP. In the case of these four programs, the surveys besides the SIPP do not report monthly participation, only annual unique participation. Since our administrative numbers are for monthly participation, we use the relationship between average monthly and annual unique participation calculated in the SIPP to adjust the estimates from the other sources. This adjustment step likely induces some error that accounts for the weaker similarity between month and dollar rates. If we just focus on the SIPP, where this adjustment step is not needed, the two rates are much closer and the dollar rate is lower than the month rate, as we saw above.

Table 16 reports average monthly participation reporting rates for the National School Lunch Program (NSLP). In the PSID and CPS, free and reduced price lunches are combined, while in the SIPP we have separate columns for the two types. Reporting seems to be quite low for the PSID at 72 percent, and for the CPS at 55 percent, on average. In the SIPP, on the other hand, more participants are reported than we see in the administrative data. For reduced price lunches, almost fifty percent more participants are reported than actually receive lunches. This result is likely due to our assumptions that all eligible family members (ages 5-18) receive lunches and that they do so for all four months of a given wave.

\section{C. Comparisons to Earlier Studies}

Estimates similar to those reported above are available in previous studies for some surveys for a subset of years and programs. Our estimates are generally comparable to those in these earlier studies, although discrepancies arise that are often due to methodological differences. $^{22}$

\footnotetext{
${ }^{22}$ See Section 5 for a comparison of our results to those from studies of microdata matches.
} 
Coder and Scoon-Rogers (1996) provide reporting rates for five of our programs for 1984 and 1990 for the CPS and the SIPP. Roemer (2000) reports reporting rates for the same five programs for 1990-1996 for the CPS and the SIPP. Our reporting rates differ from Roemer's in a number ways. His reporting rates average about one percentage point higher than our OASDI numbers, likely due to differences in accounting for decedents. His SSI and WC reporting rates are each about five to ten percentage points higher. The SSI difference appears to be due to Roemer's adjustment for the decedents, while the WC difference seems to be due to his exclusion of lump sum payments from the administrative data. Our UI and AFDC/TANF numbers tend to be within a few percentage points, with his UI numbers lower and the AFDC/TANF numbers generally higher than ours. Nevertheless, both our results and Roemer's do suggest a decline in survey quality over time as measured by benefit reporting.

Duncan and Hill (1989) have also studied the extent of benefit under-reporting in the CPS and PSID. They report that in 1979, the CPS accounts for about $69 \%$ of SSI, $77 \%$ of AFDC income, and 91\% of Social Security/Railroad Retirement income. They have also reported that in 1980 , the PSID accounts for about $77 \%$ of AFDC income, $84 \%$ of SSI income and about $85 \%$ of Social Security Income. For Social Security and AFDC, their numbers are quite similar to ours. For SSI, however, our PSID reporting rates are somewhat lower than theirs. This difference might be due to the difference in the re-weighting algorithm employed, and that we do not account for those who receive benefits but die during the survey year. To account for this latter issue, Duncan and Hill adjust the reporting rate up 5 percent.

\section{D. Summary}

Reporting rates for all programs, measured as dollars reported in a household survey divided by administrative reports of dollars of benefits paid out, are in almost all cases considerably below one. Household surveys fail to capture a large share of government transfers received by individuals.

Reporting rates vary sharply across programs. Social Security Old Age and Survivors Insurance (OASI) payments and Social Security Disability (SSDI) payments are reported at a reasonably high rate. Over eighty percent of OASI benefits are reported every year in the Current Population Survey (CPS) and the Survey of Income and 
Program Participation (SIPP) and over seventy percent in the Panel Study of Income Dynamics (PSID). The reporting rates for SSDI tend to be higher. Nevertheless, typically more than ten percent and frequently a higher share of Social Security retirement benefits are not reported.

Reporting rates are especially low for certain programs. Only about fifty percent of Workers' Compensation benefits are reported in the CPS and an even smaller share is reported in the SIPP and the PSID. Reporting rates for AFDC/TANF average below seventy percent in all surveys except the SIPP and the ACS. Average reporting rates for $\mathrm{UI}$ and the FSP range from 55 to 79 percent across surveys. The reporting rate for SSI differs sharply across surveys with over 90 percent reported in the SIPP, but typically under 70 percent in the PSID and the CE Survey.

Surveys differ systematically in their ability to capture benefit receipt. The SIPP typically has the highest reporting rate for government transfers, followed by the CPS and the PSID. There are programs, however, that the other surveys do seem to capture somewhat better. Unemployment Insurance and Workers' Compensation are reported at a slightly higher rate in the CPS than in the SIPP.

\section{E. Regression Estimates}

To summarize and quantify the differences between surveys and programs described above, we estimate a series of regressions with the reporting rate as the dependent variable. Specifically, we estimate equations of the form

$$
\text { (4) } R_{p s t}=\alpha+\sum_{p=1}^{P-1} \alpha_{p} 1_{\{\text {program }=p\}}+\sum_{s=1}^{S-1} \beta_{s} 1_{\{\text {survey }=s\}}+\sum_{t=1}^{T-1} \gamma_{t} 1_{\{\text {year }=t\}}+\varepsilon_{p s t} \text {, }
$$

where $\mathrm{R}_{\mathrm{pst}}$ is the dollar or month reporting rate for program $\mathrm{p}$ in survey $\mathrm{s}$ in year $\mathrm{t}$. We exclude the EITC because it is qualitatively different from the other programs as it is entirely imputed, and the NSLP because the data come in a different form and more imputation is required. We include separate reporting rates for OASI and SSDI, but not the combined reporting rate. We estimate separate equations for dollar and month reporting rates, using the set of programs that is available in each case. The results are reported in Table 18. For AFDC/TANF in the ACS and CE Survey, we include only the reporting rates that account for GA. 
The estimates in columns 1 and 2 indicate that the programs can be ranked by the dollar reporting rate, from best to worst in the following order: SSDI, OASI, SSI, FSP, UI, AFDC/TANF, and WC. Column 3 examines this relationship for recent years, specifically since the year 2000 . The same pattern holds in recent years, OASI is reported better than the base group (SSDI) now. The month reporting rate regressions in columns 4 through 6 are very similar to the dollar reporting rate ones, though we do not have rates for UI and WC.

Estimates of equation 4 also provide a ranking of the different surveys in terms of reporting. One should bear in mind that the dollar reporting rate is only one measure of data quality, and one that can be inflated by false positive reporting or imputation (that may lead to false positive reporting). The estimates suggest that overall dollar reporting is highest in the SIPP and CPS, followed by the ACS, PSID, and CE Survey in that order. This ordering also holds when we examine the patterns after 2000, either by interacting survey with an indicator for the years starting with 2000 (column 2), or by estimating using only data from 2000 forward (column 3). The ordering of the surveys is somewhat different for month reporting rates. Overall, the PSID is slightly better than the CPS, which in turn slightly better than the ACS. All three surveys though, have reporting rates generally well below those of the SIPP. However, the SIPP in part does well because it tends to have the highest imputation rate as we report below, while the CPS has a lower rate, and the PSID an even lower rate yet. Prior to 2004, the CE Survey did not impute income.

We also examine trends in reporting by program and dataset by regressing the dollar and month reporting rates on a constant and a time trend. ${ }^{23}$ The results (which are not in the tables) indicate that most programs in the PSID, CPS and CE Survey show a significant decline in dollar reporting over time, while there is a significant decline in month reporting for most CPS programs. The time trends in reporting in the SIPP and ACS are less pronounced. The exceptions to the general fall in reporting are SSI in the case of the ACS and the SIPP and OASI in the CPS, which have rising reporting rates.

\section{Imputation Methods and Shares}

${ }^{23}$ We estimate OLS, Cocharne-Orcutt, and Prais-Winsten versions of these regressions. 
Reporting rates are only one indicator of survey quality. Rates of survey and item nonresponse are two others. All of the surveys we examine impute answers in some cases of item nonresponse. We describe the methods used to impute these missing values below. We should emphasize that all of the reporting rates we have presented include imputed values in the survey totals. A survey's reporting rate may be high, in part, because a substantial amount of program dollars or months are imputed. In addition, as emphasized in Section 2C, reporting rates are biased upward as a measure of reporting conditional on true receipt if there are false positives. One of the most likely reasons for false positives is recipiency imputation. ${ }^{24}$ Imputed dollars or months conditional on receipt is also likely to induce error. ${ }^{25}$ Surveys may impute recipiency-whether or not a person received a given type of benefit at all—or dollars or months of benefits received conditional on reported or imputed receipt. In this section, we discuss the importance and implications of such imputation in our surveys.

\section{A. Imputation Methods}

For the ACS and the CPS, the strategy employed to impute missing data is known as "Hot-Deck" imputation or "Allocation". Basically, a hot deck is a data table/matrix which stores the values of donor values, stratified by characteristics. Missing data are assigned by using the values from a donor in the hot deck who shares similar demographic and economic background. $^{26}$

For the SIPP, a somewhat more complex algorithm is used to impute missing data. For the 1984-1993 panels, hot-deck imputation is used to impute missing data in each wave of the

\footnotetext{
${ }^{24}$ Clearly an alternative would be to exclude all observations with imputed values and reweight by scaling all weights upward by the inverse of the share of weights of non-imputed observations. However, if item nonresponse is nonrandom, then such a strategy will lead to bias.

${ }^{25}$ Not all types of imputation are necessarily bad. If the appropriate benefit schedule can be determined for an individual and one has the inputs to the formula well measured, the imputations may be more accurate than self reports. However, that is not the way imputation is done for the programs and surveys we examine. Hot deck imputation is the most common method, which likely leads to greater measurement error than self-reports.

${ }^{26}$ It is important to note that the imputation flags in the CPS-ASEC have to be used with caution. Since the CPS$\mathrm{ADF} / \mathrm{ASEC}$ is a supplement to the basic monthly CPS, there are interviewees who responded to the basic CPS survey, but not the ADF/ASEC. The imputation (allocation) flags for these individuals are set to zero (i.e. no allocation) even though data for these individuals are imputed. The variable FL-665 (available in the 1991-2008 surveys) is used to distinguish individuals who participated in the basic survey but not to the ADF/ASEC.
} 
panel. ${ }^{27}$ Beginning in the 1996 panel, however, the Census Bureau began to impute missing data in a wave by using the respondent's data in the previous wave (if available). In this study, we regard such method as a form of imputation. Readers who are interested in how the SIPP imputes missing data can refer to Chapter 4 of U.S. Census Bureau (2001) and Pennell (1993). ${ }^{28}$

To reduce non-response to the income questions, the SIPP began the use of "Dependent Interviewing" in wave 2 of the 2004 panel in which the interviewers use information from the prior wave to tackle item non-response during the actual interview. For instance, in the event of non-response, the interviewer asks "It says here that you received $\$ X$ in the last interview, does that still sound about right for the last 4 months?" Although this method is designed to reduce non-response, Moore (2006) finds that there "is evidence of improper use of dependent follow-up procedures by SIPP interviewers, resulting in very high rates of initial non-response to the wave 2 amount items in the 2004 panel." Our SIPP imputation rates for 2004 are very high, a finding in line with Moore's conclusion.

For the CE Survey, we only include "complete income reporters" and reweight the estimates. Complete income reporters are those who do report at least one major sources of income (such as wages and salaries, self-employment income, social security income). Thus, complete income reporters may have missing income data. For the CE Survey, missing income data are not imputed prior to the 2004 survey. Beginning with the 2004 survey, a regressionbased method is used to impute missing income data. If an individual indicates receipt of a source of income, but does not provide an amount, then his amount is imputed. If a respondent provides no information on income for any sources at the consumer unit level and no member of the consumer unit provides income at the individual level, and no member is imputed to be a worker, then the receipt of transfers (yes/no) is imputed, along with amounts. First, the BLS runs a regression of a type of income on demographic characteristics and a variable that equals the quarterly expenditures of a consumer unit; the data used in this regression come from the valid non-zero reporters. After estimating the regression, the estimated coefficients are perturbed by adding random noise; an estimate is then produced using the resulting coefficients. This process

\footnotetext{
${ }^{27}$ The Census Bureau also provides SIPP "full panel files" for the 1984-1993 panels that link all the waves in a panel together. Additional imputations are implemented in these full panel files.

${ }^{28}$ For those who do not respond to the SIPP interview (person non-response), the imputation flags indicate whether the hot-deck donor is imputed, not the non-responding individual. Thus one has to adjust the imputation flags for these non-respondents (see section 4-13 of U.S. Census Bureau, 2001).
} 
is performed five times in total, yielding five estimates. The imputed value is then the mean of these five estimates. See Fisher (2006) and Paulin et al. (2006) for more details.

Prior to the 1994 survey, the PSID imputed missing income data by using the hot-deck imputation method with the hot deck built using data from previous and current interviews. Beginning with the 1994 survey, however, the PSID ceased imputing missing data.

\section{B. Imputation Shares}

We report CPS, SIPP and ACS imputation shares as a consequence of item nonresponse for various transfer programs. For the PSID and CE Survey we do not have information on imputation shares. We also report total imputation rates for dollars or months that incorporate yes/no and imputation conditional on that yes/no response.

Table 19 reports the share of dollars recorded in the CPS for six of our programs that are imputed. We report both the share of dollars accounted for by observations where recipiency is imputed and the share accounted for by all types of imputation. Typical recipiency imputation shares are on the order of 10 percent, but they are frequently higher. There is substantial variation across program and over time. For most of the years since 2000, recipiency imputation exceeds 20 percent for AFDC/TANF. Imputations rates incorporating all types of imputation are necessarily larger. These rates are typically around 25 percent, but exceed 30 percent for several years for AFDC/TANF, OASDI and WC. In 2008, the imputation shares ranged from 25 percent of UI dollars to 34 percent of social security dollars. Dollar imputation rates incorporating all types of imputation have risen considerably over time, while the trend for recipiency imputation alone is less pronounced.

Table 20 reports the share of months that are imputed in the CPS for four of our programs. The numbers are similar to those for dollars for both recipiency imputations and all imputations. We should emphasize that the all imputation numbers for OASDI and SSI are analogous to the recipiency imputations in Table 19, as months for these two programs are not directly reported in the CPS and are calculated using averages based on the SIPP. In recent years, at least ten percent of months are imputed in the CPS for all four programs. Imputation rates were comparable across programs in the early 1990s, but rates for AFDC/TANF and the FSP have risen more noticeably over time. 
Table 21 reports the share of dollars imputed in the SIPP for six of our programs. In recent years for all of the programs at least ten percent of dollars are attributed to those for whom recipiency is imputed, with twenty percent typical for UI and approximately 40 percent typical for WC. The shares of dollars for all types of imputations are much higher, at least twenty percent for all six programs in recent years. It is not uncommon for these rates to exceed thirty percent in recent years. Imputation rates rise sharply over time in the SIPP, as they are less than 10 percent for recipiency in five of the six programs in 1990. Overall, the SIPP has higher imputation rates than the CPS. This difference needs to be taken into account when comparing reporting rates and other measures of data quality across surveys.

Table 22 reports the share of months imputed in the SIPP for four of the programs. Shares are sometimes below ten percent, but are more typically between ten and twenty percent. OASDI tends to have the lowest imputation shares. The shares have generally risen over time. Table 23 reports dollar imputation shares for the ACS. The shares always exceed ten percent and are fairly similar across programs.

As we did with reporting rates, we have also regressed imputation shares on a constant and a time trend. Dollar imputation rates rise significantly for all programs in the CPS and SIPP and month imputation rates rise significantly in most cases.

\section{Caveats and Biases}

Some caveats are in order. First, the reporting of benefit receipt certainly contains some individuals who mistakenly report receipt despite not receiving benefits. As with previous research, we include imputed values in our survey totals. Even if not for other reasons, due to imputed observations benefit receipt will be recorded for some people who do not truly receive transfers. As discussed in Section $2 \mathrm{C}$, false positive reporting of receipt $\left(\pi_{10}>0\right)$ likely implies that the fraction of dollars received by true recipients is strictly less than the calculated reporting rates, i.e. our reporting rates if applied to true recipients are biased upward. Results from matches of survey microdata to administrative microdata provide evidence on the extent of such false positives. In Table 24 we examine reporting rates analogous to ours from several studies that use matched 
data. Column 1 reports the month reporting rate conditional on true receipt, while column 2 reports the unconditional reporting rate that is analogous to our reporting rates. The difference between these two columns is the false positive rate. Note that the numbers in column 1 are lower than those in column 2. In most cases the difference is not more than 0.1. In some cases, however, the rates are substantial, such as for UI, WC and SSI.

Second, in the situation where we have incomplete information about the type of social security received, we apply the OASI and SSDI dollar proportions to determine participation in these programs. A more desirable method would calculate these proportions based on participation rather than dollars. Applying these proportions essentially assumes that an individual can only receive benefits from either SSDI or OASI, but not both, in a particular year. Strictly speaking, individuals can receive benefits from both programs in a year, most commonly those whose SSDI benefit switches automatically to OASI when they reach retirement age. This issue leads to a bias downward in our social security retirement and disability participation estimates.

Third, in certain years of the PSID we do not have information about benefit receipt of non-head and non-spouse family members. Although we have attempted to alleviate this issue by using the share of total benefits received by these non-head, non-spouse family members in other years and scaling up the aggregates accordingly, such methods assume that these shares are relatively stable over time. Fourth, adults may receive social security and SSI benefits on behalf of their children. Since administrative data are based on awardees, calculating weighted total benefits based on payees rather than awardees may introduce biases. Unfortunately, most of the household surveys provide little information about exactly who is the true awardee of the benefit. ${ }^{29}$ Fifth, it is important to emphasize that our survey totals do not include the institutionalized or decedents, although as explained in Section 2.B, we adjust these totals for the former for SSI, SSDI, and OASI.

We should also note that the validity of these comparisons depends on unbiased survey weights. ${ }^{30}$ The weights are based on the Census of Population, so an argument about underweighting is essentially an argument about individuals being missed in the Census count.

\footnotetext{
${ }^{29}$ The SIPP, however, does provide some information about who is the true awardee of Social Security benefits.

${ }^{30}$ As a check, for each survey and year, we have confirmed that our weighted population totals are close to Census population estimates.
} 
Unfortunately, we have no estimates of the undercount for the populations receiving transfer income. In 1990 for example, estimates are only available for broader groups such as non-blacks and blacks, women and men, renters and owners, those in large urbanized areas and those in other areas, and by age (and some cross-classifications of these groups). ${ }^{31}$ Overall estimates of the 1990 undercount are fairly low, in the range of two percent. Estimates are higher for blacks and renters, but lower for women, especially women of childbearing age.

We are also encouraged that errors in the weights are not a substantial source of bias because the reporting rates are fairly similar to rates based on comparisons to administrative microdata, in the few cases where such comparisons are available. Column 2 of Table 24 reports reporting rates based on microdata comparisons, while column 3 reports numbers from our tables that are based on comparisons of aggregates usually for the same year (but not the same months or states). ${ }^{32}$ The 1984 SIPP estimates from Marquis and Moore (1990) indicate that microdata based reporting rates are similar to ours based on aggregates. ${ }^{33}$ The same is true for the other studies, except for SSI for two years in one of the studies. ${ }^{34}$ The estimates from the microdata match studies are often quite close to our numbers, and do not show a pronounced tendency to be lower. Our reporting rates based on aggregates are particularly close (or higher) for FSP and TANF, the programs most targeted to the poor, the group that might be most plausibly underweighted or under-represented. That these reporting ratios in matched administrative and survey data are comparable to our main estimates suggests that weighting is not a substantial source of bias.

\footnotetext{
${ }^{31}$ See Hogan (1993) and Robinson et al. (1993) for 1990 Census undercount estimates.

${ }^{32}$ In some cases we must substitute dollar for month reporting rates.

${ }^{33}$ There is a large difference for WC, but this may be due, in part, to the fact that for WC and UI, our estimates are based on dollars reported because months are not available, while the microdata estimates are based on months reported.

${ }^{34}$ In the case of Huynh et al. (2002) and Sears and Rupp (2003) another source of noncomparability between columns 2 and 3 is that the administrative microdata behind column 2 exclude those under 18 (who may be especially likely to not report receipt), while the survey data behind column 3 include those under 18.
} 


\section{Reasons for Under-reporting}

The reasons for benefit receipt under-reporting in household surveys have been catalogued by several authors. ${ }^{35}$ Interviewees may forget receipt or confuse the names of programs. They may misremember the timing of receipt or who are the true recipients of a program within a family. Errors may be due to a desire to reduce interview burden, the stigma of program participation, or the sensitivity of income information. Survey and interviewer characteristics such as the interview mode (in person or by phone), respondent type (self or proxy) may matter for the degree of under-reporting. Information on the extent of underreporting, how it varies across programs, surveys and time should be informative about the plausibility of different explanations for under-reporting. For example, comparisons of programs with different degrees of stigma, and surveys with different question timing and wording, should shed some light on the reasons for mis-reporting.

The different explanations for under-reporting suggest different approaches to improve reporting. If the pattern of mis-reporting seems most consistent with recall biases, then changing the timing of the questions relative to the period of receipt may be warranted. If interviewee time burden seems to be the explanation, then the length of the interview may need to be altered. If the stigma of program participation is a major issue, then a focus on question wording and the way interviewers ask the questions may be warranted. The results could also suggest that some dollar items should be calculated based on reported receipt and demographic characteristics, or that respondents should be encouraged to obtain check stubs. Some items could also be obtained through matching to administrative data.

\section{A. Differences Across Programs}

A standard explanation of under-reporting is the stigma of reporting receipt of "welfare" programs, and the inclination to give "socially desirable" answers (Sudman and Bradburn 1974). This explanation is consistent with the low reporting rates of four of the programs most associated with "welfare" or idleness, AFDC/TANF, the FSP, UI and WIC. There has been a noticeable decline over time in AFDC/TANF and food stamp reporting, which is broadly

\footnotetext{
${ }^{35}$ Marquis and Moore (1990) provide nice examples for the SIPP, while Bound, Brown and Mathiowetz (2001) and Groves (2004) provide more general discussions.
} 
consistent with the stigma explanation as the stigma associated with these programs has arguably risen over time. ${ }^{36}$ However, some of the patterns of reporting by program do not fit with a stigma explanation for under-reporting. Workers' Compensation has the lowest reporting rate but is presumably not a program that greatly stigmatizes its recipients, given that the program is for those injured while working.

A second common explanation for under-reporting is that respondents forget that they receive transfers. Benefits that an individual regularly receives or that account for a substantial fraction of total resources are arguably easier to recall. An example of such a program is OASI, which is often continuously received for many years and may be the only major source of income for many recipients. OASI is reported at a high rate, generally above eighty percent and often higher. By contrast, TANF benefit receipt is much more likely to be sporadic and potentially harder to recall. With the reform of welfare in the mid-1990s the typical time on welfare fell and the likelihood of return to the rolls decreased (U.S. House of Representatives 2004). Reporting rates seem to have fallen at roughly the same time, though the PSID drop seems to precede welfare reform. Receipt of FSP also tends to be more sporadic than OASI, but the pattern of receipt has not changed as much as that of TANF. FSP reporting has dropped in recent years in the PSID and the CPS, and the decline has been less pronounced than for TANF, providing additional evidence that the regularity of receipt affects reporting.

How familiar an interviewer is with a particular program and how common it is to receive it might also affect reporting because the ability of the interviewer to infer receipt might affect the extent to which they probe respondents about particular programs. Workers' Compensation is received by a small fraction of the population and has the lowest reporting rate. Workers' Compensation may also be the program of which the general public has the least knowledge. It may also be hard for an interviewer to guess that a given person is a recipient and probe further when asking the questions about receipt of Workers' Compensation. By contrast, an interviewer will know that anyone 65 or older is likely to be an OASI recipient.

Another explanation for under-reporting for a given program is that its name may be confused with that of another program for which the benefits are reported instead. TANF benefits might be reported as general assistance payments, OASI, SSDI, and SSI might be

\footnotetext{
${ }^{36}$ Opinion surveys provide some evidence of increased stigma. Data from the General Social Survey show that more than 40 percent of respondents report that spending on welfare is too high in the U.S., and this fraction increased sharply starting in 1993 (Scholz and Levine 2001).
} 
confused, or SSDI and Workers' Compensation might be confused. The surveys employ various techniques to avoid this problem, such as asking specifically about the color of checks received in the case of the PSID. We should also note that the reporting rate for SSDI in the PSID is not noticeably different whether we impute the division of OASDI into OASI and SSDI or whether we use self reports. ${ }^{37}$ It is plausible that the recent changes in the names of state and federal welfare programs might have confused respondents into saying that they were not receiving TANF, but other welfare instead. However, the reporting rate for a broader welfare measure that combines TANF and general assistance tends to be lower than that for TANF alone in most survey years, suggesting that such confusion is not responsible for the low reporting rates.

We also find the puzzling result that the EITC is sharply under-imputed in the CPS. This result suggests a problem with survey misreporting of earnings or children, or tax noncompliance.

\section{B. Differences Across Surveys}

The finding that the SIPP has higher program reporting rates than the other surveys is consistent with the focus of the survey on program participation. Conversely, it is not surprising that the CE Survey has low program reporting rates given the focus of the survey on collecting detailed consumption data. Nevertheless, the survey characteristics and methods that lead to high or low reporting merit exploration. The SIPP has the most detailed questions about program receipt. ${ }^{38}$ The surveys differ across many dimensions as is indicated in Appendix Table 3 which summarizes the survey characteristics including frequency, target population, and recall period. Given the many differences, it may be difficult to isolate the effect of a given characteristic. The recall period is the previous four months for the SIPP, the calendar year for the PSID and CPS, and the previous twelve months for the ACS and CE Survey. The only survey for which interviewees are legally required to respond is the ACS, possibly accounting for its high reporting rate for TANF and some other programs. The PSID is the only survey which provides monetary compensation to respondents. Most surveys use a combination of phone and in-person interviewing, while the ACS also relies on mail back responses and the CE Survey uses only in-person interviewing.

\footnotetext{
${ }^{37}$ We impute based on the interaction of demographics and year as described in the Appendix.

38 Though Czajka and Denmead (2008) observe that a small number of questions sometimes seem to do a good job of measuring mean income.
} 
Changes in survey procedures over time potentially provide evidence on reasons for under-reporting. Evidence on respondent recall biases comes from the PSID, which moved to asking about FSP and SSI benefits received two years earlier rather than one year earlier for odd numbered years starting in 1997 (2003 for TANF, UI and WC; see Appendix Table 1). The longer recall period seems to have resulted in a decrease in reporting, as the dollar reporting rate is lower in each odd numbered year than the following even numbered year (except 2003-2004 for FSP and 1997-1998 and 1999-2000 for SSI).

Reduction or elimination of in-person interviewing seems to have little effect on reporting rates. For example, reporting rates do not change much after the 1996 reduction of inperson interviewing in the SIPP. This result is consistent with the Groves (2004) observation that there is no robust evidence of a difference in errors between in-person and phone interviewing. An exception may be the sharp fall in AFDC reporting in the PSID after the move to telephone interviewing in 1973 (1972 income). There is some evidence from the PSID and the CPS that a change to CATI/CAPI decreases reporting. In the case of the SIPP, however, there does not appear to be a fall in reporting that coincides with the introduction of CATI/CAPI. These analyses are complicated by simultaneous changes in the questionnaire in the cases of both the PSID and the CPS.

We examine the effects of survey changes on reporting rates more directly with a number of different regression specifications (the results of these analyses are not reported but are available upon request), focusing on survey years without multiple contemporaneous changes. For example, we study the effect of explicitly mentioning the name of a program on the reporting accuracy for that program. Beginning in the 1978 PSID survey, for some programs the interviewer mentions the name of the program when asking about the amount of dollars received by the non-head non-spouse family members. ${ }^{39}$ Using a regression discontinuity framework, our estimates of the effect of this change on reporting are small and not statistically significant. ${ }^{40}$

\footnotetext{
${ }^{39}$ In the other years, the interviewer asks the interviewee to recall what types of income were received. OASDI is explicitly asked starting in 1978 and AFDC starting in 1984. Starting in 1985 WC is explicitly asked, but we do not focus on this change because there were other survey changes implemented in 1985 .

${ }^{40}$ Specifically, we regress the reporting rate of a program on a constant, a time trend, time trend interacted with the post-change period, and a post-change period indicator variable. The coefficient of interest is that of the postchange indicator variable. We use only the 10 years of data surrounding the change. We correct for autocorrelation using the Prais-Winsten method.
} 
The estimated effects are also jointly statistically insignificant. ${ }^{41}$ These results suggest that imperfect recipiency recall may not be a strong reason for under-reporting. Another survey change we examine is the addition of bracketed responses. Starting in 2001, when a specific amount is not provided, the CE Survey asks interviewees whether the amount falls within certain ranges. There is some evidence that this change increased the reporting rates of TANF and SSI (by 5 and 23 percentage points respectively), while it decreased the reporting rate of OASI (by 9 percentage points). These estimated changes are jointly significant at the 1 percent level.

\section{Some Adjustment Methods}

Reporting rates calculated as above can be used to adjust existing data analyses. In particular, the reporting rates we provide can be used to adjust estimated program effects on the income distribution as well as estimates of program takeup. A takeup rate is typically measured as the fraction of eligible individuals or families that receive a given transfer. A conservative adjustment to the typical takeup rate can be obtained by multiplying the takeup rate by the inverse of the reporting probability. For example, Blank and Ruggles (1996) examine the Food Stamp takeup rate in SIPP during 1986-1987. Their reported takeup rate is 0.52. Since our average monthly participation reporting rate for these years averages 0.876 , an adjusted takeup rate for this period is $0.52 / 0.876=0.59$. This adjustment is likely conservative because our reporting rate is likely to be too high because some true non-recipients report receipt. While false positives could bias the takeup rate upward, we are implicitly assuming that the eligibility calculations and the likely exclusion of imputed observations imply that there are few false positives in the original analysis.

Other adjustments are possible in more complicated situations. When estimating the effect of a program on the income of a group, one can consider scaling up benefit receipt by one over the dollar reporting rate. As long as non-reporting recipients have the same distribution of characteristics as reporting recipients (where the set of characteristics is those that are used as conditioning variables), the approach is unbiased. One application is to scale up benefits for the group of potential recipients. If there are no false positives from outside the group of potential recipients, then scaling by the inverse of the dollar reporting rate provides the amount of program

\footnotetext{
${ }^{41}$ We replace the after variable by after* program interactions in the regression and perform an F-test of whether all the after*program interaction coefficients are zero. The test statistic has a p-value of 0.25 .
} 
benefits received by potential recipients. If there are false positives from outside the group, then the rescaling is a downward biased estimate of benefits received by the group. An example of such an adjustment in the case of UI, FSP, WC, AFDC/TANF, SSI, SSDI and OASI is Meyer and Mok (2008). Other studies have assumed that under-reporting is constant in proportional terms across deciles or quintiles of the income distribution. Examples of adjustments based on this assumption can be found for the FSP and AFDC/TANF in Primus et al. (1999) and for unemployment insurance in Anderson and Meyer (2006).

However, in many analyses of income distributions or the distributional effects of transfers, it will be difficult to adjust the analyses for under-reporting using aggregate reporting rates. One often needs to know exactly who under-reported, and by how much. An example of the difficulties of trying to make such an adjustment can be found in Meyer and Sullivan (2006) for the case of Food Stamps and AFDC/TANF in the CE Survey.

A type of analysis that might be particularly sensitive to under-reporting is analyses of the probability that a member of a disadvantage population neither works nor receives welfare. Blank and Kovak (2008) recently found a rise in the share of single mothers who are neither working nor receiving welfare; these women are referred to as "disconnected single mothers." Blank and Kovak estimate that the among low-income single mothers (defined as those with family income below $200 \%$ of the poverty line), the fraction who are disconnected single mothers has risen from $18.8 \%$ in 1990 to $24.9 \%$ in 2003 using the SIPP, and from $9.9 \%$ in 1990 to $20.0 \%$ in 2005 using the $\mathrm{CPS} .^{42}$

We use our reporting rates to reexamine the estimates reported in Blank and Kovak (2008). Given that they rely on the reported fraction of poor single mothers who are not working and not receiving welfare, their rate may be overstated as some of those who receive welfare do not report it. Under fairly reasonable assumptions, ${ }^{43}$ the Blank and Kovak estimate is overstated by $\mathrm{k}(1-\mathrm{y}) / \mathrm{y}$, where $\mathrm{k}$ is the observed probability of not working and receiving welfare (among

\footnotetext{
${ }^{42}$ Blank and Kovak (2008) define disconnected single mothers in the CPS as those who did not receive welfare and did not have earnings in the calendar year, while in the SIPP they consider welfare recipiency and earnings in a month. Thus the CPS rates are considerably lower than those obtained in the SIPP.

${ }^{43} \mathrm{We}$ assume 1) there is no failure to report work, and 2) true welfare recipients who work are as likely to fail to report receipt as those who do not work. The first assumption biases us towards a higher rate of disconnected single mothers. We motivate the second assumption by considering that welfare recipients who work may be more willing to report due to lower stigma, but yet the amount of AFDC/TANF they receive may be too small for them to bother reporting. Also, interviewers may be less likely to probe for welfare information if the individual is working. These opposing forces may imply similar average reporting rates between those who work and those who do not.
} 
poor single mothers) and $\mathrm{y}$ is the AFDC/TANF month reporting rate of the corresponding year. ${ }^{44}$ Using this adjustment factor, we adjust the Blank and Kovak estimates.

Table 25 reports our results. Panels A and B report the results for the SIPP and the CPS respectively. In column 1 of each panel, the estimates from Blank and Kovak (2008) are shown. Column 2 reports the adjustment factor and column 3 reports the adjusted fraction of disconnected single mothers. Accounting for under-reporting, we see that the fraction of disconnected single mothers is somewhat lower than that reported by Blank and Kovak (2008). In 1990, Blank and Kovak (2008) suggest that disconnected single mothers constitute 19\% and $10 \%$ of the poor single mothers population in the SIPP and the CPS respectively. After correcting for under-reporting, these fractions drop to $10 \%$ and $2 \%$ for the SIPP and the CPS respectively. Nevertheless, Blank and Kovak's finding that the fraction of single mothers who are disconnected has risen is still evident in our adjusted numbers. In fact, after correcting for under-reporting, the rise in the disconnected single mothers population is more serious than what Blank and Kovak suggest — between 1990-2005 the adjusted numbers suggest that the fraction of disconnected single mothers has doubled in the SIPP and risen by a factor of eight in the CPS.

\section{Conclusions and Extensions}

We provide estimates of the extent of under-reporting of dollars and months of participation for ten large transfer programs in five major household surveys. We find that under-reporting is common and has increased over time. Less than half of Workers' Compensation benefits are typically reported, and only about two-thirds of Food Stamp Program, TANF, WIC and Unemployment Insurance benefits are commonly reported. Three-quarters of SSI benefits and a much larger share of SSDI and OASI benefits tend to be recorded. There is substantial variation across surveys, with the CE Survey typically having the lowest reporting rate and the SIPP having the highest rate for most programs.

\footnotetext{
${ }^{44}$ Formally, consider a single mother who is either working $(\mathrm{W})$ or not working $(\mathrm{NW})$, and who either receives or does not receive welfare (B and NB), and who either reports or does not report welfare recipiency (R and NR). This situation yields eight possibilities. Blank and Kovak (2008) estimate the observed fraction of poor single mothers who are not working and not receiving welfare, which is equivalent to the sum of Prob(NW $\cap \mathrm{NB} \cap \mathrm{NR})$ and Prob(NW $\cap \mathrm{B} \cap \mathrm{NR}$ ). Assuming no false positives, the true fraction of disconnected single mothers should only be Prob(NW $\cap$ NB $\cap$ NR), thus the Blank and Kovak's estimate is overstated by Prob (NW $\cap \mathrm{B} \cap \mathrm{NR})$.
} 
Over time, the reporting of many programs in the surveys has sharply deteriorated. We have also seen a noticeable rise in the share of responses that are imputed. This rise in imputation and under-reporting is part of an overall pattern of decline in the quality of data from U.S. household surveys. Other papers have shown a rise in survey nonresponse and item nonresponse and a drop relative to alternative sources (Atrostic et al. 2001, Meyer and Sullivan 2007b, 2009).

The patterns of under-reporting that we find do not seem to be consistent with a simple story of stigma or the sensitivity of income reporting. While these reasons are plausible explanations for the low FSP and TANF reporting rates, they cannot explain the very low WC reporting rate. We suspect that other factors, including continuity of receipt, the ease of reporting, the survey structure, and a desire to reduce the length of interviews play a large part in determining the degree of under-reporting.

We have also shown how our estimates can be used to correct the findings of recent studies. We can extend these results by calculating aggregate based reporting rates for demographic groups, regions or states to make more refined adjustments. Ideally one would also use microdata to match these surveys to program data. It would be useful to analyze such matches to understand how mis-reporting varies with respondent and interviewer characteristics, and to assess the extent of false positive reporting by nonrecipients to better adjust studies of the effects of transfer programs. 


\section{$\underline{\text { References }}$}

Anderson, Patricia M. and Bruce D. Meyer. 2006. "Unemployment Insurance Tax Burdens and Benefits: Funding Family Leave and Reforming the Payroll Tax," National Tax Journal, 77-95.

Atrostic, B. K, Nancy Bates, Geraldine Burt, and Adrian Silberstein. 2001. "Nonresponse in U.S. Government Household Surveys: Consistent Measures, Recent Trends, and New Insights," Journal of Official Statistics, 17:209-226.

Bitler, M., J. Currie and J. K. Scholz. 2003. "WIC Eligibility and Participation," Journal of Human Resources, 38:S, 1139-1179.

Blank, Rebecca M. and Brian Kovak. 2008. "The Growing Problem of Disconnected Single Mothers," National Poverty Center Working Paper \#07-28.

Blank, Rebecca M. and Patricia Ruggles (1996): "When Do Women Use AFDC \& Food Stamps? The Dynamics of Eligibility vs. Participation," Journal of Human Resources 31 , 57-89.

Bollinger, Christopher and Martin David (1997). "Modeling Discrete Choice with Response Error: Food Stamp Participation." Journal of the American Statistical Association, 92 (439) pp. 827-835.

Bollinger, Christopher and Martin David (2001), Estimation with Response Error and Nonresponse: Food-Stamp Participation in the SIPP, Journal of Business and Economic Statistics, 19:2, 129-141.

Bound, John, Charles Brown, and Nancy Mathiowetz (2001), "Measurement Error in Survey Data," in Handbook of Econometrics. Volume 5, ed. by J.J Heckman and E. Leamer. Elsevier: Amsterdam.

Card, David, Andrew K.G. Hildreth and Lara D. Shore-Sheppard (2001), "The Measurement of Medicaid Coverage in the SIPP: Evidence from California 1990-1996" NBER Working Paper 8514.

Charles, Kerwin K. 2003. "The Longitudinal Structure of Earnings Losses among Work-Limited Disabled Workers." Journal of Human Resources 38(3): 619-46

Coder, John and Lydia Scoon-Rogers. 1996. "Evaluating the Quality of Income Data Collected in the Annual Supplement to the March Current Population Survey and the Survey of Income and Program Participation," Housing and Household Economic Statistics Division, Bureau of the Census.

Currie, Janet. 2006. "The Take-up of Social Benefits," in Alan J. Auterbach, David Card, and john M. Quigley, eds. Public Policy and the Income Distribution, Russell Sage Foundation: New York.

Czajka, John L. and Gabrielle Denmead. 2008. "Income Data for Policy Analysis: A Comparative Assessment of Eight Surveys," Mathematica Policy Research.

Doyle, Pat, Betsy Martin and Jeff Moore. 2000. "The Survey of Income and Program Participation (SIPP) Methods Panel Improving Income Measurement." The Survey of Income and Program Participation Working Paper No. 234.

Duncan, Greg J. and Daniel H. Hill. 1989. “Assessing the Quality of Household Panel Data: The Case of the Panel Study of Income Dynamics." Journal of Business and Economic Statistics, 441-52. 
Engelhardt, Gary and Jon Gruber. 2006. "Social Security and the Evolution of Elderly Poverty," in Alan J. Auterbach, David Card, and john M. Quigley, eds. Public Policy and the Income Distribution, Russell Sage Foundation: New York.

Fisher, Jonathan D. 2006. "Income Imputation and the Analysis of Consumer Expenditure Data." Monthly Labor Review, November 2006: 11-17.

Groves, Robert M. 2004. Survey Errors and Survey Costs. Hoboken, NJ: John Wiley \& Sons.

Hogan, Howard. 1993. "The 1990 Post-Enumeration Survey: Operations and Results.” Journal of the American Statistical Association 88(3): 1047-1060.

Hotz, V. Joseph and John Karl Scholz. 2002. "Measuring Employment and Income for LowIncome Populations With Administrative and Survey Data." In Studies of Welfare Populations: Data Collection and Research Issues, eds. Michele Ver Ploeg, Robert A. Moffitt, and Constance F. Citro, 275-313. Washington, DC: National Academy Press.

Huynh, Minh, Kalman Rupp, and James Sears. 2002. "The Assessment of Survey of Income and Program Participation (SIPP) Benefit Data using Longitudinal Administrative Records." Social Security Administration.

Joint Economic Committee Democrats. 2004. "Reduction in Poverty Significantly Greater in the 1990s than Official Estimates Suggest," Policy Brief, August.

Jolliffe, Dean, Craig Gundersen, Laura Tiehen, and Joshua Winicki (2005). "Food Stamp Benefits and Child Poverty," American Journal of Agricultural Economics, August, 569581.

Lerman, Robert I. and Kelly S. Mikelson, 2004. "Examining the Relationship between the EITC and Food Stamp Program Participation Among Households with Children,” Working Paper, American University.

Marquis, Kent H. and Jeffrey C. Moore. 1990. "Measurement Errors in SIPP Program Reports." In Proceedings of the 1990 Annual Research Conference, 721-745. Washington, DC.: U.S. Bureau of the Census.

McGarry, Kathleen. 2002. "Guaranteed Income: SSI and the Well Being of the Elderly Poor," in The Distributional Aspects of Social Security and Social Security Reform, ed. by Martin Feldstein and Jeffrey B. Liebman, Chicago: University of Chicago Press, 2002.

Meyer, Bruce D. 2007. "The U.S. Earned Income Tax Credit, its Effects, and Possible Reforms," Swedish Economic Policy Review 14: 55-80.

Meyer, Bruce D. and Wallace K.C. Mok. 2008. "Disability, Earnings, Income and Consumption." Manuscript, University of Chicago.

Meyer, Bruce D. and James X. Sullivan. 2003. "Measuring the Well-Being of the Poor Using Income and Consumption." Journal of Human Resources, 38(Supplement): 1180-1220.

Meyer, Bruce D. and James X. Sullivan. 2006. "Consumption, Income and Material Well-Being After Welfare Reform.” NBER Working Paper 11976.

Meyer, Bruce D. and James X. Sullivan. 2007a. "Reporting Bias in Studies of the Food Stamp Program." Unpublished manuscript.

Meyer, Bruce D. and James X. Sullivan. 2007b. "Further Results on Measuring the Well-Being of the Poor Using Income and Consumption," NBER Working Paper 13413.

Meyer, Bruce D. and James X. Sullivan. 2009. "Five Decades of Consumption and Income Poverty," NBER Working Paper 14827, March.

Moore, Jeffrey C., Kent H. Marquis, and Karen Bogen. 1996. "The SIPP Cognitive Research Evaluation Experiment: Basic Results and Documentation." The Survey of Income and Program Participation, Working Paper No. 212. Washington D.C.: U.S. Census Bureau. 
Moore, Jeffrey C. 2006. "The Effects of Questionnaire Design Changes on General Income Amount Nonresponse in Waves 1 and 2 of the 2004 SIPP Panel." Research Report Series (Survey Methodology \#2006-4). Statistical Research Division, U.S. Census Bureau, Washington, DC.

Moore, Jeffrey C., Nancy Bates, Joanne Pascale, Julia Klein Griffiths and Aniekan Okon. 2006a. "Use of Dependent Interviewing Procedures to Improve Data Quality in the Measurement of Change.” Research Report Series (Survey Methodology \#2006-2). Statistical Research Division, U.S. Census Bureau, Washington, DC.

Moore, J. C., Stinson, L.L. and Welniak, E. J. Jr. 2000. "Income Measurement Error in Surveys: A Review." Journal of Official Statistics, 14:4, 331-361.

Paulin, Geoffrey, Jonathan D. Fisher and Sally Reys-Morales. 2006. "User's Guide to Income Imputation in the CE." Bureau of Labor Statistics.

Pennell S. G. 1993. "Cross-Sectional Imputation and Longitudinal Editing Procedures in the Survey of Income and Program Participation" U. S. Department of Commerce, Census Bureau.

Primus, Wendell, Lynette Rawlings, Kathy Larin, and Kathryn Porter. 1999. "The Initial Impacts of Welfare Reform on the Incomes of Single-Mother Families." Washington, DC: Center on Budget and Policy Priorities.

Remler, Dahlia K and Sherry A. Glied. 2003. "What Other Programs Can Teach Us: Increasing Participation in Health Insurance Programs." American Journal of Public Health 93(1): 67-74.

Robinson, J. Gregory, Bashir Ahmed, Prithwis Das Gupta and Karen A. Woodrow. 1993. "Estimation of Population Coverage in the 1990 United States Census Based on Demographic Analysis." Journal of the American Statistical Association 88(3): 10611071.

Roemer, Marc I. 2000. "Assessing the Quality of the March Current Population Survey and the Survey of Income and Program Participation Income Estimates, 1990-1996." Staff Papers on Income, Housing and Household Economic Statistics Division. Washington D.C.: U.S. Census Bureau.

Scholz, John Karl, and Kara Levine. 2001. "The Evolution of Income Support Policy in Recent Decades." In Sheldon Danziger and Robert Haveman, eds., Understanding Poverty, Cambridge, MA: Harvard University Press, 193-228.

Scholz, John Karl, Robert Moffitt, and Benjamin Cowan. 2008. "Trends in Income Support." Working Paper, University of Wisconsin, Madison.

Sears, James and Kalman Rupp. 2003. "Exploring Social Security Payment History matched with the Survey of Income and Program Participation. Social Security Administration.

Stephens, Mel. 2001. "The Long-Run Consumption Effects of Earnings Shocks." Review and Economics and Statistics 83(1):28-36.

Sudman, Seymour and Norman M. Bradburn. 1974. Response Effects in Surveys. Chicago: NORC/Aldine Publishing Company.

Taeuber, Cynthia, Dean M. Resnick, Susan P. Love, Jane Stavely, Parke Wilde, and Richard Larson. 2004. "Differences in Estimates of Food Stamp Program Participation Between Surveys and Administrative Records" working paper, U.S. Census Bureau.

U.S. Census Bureau. 2001. "Survey of Income Program Participation Users' Guide" Third Edition. Washington D.C.: U.S. Census Bureau. 
U.S. Census Bureau. 2008. "Income, Poverty, and Health Coverage in the United States: 2007" August.

U.S. Census Bureau. 2007. "The Effects of Taxes and Transfers on Income and Poverty in the United States: 2005," March.

U.S. Department of Health and Human Services. 2008. "Indicators of Welfare Dependence: Annual Report to Congress 2007.” U.S. Department of Health and Human Services, Washington, D.C.

U.S. Department of Labor. Various Years. "Unemployment Insurance Financial Data Handbook.” Employment and Training Administration. ET Handbook No. 394.

U.S. House of Representatives (2004). 2004 Green Book. Committee on Ways and Means. Washington DC: USGPO.

U.S. Social Security Administration. Various Years. "Annual Statistical Supplement to the Social Security Bulletin." U.S. Social Security Administration, Office of Research, Evaluation and Statistics. 


\section{Data Appendix}

\section{The Household Surveys}

\section{A. Surveys and Samples}

- Panel Study of Income Dynamics (PSID) - We use the 1968-1997, 1999, 2001, 2003, and first release 2005 waves. The initial sample of the PSID consisted of two independent samples: 1) A National Sample (2,930 families) of the civilian noninstitutionalized population of the 48 conterminous states and 2) The SEO (Survey of Economic Opportunity) sample, which consisted of 1,972 low income families residing in Standard Metropolitan Statistical Areas (SMSAs) and non-SMSAs in the southern regions. In the 1990 wave, a sample of 2,043 Latino households was added, but we do not include them in this study. However, we do include the 1997 immigrant sample, which consists of 441 families.

- Survey of Income Program Participation (SIPP) - We use the 1984-1993, 1996, 2001 and 2004 panels. The periods covered by each panel can be seen in the table below.

\section{SIPP Survey Period, by Panel}

\begin{tabular}{|l|l|l|l|}
\hline \hline SIPP Panel & Begin (reference month) & End (reference month) & Number of Waves \\
\hline 1984 & June 1983 & July 1986 & 9 \\
\hline 1985 & October 1984 & July 1987 & 8 \\
\hline 1986 & October 1985 & March 1988 & 7 \\
\hline 1987 & October 1986 & April 1989 & 7 \\
\hline 1988 & October 1987 & December 1989 & 6 \\
\hline 1989 & October 1988 & December 1989 & 3 \\
\hline 1990 & October 1989 & August 1992 & 8 \\
\hline 1991 & October 1990 & August 1993 & 8 \\
\hline 1992 & October 1991 & December 1994 & 9 \\
\hline 1993 & October 1992 & December 1995 & 9 \\
\hline 1996 & December 1995 & February 2000 & 13 \\
\hline 2001 & October 2000 & December 2003 & 9 \\
\hline 2004 & October 2003 & Still Ongoing & 4 (as of Sept. 2008) \\
\hline
\end{tabular}

The SIPP sample consists of individuals residing in the United States, excluding people who are:

a) Living in a household on a temporary basis and have a residence elsewhere.

b) Armed forces members who are in the household on a temporary basis.

c) Students whose living quarters are located elsewhere.

d) Inmates in an institution.

e) Nursing home residents.

f) Citizens of foreign countries. 


\section{- Current Population Survey - Annual Demographic File/Annual Social and}

Economic Supplement (CPS-ADF/ASEC) - We use the 1976-2008 surveys. The CPS$\mathrm{ADF} / \mathrm{ASEC}$ sample universe is the civilian non-institutional population living in the US and members of the Armed Forces living in civilian housing units on a military base or in a household not on a military base.

- American Community Survey (ACS) - We use the 2000-2006 surveys. The coverage of this survey is the non-institutionalized households and also excludes those in college dormitories and other group quarters.

- Consumer Expenditure Survey (CE Survey) - We use the 1980-2006 surveys. The eligible population is US civilian non-institutionalized persons. The survey excludes people such as patients, inmates, and those who live in camps, communes, convents, monasteries, flophouses, halfway houses, non-staff units in homes for the aged, infirm, or needy, transient quarters in hotels or motels and missions. For our analyses, we only include "complete income reporters" and reweight the estimates accordingly.

\section{B. Weighting}

Weights are needed to compute a population estimate.

- PSID: Email correspondence with the staff at the PSID Statistical Design Group indicated that although PSID weights in the publicly available datasets are suitable to compute scaling invariant statistics like the weighted mean, they are nevertheless unsuitable for the computation of weighted population totals. This situation occurs because PSID weights are not exactly calibrated to external population totals for families and individuals. The recommended approach is to scale the PSID weights linearly using an external dataset, based on characteristics such as age and gender. Doing so makes the sum of the revised PSID weights equal to the total population of the United States in any given year.

We use the CPS-ADF/ASEC as the basis for revising the PSID weights for two reasons. First, our calculations show that the sum of the weights in the CPS-ADF/ASEC matches the U.S. population very well in any given year. Second, the sample frame of the CPSADF/ASEC is very similar to that of the PSID. Third, CPS-ADF/ASEC data are available for every year since 1968, the year that the PSID survey began.

An important decision to make in this scaling strategy is the choice of individual characteristics to use for stratification when determining the revised PSID weights. If one chooses too few characteristics, it is sub-optimal if there is considerable heterogeneity across the population. If one chooses too many characteristics because the PSID is a small dataset, one may have few or no PSID observations in a particular stratum (combination of characteristics), making scaling sensitive or impossible. In addition, the PSID has already emphasized that the original PSID weights are designed to provide the correct proportionate representation of individual characteristics and family 
types in the US household population. Thus, the marginal bias reduction gain involved in introducing an extra characteristic may well be small.

We chose age and gender as the basis for scaling, simply because they are the two most clearly defined characteristics in both the PSID and the CPS-ADF/ASEC datasets. ${ }^{45} \mathrm{We}$ defined 19 age groups $(0-4,5-9,10-14,15-19,20-24,25-29, \ldots, 80-84,85-89$ and 90 and above) and two gender groups. Together, these constitute 38 strata, upon which our scaling will be based. To scale the PSID individual weights, we first compute the original weighted PSID population (using original PSID individual weights) and weighted CPS-ADF/ASEC population in a particular stratum $\mathrm{k}$, denoted as $\mathrm{N}_{\mathrm{p}, \mathrm{k}}$ and $\mathrm{N}_{\mathrm{c}, \mathrm{k}}$ respectively. Then we compute the ratio of these populations in this stratum $R_{k}$, i.e. $R_{k}=$ $\mathrm{N}_{\mathrm{c}, \mathrm{k}} / \mathrm{N}_{\mathrm{p}, \mathrm{k}}$. Finally, for each person, $\mathrm{i}$, in this stratum, we multiply his original PSID individual weight $\mathrm{W}_{\mathrm{i}, \mathrm{k}, \mathrm{p}}$ by this ratio, yielding his revised PSID individual weight $\hat{W}_{i, k, p}$, i.e. $\hat{W}_{i, k, p}=W_{i, k, p} R_{k}$. We use the revised PSID weights to compute the PSID weighted totals in this paper.

- CPS-ADF/ASEC: Individual weights are used. The only exception is the calculation of Food Stamp totals (1988 survey onwards), where we use household weights because Food Stamp receipts are reported at the household level.

- SIPP: Calculating weights for the SIPP is non-trivial because of the overlapping panels. We follow an approach similar to that in the SIPP Users' Guide 2001 (pp. 8-19 to 8-23). Essentially, for each program, we compute the total weighted receipts (individual monthly weights are applied) in each month. Then, for the overlapping months, we weight each of the monthly estimates in proportion to the number of individuals included in that estimate. For example, there are three monthly estimates for January 1986, one each from the 1984, 1985 and 1986 panels. The number of individuals who were interviewed in the waves covering these months is 32,008, 33,043, and 30,566, respectively. Thus, the weights are $0.335,0.346$ and 0.32 when combining the three January 1986 estimates into one. ${ }^{46}$

- ACS: Individual weights are used throughout, except for Food Stamps (benefit dollars and participation aggregates), where household weights are used.

- CE Survey: Consumer Unit weights are used. For individual reported benefits such as social security and SSI (these benefits come from the Member Files), we first obtain the consumer unit total (sum across family members) then apply the consumer unit weights.

\footnotetext{
${ }^{45}$ Race is not as clearly defined. First, the PSID only has the race of the head of household and the spouse (beginning in 1985). Second, both the CPS and the PSID are unclear about the treatment of people with multiple racial backgrounds.

${ }^{46}$ Prior to applying these weights to the estimates, we have adjusted each of the estimates according to the number of rotation groups it represents to obtain a population estimate for that panel. For example, a monthly estimate which is based on 3 rotation groups will be multiplied by $4 / 3$ so it becomes a population estimate for that panel (since each rotation group represents $1 / 4$ of the population). See pages 8-14 in the SIPP User Manual for a detailed explanation.
} 


\section{Technical Details/Assumptions}

SIPP - Calendar Years 1983 and 2000

There are two calendar years in which the SIPP did not conduct interviews for all the months. In 1983, there are no interviews for January to May. In 2000, there are no interviews for March to September. For these years, we annualize the aggregate dollar estimates by taking the average across the months available and multiply the result by 12 .

\section{Fiscal Year to Calendar Year Conversion}

Administrative aggregates for some programs (see sections 2 and 3 in this appendix) are originally reported on a fiscal year basis. The adjustment from fiscal to calendar year is done as follows: For the calendar year 1977 onwards, we take one quarter of the amount in the next fiscal year and three quarters of the amount in the current fiscal year. For the calendar years before 1977, we take one half from each of the current and the next fiscal year.

\section{Missing data/Non-response}

Those who answered "don't know" or "refused" are treated as missing data, and hence, they are treated as non-recipients.

\section{Other Income in the CPS-ADF/ASEC}

Note that in the CPS-ADF/ASEC, beginning with the 1988 surveys, there is also a question asked at the end of the income section regarding "other income" received and the type of this other income. The possible types of "other income" include AFDC, Social Security, Worker's Compensation and Unemployment Compensation, amongst many other private income types. We therefore use these responses and add them to the amount they reported in the sections preceding the other income question. We do not include Unemployment Compensation because there is no indication as to whether it is state unemployment insurance. These factors are generally small; for Unemployment Compensation, it is usually less than $1 \%$ in a typical year.

PSID - Adjusting aggregate benefits to account for non-head, non-spouse members of the family

In certain years of the PSID, certain benefits are only reported for the head of household and the spouse. To account for this survey issue, we calculate the share of benefits received by non-head, non-spouse family members (in the years when they are available). We apply this share to scale up the benefit estimates in the appropriate years.

\section{CE Survey - Computing Calendar Year Aggregates}


The reference period in the CE Survey is the previous 12 months. We therefore allocate the individual's reported benefit receipt based on the fraction of the last 12 months that falls in the previous calendar year and the fraction that falls in the current calendar year. For example, for an individual who is interviewed in January, we would allocate his entire benefit receipt to the previous calendar year. Similarly, for an individual who is interviewed in April, we would say that three quarters of his reported benefit receipt belong to the previous calendar year and one quarter belongs to the current year.

\section{CE Survey - Complete Income Reporters}

We count only the complete income reporters and reweight the results by the inverse of the fraction of complete income reporters in the sample.

\section{Identifying recipients in the PSID}

One of the major shortcomings of the PSID is the lack of individual data in certain waves of the survey. In this section, we explain how we obtain aggregates when there is incomplete information regarding individual recipiency. Readers may find it helpful to read this section in conjunction with Appendix Table 1, which tabulates, by survey and benefit year, the availability of benefit data.

- Survey years 1968-1970: Benefits such as OASDI, UI and WC are only reported for the family head. Thus, the aggregates calculated will understate the actual amounts received by all PSID families. We thus do not report estimates for these programs in these years.

- Survey years 1971-1974: During these survey years, AFDC and Social Security are reported as the combined amounts received by the head of household and the spouse. We use the response to the type of income question in the PSID individual file to decide who the recipient is. The main possible responses are: Labor Income Only, Transfer Income Only, Asset Income Only, Combination Including Labor Income, and Combination Excluding Labor Income. An individual is assumed to receive AFDC and Social Security if the answer to the above question suggests that transfer income is received. After we determine whether the head and/or the spouse received transfer income, we divide the reported amount of benefit equally. If only the head of the family is reported to receive transfer income, all AFDC and Social Security income received by this family will be allocated to the head. If both the head and the spouse are reported to receive transfer income, the head and the spouse will each get half of the reported AFDC and Social Security Income.

- Survey Years 1975-1993: In these survey years, there are two issues to confront. First, we again see that AFDC, SSI and Social Security benefits are reported as the combined amount received by the head and the spouse in 1975-1985. Second, all benefits (except Social Security in 1984-1992 waves) received by other family unit members (OFUMs) are also reported as combined amounts. Both issues can be tackled by using the type of transfer received question in the PSID individual file. The question asks what type of transfer was received, and the main possible responses are: 1) AFDC only; 2) Other 
welfare only; 3) Social Security only; 4) Other retirement pay, pensions, annuities only; 5) Unemployment, Worker Compensation only; 6) Alimony, child support only; 7) Help from relatives only; 8) Supplemental Security Income Only; and 9) Any combination. Thus, we assess what types of benefits each person in the family received using the response to the above question. In the event that the individual answered "Any Combination," we assume that he received several kinds of transfers. Again, we divide the reported benefit amount equally between all recipients if more than one individual reports recipiency of the benefit. ${ }^{47}$

- Survey years 1994-2003: Most benefits (except Food Stamps, Social Security and SSI (for 2 years)) are reported separately for the head and the spouse only. See the Social Security and SSI sections for more detail on how aggregates are obtained. In addition, the data format changed beginning in the 1994 wave, with most benefits now reported in the following format: First, how much benefit was received (the amount question)? Second, the frequency (per year, per month, per week, per two weeks etc) of the said amount (the frequency question). Third, during which months was the benefit received? Two sets of these responses are available, one for the head and one for the spouse. To determine the annual amount received based on these questions, we first determine the monthly amount received using the amount and the frequency questions. We then multiply the result by the number of months this benefit was received. However, if the individual answered "per year" in the frequency question, we assume that the reported dollars in the amount question is the annual amount he received. The reason for doing so is that the individual may have received the entire reported amount in one month, and obtaining the annual amount by the preceding method will understate the actual amount received.

- Survey year 2005: The public release of this wave contains the benefit amount received by the head and the spouse separately for 2004, reported just like the 1994-2003 waves. ${ }^{48}$ In addition, the amount received by the entire family for 2003 is also available for all benefits. The individual file also includes indicator variables regarding individual recipiency of a particular type of benefit in 2003. Thus, for 2003, we divide the reported family amount equally between all persons in the family who reported receiving a particular type of benefit.

Based on these rules, we determine the amount of each type of benefit each member of the family received. The annual aggregate is obtained simply by multiplying the individual amount by the individual revised weight and then summing the result across all individuals in the year. In the case of Food Stamps and SSI (in 1997 and 1999), the annual aggregate is obtained

\footnotetext{
${ }^{47}$ If the benefit is reported as the combined amount received by the head and the spouse (denoted as $(\mathrm{H}+\mathrm{W})$ ), then we divide this amount only between the head and the spouse. If more than one OFUM received a particular type of benefit, we divide the total amount received by the OFUMs by the number of OFUMs who received the benefit. In other words, the reported amount received by the head and the spouse is always distributed between the head and the spouse only. Similarly, the amount received by the OFUMs is always distributed between the OFUMs.

${ }^{48}$ The first public release of this wave also includes variables representing the benefit amounts received by the OFUMs in 2004, but all values are zero. It is likely that these variables will be made available in future public releases.
} 
by multiplying the family amount by the revised family weight (average revised weight of the head and the spouse) and then summing across all families.

\title{
2. Administrative Data Sources and Details of the Calculations by Program - Benefit Dollars
}

\begin{abstract}
A. Aid to Families with Dependent Children and Temporary Assistance for Needy Families (AFDC/TANF)
\end{abstract}

Administrative Data Sources

(1970-2004)

U.S. Department of Health and Human Services. 2008. "Indicators of Welfare Dependence: Annual Report to Congress 2007." U.S. Department of Health and Human Services, Washington, D.C.

(1970-2004 data on the territories)

U.S. Social Security Administration. Various Years. "Annual Statistical Supplement to the Social Security Bulletin.” U.S. Social Security Administration, Office of Research, Evaluation and Statistics.

Note: The administrative estimates have been adjusted to exclude amounts paid to Guam, Puerto Rico and Virgin Islands using various years of Annual Statistical Supplement of the Social Security Administration.

(1970-2004 data on General Assistance)

U.S. Bureau of Economic Analysis. 2009. U.S. Department of Commerce, U.S. Bureau of Economic Analysis. Table 3.12. http://www.bea.gov/national/nipaweb/SelectTable.asp (accessed June, 2009).

Adjustments to the Administrative Aggregates due to Institutionalized Individuals

No adjustment is made to account for institutionalized individuals. ${ }^{49}$

\section{Technical Notes}

- PSID: For the 1968 survey, the amount of AFDC is the family total. For the 1969-1970 surveys, we know only the amount of AFDC received by the head of the family. For the 1971-1974 surveys, AFDC is the combined amount received by the head and the spouse. For 1975-1985 surveys, the head and spouse combined amount and the other family members' combined amount are each available. For the 1986-1993, the dataset has the amount of AFDC received by the head and the spouse separately, but for other family members, only the combined amount is available. Beginning in the 1994 survey, only the

\footnotetext{
${ }^{49}$ Using the 2000 Census, we find that about $9.4 \%$ of total reported welfare income (AFDC/TANF and General Assistance) was received by the institutional population. This suggests a high level of misreporting among the institutional population since we expect that they are not eligible for AFDC/TANF.
} 
amount received by the head and the amount received by the spouse are recorded, except in the 2005 survey, when the amount received by the family is recorded for 2003 . We therefore scale up the benefits to account for the non-head, non spouse family members in 1970-1973, 1993-2002, and 2004.

- SIPP: Reported consistently.

- CPS-ADF/ASEC: For the 1968-1975 surveys, AFDC is combined with old age assistance, aid to the blind and to the disabled. There are no variables that indicate which benefit the person received. From the 1976 survey, AFDC/TANF is combined with Other Welfare, but there are variables indicating whether the person received each of these benefits. We use these variables to count only those who receive only AFDC/TANF.

- ACS: The ACS reports the amount of Public Assistance received, which includes TANF and General Assistance.

- CE Survey: The CE Survey reports the amount of public assistance, welfare, and other cash assistance.

\section{B. Food Stamps}

\section{Administrative Data Sources}

(1973-2002)

Administrative totals for 1967-2002 were kindly provided to us (via email) by the Food and Nutrition Service.

(2003-2004)

Food and Nutrition Service. 2006. U.S. Department of Agriculture, Food and Nutrition Service. http://www.fns.usda.gov/pd/fspmain.htm (accessed April, 2006).

(2005-2007)

Food and Nutrition Service. 2008. U.S. Department of Agriculture, Food and Nutrition Service. http://www.fns.usda.gov/pd/fspmain.htm (accessed September 10, 2006).

Notes: The administrative aggregates have been adjusted to remove payments received by people in Puerto Rico, Guam and Virgin Islands. Note that Puerto Rico implemented Food Stamps beginning in fiscal Year 1975 until June of Fiscal Year 1982. Using U.S. Department of Health and Human Services (2008), the share of Food Stamps payments for Puerto Rico during FY1975-FY1982 is 9.87\%. The share of Food Stamps payments for Guam and Virgin Islands is estimated to be $0.3 \%$.

Adjustments to the Administrative Aggregates due to Institutionalized Individuals 
No adjustment is made to account for institutionalized individuals.

\section{Technical Notes}

- PSID: There are Food Stamps questions in all the surveys except the 1973 survey. Note that the Food Stamps estimates prior to 1973 are implausibly large and hence are excluded in the table. Because free food was initially included (in the 1968 survey, the survey question was: Did you (family) get any free food, clothing, or food stamps worth more than $\$ 50$ in 1967? If yes, how much did that save you last year?), the longitudinal nature of the survey may have caused respondents in the subsequent waves to include free food when asked about Food Stamps. Since Food Stamps are reported on a family basis, we apply the revised family weights in obtaining the aggregate.

- SIPP: Asked consistently.

- CPS-ADF/ASEC: Food Stamp questions are asked beginning with the 1980 survey. These questions are asked at the household level and so are weighted using the household weight. Food Stamps data from the 2008 survey are withheld.

- CE Survey: The CE Survey reports the value of Food Stamps received. Food Stamps data for the 1982-1985 surveys are obtained from the Income File rather than from the Consumer Unit (Family) files. Food Stamps values beginning in the 2001 survey include electronic benefits.

\section{Social Security}

\section{Administrative Data Sources}

(1967-2007)

U.S. Social Security Administration. 2008. U.S. Social Security Administration.

http://www.socialsecurity.gov/OACT/STATS/table4a4.html (accessed September 10, 2008).

(1967-2007 data on the territories)

U.S. Social Security Administration. Various Years. "Annual Statistical Supplement to the Social Security Bulletin.” U.S. Social Security Administration, Office of Research, Evaluation and Statistics.

Notes: The administrative estimates have been adjusted to exclude amounts paid to American Samoa, Guam, Puerto Rico, Virgin Islands and those living outside the U.S.

\section{Adjustments to the Administrative Aggregates due to Institutionalized Individuals}

We use the 1970, 1980, 1990 and 2000 census data to estimate the fraction of total Social Security received by the institutional population (individuals in correctional facilities, mental institutions, and institutions for the elderly, the handicapped and the poor, and those in military facilities). We adjust the administrative aggregates downward by applying the 1970 fraction 
(2.93\%) to the 1967-1974 aggregates, the 1980 fraction (1.43\%) to the 1975-1984 aggregates, the 1990 fraction (2.75\%) to the 1985-1994 aggregates, and the 2000 fraction (3.39\%) to the 1995-2004 aggregates. We also use the 2006 ACS to estimate the fraction of total Social Security received by the institutional population (3.2\%), and apply these fractions to the 20052007 administrative aggregates.

\section{Inclusion of Railroad Retirement Benefits}

In the CE Survey and the CPS-ADF/ASEC (1968-1975 surveys), Railroad Retirement benefits and Social Security benefits are combined. Hence, we adjust the administrative aggregates for these surveys by including Railroad Retirement benefits. We also assume that SSDI recipients cannot get Railroad Retirement benefits - hence, we adjust only the OASI aggregates for the aforementioned surveys to include Railroad Retirement benefits.

\section{Dividing Social Security Income}

Social security income in the surveys we examine is sometimes reported without specifying the type of social security, and deducing whether it is SSDI or OASI becomes virtually impossible. In these circumstances, we use the data published in the various issues of Annual Statistical Supplements to calculate, for each year, age, gender, and schooling status, the proportion of social security dollars that is paid to OASI and SSDI recipients. ${ }^{50}$ We use these proportions to determine the amount of SSDI and OASI the individual received whenever we have incomplete information about why he received social security or whenever he received money from both the SSDI and OASI programs without specifying the amount received from each type separately. ${ }^{51}$

\section{Technical Notes}

- PSID: For the 1968-1969 waves, benefit amounts are reported for the head only and are coded in bracketed form. We take the midpoint of each bracket as the amount the individual receives. For 1984-1993 waves, the type of social security is reported. If the individual reported receiving both SSDI and OASI, then his amount of social security income will be divided between the two programs using the Annual Statistical Supplements. For the 1994-2003 waves, in general we have only the total amount of social security income received by the family. To decide which member in the family received social security should the family social security receipt be positive in a particular year, we adopt two approaches: First, we use the panel structure of the PSID, and if the individual received social security in the 1993 wave (1992 for OFUMs), we

\footnotetext{
${ }^{50}$ To reduce computational burden, these proportions are calculated for the following age groups only: $0-17,18,19$, $20,21,22,23,24,25-29,30-34,35-39,41-44,45-49,50-54,55-59,60,61,62,63,64,65+$. One set of these proportions are calculated for men and women separately. A separate set of proportions is also calculated for those students who were 18-24.

${ }^{51}$ Note that the demographic data published in the Annual Statistical Supplements represents what happened in December of each year. Thus, in constructing the official proportions for each calendar year, we take the average of these proportions in the two adjacent years.
} 
assume that this individual always received social security in the 1994-2003 waves. Second, if the individual is reported as being permanently disabled or retired, we assume he received social security. The amount of social security received by the family will be divided equally between family members who we determine to be social security recipients, and the amount of OASI and SSDI each member received is then determined using the proportions obtained from the Annual Statistical Supplements. For the 2005 wave, we only have the amount of social security the family received in 2003, but we also know which member of the family received social security in 2003 . Therefore, we divide the amount equally between recipients in the family and again determine OASI and SSDI amounts based on the proportions obtained in the Annual Statistical Supplements. We also scale up the benefits to account for the non-head, non spouse family members in 1970-1973.

- SIPP: Two variables that indicate the first two reasons for receiving social security income are available but are only asked once (the first time the individual indicated receipt of social security) in the 1984-1993 panels. Hence, we assume that the reasons for receiving social security are the same for all the waves in these panels. For the 1996 panel, the reasons for receiving social security are not asked in waves 2-8; thus, we take the nearest answer available. As such, reasons for receiving social security from wave 2 to wave 5 (second month) are the same as those in wave 1 . When the reasons for receiving social security imply that the individual may have received from both the SSDI and OASI programs, we use the Annual Statistical Supplements to obtain the amounts of SSDI and OASI for this individual as described above.

- CPS-ADF/ASEC: The data include the total social security income received by the individual, with no information about the type of social security received until 2001. For the 1968-1987 surveys, social security income is combined with railroad retirement. For the 1976-1987 surveys, two variables indicating whether the person received social security and railroad retirement benefits are available. However, we cannot precisely distinguish the two benefits when both benefits are received. If the person indicated he received both railroad retirement benefits and social security, we treat the entire sum as social security for these years. Since no information on type of social security received is available until 2001, we determine the amount of SSDI and OASI the individual received using the Annual Statistical Supplements as described above.

- ACS: The data include the total social security income received by the individual, with no information about the type of social security received. We use the Annual Statistical Supplements to determine the amounts of SSDI and OASI.

- CE Survey: The Member files of the CE Survey report, for each member in the Consumer Unit, the total amount of Social Security and Railroad Retirement income received. We use the Annual Statistical Supplements to determine the amounts of SSDI and OASI as described above.

\section{Supplemental Security Income}




\section{Administrative Data Sources}

(1974-2005)

U.S. Social Security Administration. 2005. "2005 SSI Annual Report.” U.S. Social Security Administration, Office of the Chief Actuary. Tables IV C1, C4, C5.

(2006-2007)

U.S. Social Security Administration. 2008. "2008 SSI Annual Report.” U.S. Social Security Administration, Office of the Chief Actuary. Tables IV C1, C4.

(1978-2006 data on the territories)

U.S. Social Security Administration. Various Years. "Annual Statistical Supplement to the Social Security Bulletin." U.S. Social Security Administration, Office of Research, Evaluation and Statistics.

The administrative aggregates have been adjusted to exclude SSI dollars received by people living in Mariana Islands. Only people living in the states of the U.S., the District of Columbia and those in Mariana Islands are eligible for SSI.

\section{Adjustments to the Administrative Aggregates due to Institutionalized Individuals}

We use the 2000 census data to estimate the fraction of total SSI dollars received by the institutional population (individuals in correctional facilities, mental institutions, and institutions for the elderly, the handicapped and the poor, and those in military facilities). The result suggests that the fraction is about $4.50 \%$, and we adjust the 1974-2004 administrative aggregates downwards using this number throughout. ${ }^{52}$ We also use the 2006 ACS to estimate the fraction of total SSI received by the institutional population (3.2\%), and apply these fractions to the 2005-2007 administrative aggregates.

\section{Technical Notes}

- PSID: Beginning in the 1994 survey, SSI is only reported for the head and the spouse. However, in the 1999 and 2001 surveys, SSI for the family is also reported for the prior survey year (1997 and 1999 respectively). To calculate the weighted total SSI benefits in these two years, we apply the revised family weights since there is virtually no information regarding individual recipiency. We also scale up the benefits to account for the non-head, non spouse family members in 1993-2002 and 2004.

\footnotetext{
${ }^{52}$ We use only the 2000 Census because it is the only census data that reports SSI as a separate category. In the 1970-1990 census data, SSI, AFDC, General Assistance and other welfare are lumped together as "Welfare Income". Roemer (2000) uses the 1990 census and assumes that all welfare income received by institutionalized individuals is SSI and estimated that $7.4 \%$ of total SSI is paid to these individuals. Using the 2000 census, we find that only $4.5 \%$ of total SSI is paid to the institutionalized individuals and that the amount of AFDC/TANF received by institutionalized individuals is about $3.7 \%$ of the total SSI. These results suggest that the $7.4 \%$ adjustment Roemer (2000) uses may be overstated.
} 
- SIPP: The SSI question only asks about federal SSI. We assume that reported amounts include state supplementation because there is not a separate question about state funded SSI, and we believe it is unlikely respondents understand the financing of the program.

- CPS-ADF/ASEC: Questions about SSI are asked consistently beginning with the 1976 survey.

- ACS: Amount of SSI received by the individual is available.

- CE Survey: The Member Files of the CE Survey report the amount of SSI received.

\section{E. Unemployment Insurance}

\section{Administrative Data Sources}

(1976-2004)

U.S. Department of Labor. Various Years. "Unemployment Insurance Financial Data Handbook.” ET Handbook No. 394. U.S. Department of Labor, Employment and Training Administration.

(2005-2007)

U.S. Department of Labor. 2008. U.S. Department of Labor - Employment and Training Administration. http://workforcesecurity.doleta.gov/unemploy/content/data.asp (accessed September 12, 2008).

Note: The administrative aggregates have been adjusted to exclude payments to Puerto Rico and Virgin Islands.

Adjustments to the Administrative Aggregates due to Institutionalized Individuals

No adjustment is made to account for institutionalized individuals.

\section{Technical Notes}

- PSID: Unemployment Insurance and Workers' Compensation are combined in the 19681976 surveys. In addition, they are not reported for every family member. See Appendix Table 1 for more information. In calculating the average reporting rate, we only include the 1976-2004 years (i.e. 1977-2005 surveys). We also scale up the benefits to account for the non-head, non spouse family members in 1993-2002, and 2004.

- SIPP: Reported Consistently as "Amount of State Unemployment Compensation". SIPP also has "Supplemental Unemployment Compensation" and "Other Unemployment Compensation". The combined sum of these two non-state unemployment benefits never exceeds $5 \%$ of the total administrative state UI benefits payouts. In a typical year, total Supplemental Unemployment Compensation in the SIPP constitutes only about $2 \%$ of the administrative UI total. For Other Unemployment Compensation, that percentage is 
around $1 \%$. Thus, we only count State Unemployment Compensation when computing UI weighted totals.

- CPS-ADF/ASEC: For the 1968-1987 surveys, Unemployment Insurance and Workers' Compensation are combined into one category. In some of the years, the category also includes veterans' benefits. See Appendix Table 2 for more detail. In calculating the average reporting rate, we only include the years 1987-2007.

- CE Survey: The CE Survey reports the amount of unemployment compensation received.

\section{F. Workers' Compensation}

\section{Administrative Data Sources}

(1976-1986)

Nelson Jr., William J. 1992. "Workers' Compensation: 1984-88 Benchmark Revisions." Social Security Bulletin 55(3):41-58.

(1987-2006)

Sengupta, I., V. Reno, and J.F. Burton, Jr. 2003. “Workers' Compensation: Benefits, Coverage, and Costs." National Academy of Social Insurance, Washington D.C.

Note: We consider only cash payments, obtained by removing the medical portion of the total program cost.

Adjustments to the Administrative Aggregates due to Institutionalized Individuals

No adjustment is made to account for institutionalized individuals.

\section{Technical Notes}

- PSID: Unemployment Insurance and Workers' Compensation are combined in the 19681974 waves. In addition, they are not reported for every family member. See Appendix Table 1 for more information. In calculating the average reporting rate, we only include the years 1976-2004. We also scale up the benefits to account for the non-head, non spouse family members in 1993-2002 and 2004.

- SIPP: Reported consistently as “Amount of Workers' Compensation”

- CPS-ADF/ASEC: For the 1968-1987 surveys, Unemployment Insurance and Workers' Compensation are combined as one category. In some of the years, the category also includes veterans' benefits. See Appendix Table 2 for more details. In calculating the average reporting rate, we include only the years 1987-2006. 
- CE Survey: The CE Survey reports the amount of Worker's Compensation and Veterans' Benefits (include education benefits, but excluding military retirement benefits) combined.

G. Earned Income Tax Credit

Administrative Data Sources

(1991-2003)

U.S. Government Printing Office. 2004. 2004 Green Book. US House of Representatives

Committee on Ways and Means, Washington D.C. Table 13-14.

(2004-2006)

U.S. Office of the President of the United States. 2008. "Historical Tables for the Budget of the United States Government - Fiscal Year 2009." The White House, Office of Management and Budget, Washington D.C.

Adjustments to the Administrative Aggregates due to Institutionalized Individuals

No adjustment is made to account for institutionalized individuals.

Technical Notes

- PSID: The PSID does not have information on EITC

- CPS-ADF/ASEC: Reported consistently from the 1992 survey onwards.

\section{Administrative Data Sources and Details of the Calculations by Program - Benefit Participation}

A. Aid to Families with Dependent Children and Temporary Assistance for Needy Families (AFDC/TANF)

Administrative Data Sources

(1980-2007)

Administration for Children and Families. 2008. U.S. Department of Health and Human Services, Administration for Children and Families. http://www.acf.hhs.gov/programs/ofa/datareports/caseload/caseload archive.html (accessed September 10, 2008).

Note: We use the fraction of dollars received by those living in the territories to adjust the administrative aggregates downward to account for those living outside the 50 states and DC. This adjustment is small, typically below $0.7 \%$.

Adjustments to the Administrative Aggregates due to Institutionalized Individuals 
No adjustment is made to account for institutionalized individuals.

\section{Technical Notes}

We compute average monthly participation at a family level. All numbers are weighted using family weights.

- PSID: For the 1994 and later waves, it asks, for each month, whether AFDC/TANF were received separately for the head and the spouse. We assume, therefore, that either participation of the head or the spouse constitutes family participation.

- SIPP: Information on monthly recipiency is available. Note again that we do not have complete calendar year coverage for 1983 and 2000. Specifically, the SIPP does not cover January 1983-May 1983 and March 2000-September 2000. Thus, we adjust the administrative monthly average participation so it covers the same months for these two years as the SIPP.

- CPS-ADF/ASEC: The survey asks the number of months Public Assistance was received (1988-2008 surveys). ${ }^{53}$ Note that since public assistance included General Assistance, we have made adjustment so those who received only General Assistance are not counted.

\section{B. Food Stamp Program}

\section{Administrative Data Sources}

(1973-2002)

Administrative totals for 1967-2002 are kindly provided to us (via email) by the Food and Nutrition Service.

(2003-2004)

Food and Nutrition Service. 2006. U.S. Department of Agriculture, Food and Nutrition Service. http://www.fns.usda.gov/pd/fspmain.htm (accessed April, 2006).

(2005-2007)

Food and Nutrition Service. 2008. U.S. Department of Agriculture, Food and Nutrition Service. http://www.fns.usda.gov/pd/fspmain.htm (accessed September 10, 2006).

Adjustments to the Administrative Aggregates due to Institutionalized Individuals

\footnotetext{
53 In the codebooks, this question was phrased in many years as: "In how many months of 19.. did ... receive social security payments?" This question was asked under the public assistance section and was asked immediately after the question of whether AFDC was received. Thus, we conjecture that the term "social security" in the above months question is a typographical error.
} 
No adjustment is made to account for institutionalized individuals.

\section{Technical Notes}

We look at participation at a household level; this is primarily due to the limitations of the surveys. In the SIPP, the coverage indicator (i.e. whether a person is covered by food stamps) is not asked if the person is under 15 years of age. This issue becomes complicated when there are multiple families living in a household, and they can be related or not related. Note that Food Stamps distributions are officially determined on a household basis. The CPSADF/ASEC mainly asks only the number of children covered by food stamps. It is then not clear whether the spouse is also covered by food stamps.

- PSID: For the 1994 and later waves, it asks, for each month, whether food stamps were received. Prior to the 1994 surveys, it asked instead how many months in the previous calendar year did the individual use food stamps (monthly recipiency also available for 1984-1993 waves). Basically, we have information about how many months did the individual use/receive food stamps for the calendar years 1975-2002. The PSID also asked the number of persons in the family covered by food stamps, but we will not use this data as we are comparing household participation.

- SIPP: Information on monthly recipiency is available. Note again that we do not have complete calendar year coverage for 1983 and 2000. Specifically, SIPP does not cover January 1983-May 1983 and March 2000-September 2000. Thus, we adjust the administrative monthly average participation so they cover the same months for these two years as the SIPP.

- CPS-ADF/ASEC: The CPS-ADF/ASEC asked the number of persons covered and the number of months covered by food stamps. These questions are asked in the 1980-2008 surveys.

\section{National School Lunch Program (NSLP)}

\section{Administrative Data Sources}

(1979-1988, 2002-2006)

Food and Nutrition Service. 2008. U.S. Department of Agriculture, Food and Nutrition Service. http://www.fns.usda.gov/pd/slsummar.htm (accessed September 25, 2008).

Note: These data show the average monthly participation (excluding June-August) of Free, Reduced Price and Full Price lunches for the fiscal years 1969-2007. We convert fiscal years to calendar years, taking into account that the summer months are excluded. Specifically, for the fiscal years 1979 and onwards, we calculate average monthly participation of calendar year $t$ by taking $2 / 3$ of the average monthly participation in fiscal year $t$ and $1 / 3$ of the average monthly participation in the fiscal year $\mathrm{t}+1$.

(1989-2001) 
Administrative totals for 1980-2002 were kindly provided to us (via email) by Food and Nutrition Service. These data include monthly participation numbers for the Free, Reduced Price and Full Price lunches under the NSLP. Participation during the summer season (June-August) is excluded in computing the average monthly participation for the year.

\section{Technical Notes}

In the CPS-ADF/ASEC and PSID, the data yield only unique participation of free or reduced price lunch estimates. We use the SIPP to approximate average monthly participation of free or reduced price lunches using these unique participation estimates.

- SIPP: We use the response to the household-level question: "In the past 4 months, were the lunches free, reduced-price, or were they full-price?" to calculate participation. Note that this question is asked only once per wave and the answer to the question covered the 4 reference months (the 4 months before the survey month). Since the answer to this question covers all the children in the household, we assume that every eligible child (518 years of age) in a participating family receive the reported type of lunch from the NSLP.

- PSID: We use the family-level question "During the (previous year), did any child in your family between 5 and 18 years old receive free or reduced-cost lunches at school?" The response to this question yields a unique annual participation count, and we therefore convert these estimates to average monthly participation using the SIPP. Note that a person may have had both reduced price and free lunches in a year so that these unique participation count numbers may understate their true values. Also, we assume that every eligible child (5-18 years of age) in a participating family received lunches from the NSLP.

- CPS-ASEC: The survey asks about the number of children in the household receiving free or reduced price lunch. Thus, we cannot estimate numbers of free lunch and reduced price lunch recipients separately. We also do not know exactly which child in the household is a recipient. To calculate participation, we first calculate the average weight of those in the household who are between ages 5 and 18, multiply this average weight by the number of children who receive free or reduced price lunches, and sum the result across households. This method yields unique participation, and we convert it to average monthly participation as described above.

D. Social Security

Administrative Data Sources

(1974-2007)

U.S. Social Security Administration. 2008. U.S. Social Security Administration. http://www.ssa.gov/OACT/STATS/OASDIbenies.html (accessed September 15, 2008). 
Note: Official Data give current participation as of December of each year. We compute average monthly participation of year $t$ by taking the average of participation numbers in December of year $\mathrm{t}$ and year $\mathrm{t}-1$.

We use the fraction of dollars received by those living in the territories or outside the U.S. to adjust the administrative aggregates downwards to account for those living outside the 50 states and DC. These data are obtained from U.S. Social Security Administration (various years). Typically, payments to those living in the territories/outside the U.S. constitute about $3 \%$ of the total.

\section{Adjustments to the Administrative Aggregates due to Institutionalized Individuals}

We use the 1970, 1980, 1990 and 2000 census data to estimate the fraction of Social Security benefit recipients who are institutionalized. We adjust the administrative aggregates downward by applying the 1970 fraction (3.49\%) to the 1967-1974 aggregates, the 1980 fraction (2.48\%) to the 1975-1984 aggregates, the 1990 fraction (3.43\%) to the 1985-1994 aggregates, and the 2000 fraction (3.59\%) to the 1995-2004 aggregates. We also use the 2006 ACS to estimate the fraction of total Social Security recipients who are institutionalized $(3.52 \%)$, and apply these fractions to the 2005-2007 administrative aggregates.

\section{Technical Notes}

In the PSID, CPS-ADF/ASEC, ACS (and sometimes SIPP), we do not know the type of social security the individual received (OASI or SSDI). Using data from the Annual Statistical Supplements, we look at the fraction of dollars spent on SSDI/OASI for someone in the same age and gender group, and we determine OASI/SSDI participations by splitting the individual's weight according to these fractions. ${ }^{54,55}$

Since we can obtain only unique participation in the PSID, CPS-ADF/ASEC and the ACS, we use the SIPP and obtain the ratio of unique participation to average monthly participation estimates, then we convert unique participation in the PSID, CPS-ADF/ASEC and the ACS using these ratios.

- PSID: These data give unique participation in a calendar year, and we convert to average monthly participation using the SIPP as described above. Note that in the 1975-1983 surveys, the type of social security (SSDI or OASI) is unknown. We therefore split the weight of the individual according to the fraction of social security dollars spent on SSDI/OASI as described above.

\footnotetext{
${ }^{54}$ Alternatively, we could calculate these fractions by looking at the share of people (rather than dollars) who receive SSDI/SSDI for a given age and gender group.

${ }^{55}$ A major limitation of this method of determining OASI/SSDI participation is that certain individuals may receive both types of social security benefits in a given year. One possible improvement would be to adjust our method by looking at the percentage of people who receive SSDI or OASI or both using the SIPP.
} 
- CPS-ADF/ASEC: These data indicate unique participation in a calendar year, and we convert to average monthly participation using the SIPP as described above. Since the type of social security is unknown, we split the weight of the individual according to the fraction of social security dollars spent on SSDI/OASI as described above.

- ACS: These data indicate unique participation in a calendar year, and we convert to average monthly participation using the SIPP as described above. Since the type of social security is unknown, we split the weight of the individual according to the fraction of social security dollars spent on SSDI/OASI as described above.

- SIPP: SIPP data can indicate both unique and average monthly participation. In the event that we do not know the type of social security received, we split the weight of the individual according to the fraction of social security dollars spent on SSDI/OASI as described above.

\section{E. Supplementary Security Income}

\section{Administrative Data Sources}

(1974-2007)

U.S. Social Security Administration. Various Years. "Annual Statistical Supplement to the Social Security Bulletin." U.S. Social Security Administration, Office of Research, Evaluation and Statistics.

Note: Official Data give current participation as of December of each year. We compute average monthly participation of year $t$ by taking the average of participation numbers in December of year $t$ and year $t-1$.

\section{Adjustments to the Administrative Aggregates due to Institutionalized Individuals}

We use the 2000 Census data to estimate the fraction of SSI recipients who are institutionalized (individuals in correctional facilities, mental institutions, and institutions for the elderly, the handicapped and the poor, and those in military facilities). ${ }^{56}$ The fraction is estimated to be about $4.50 \%$. We adjust the 1974-2004 average monthly participation numbers using this fraction because SSI participation is not available in earlier Censuses. We also use the 2006 ACS to estimate the fraction of total SSI recipients who are institutionalized (3.66\%), and apply this fraction to the 2005-2007 administrative aggregates.

\section{Technical Notes}

We compute SSI participation at the individual level. Since we can obtain only unique participation in the PSID, CPS-ADF/ASEC and the ACS, we use the SIPP and obtain the ratio of

\footnotetext{
${ }^{56}$ In the 1970,1980 and 1990 census, SSI is combined with general assistance and AFDC, while the 2000 census reports SSI as a separate category. This makes identifying the number of SSI recipients difficult in the 1970, 1980 and 1990 census data. Thus, we use only the 2000 census data to estimate the number of SSI recipients that are institutionalized.
} 
unique participation to average monthly participation estimates, then we convert unique participation in the PSID, CPS-ADF/ASEC and the ACS using these ratios.

- PSID: These data give unique participation in a calendar year, and we convert to average monthly participation using the SIPP as described above. We also scale up the participation aggregates to account for the non-head, non-spouse family members in 1993-2004.

- CPS-ADF/ASEC: These data give unique participation in a calendar year, and we convert to average monthly participation using the SIPP as described above.

- ACS: These data give unique participation in a calendar year, and we convert to average monthly participation using the SIPP as described above.

- SIPP: SIPP data can give both unique and average monthly participation.

F. Women, Infants and Children (WIC)

Administrative Data Sources

(1973-2002)

Administrative totals for 1980-2002 were kindly provided to us (via email) by Food and Nutrition Service.

(2003-September 2004)

Food and Nutrition Service. 2006. U.S. Department of Agriculture, Food and Nutrition Service. http://www.fns.usda.gov/pd/WIC Monthly.htm (accessed April, 2006).

(October 2004-December 2007)

Food and Nutrition Service. 2008. U.S. Department of Agriculture, Food and Nutrition Service. http://www.fns.usda.gov/pd/wicmain.htm (accessed August 28, 2008).

Adjustments to the Administrative Aggregates due to Institutionalized Individuals

No adjustment is made to account for institutionalized individuals.

\section{Technical Notes}

- SIPP: Participation in WIC is determined by the survey response to the question: "Was the person covered by WIC for this month?"

- PSID: Family participation in the WIC program is determined by the survey question "During the (previous year), did anyone in the family get food through the WIC program?" Note that this is a family question, so we cannot identify who in the family received WIC. The following assumption is made: If the family 
reported participating, then we assume that those in this family who were: 1) Females who were 15-45 years of age in the survey year or 2) Children between 0-5 years of age (in the survey year) participated the WIC program. The question response yields a unique participation count, which we convert to average monthly participation.

- CPS-ADF/ASEC: The question structure is very similar to the PSID. Thus, we proceed in the same fashion as we have done for the PSID. Though CPSADF/ASEC also asked the number of people in the household receiving WIC, we do not use this variable because it is not so clear whether this implies participation (an adult might receive WIC only because of his/her children). 


\section{Social Security Imputation Algorithm}

In section 2B, we describe our methodology for splitting social security dollars into SSDI and OASI when no information regarding the type of social security received is available. The fractions of total social security dollars in the surveys that are subjected to our strategy in order to estimate OASI and SSDI are tabulated in the table below. ${ }^{57}$

\section{Share of Social Security Dollars for which Retirement/Disability/Survivors is uncertain}

\begin{tabular}{ccc}
\hline \hline Calendar Year & PSID & SIPP \\
\hline 1983 & 0.016 & 0.127 \\
1984 & 0.011 & 0.170 \\
1985 & 0.011 & 0.167 \\
1986 & 0.012 & 0.165 \\
1987 & 0.015 & 0.147 \\
1988 & 0.026 & 0.114 \\
1989 & 0.016 & 0.099 \\
1990 & 0.028 & 0.080 \\
1991 & 0.032 & 0.106 \\
1992 & 0.047 & 0.110 \\
1993 & & 0.107 \\
1994 & & 0.131 \\
1995 & & 0.140 \\
1996 & & 0.075 \\
1997 & & 0.103 \\
1998 & & 0.066 \\
1999 & & 0.049 \\
2000 & & 0.050 \\
2001 & & 0.045 \\
2002 & & 0.044 \\
2003 & & 0.046 \\
2004 & & 0.048 \\
2005 & & 0.039 \\
\hline
\end{tabular}

Note: This table shows, for each calendar year and each survey, the percentage of total Social

Security Benefits that must be subjected to the imputation algorithm to separately obtain SSDI and OASI.

Note that the SIPP has higher imputation rates than those of the PSID because of: 1) Lack of program information about Children's Social Security benefits, which is about $4 \%$ in each year in the SIPP; and 2) When the individual is asked to report up to two reasons for receiving social security, one possible response is "Spouse or Dependent Child" and such social security income will be subjected to imputation. ${ }^{58}$ The SIPP imputation rates in 1998-2003 are lower than those in the earlier years because the reason for social security receipt is available in every wave (and it is subjected to changes between waves). In 1983-1995, however, these responses

\footnotetext{
${ }^{57}$ For CPS-ADF/ASEC and the CE Survey, the type of social security received is never asked.

${ }^{58}$ In the PSID (1984-1993 surveys), the type of social security received by the individual is categorized into one of the following: Disability, Retirement, Survivor benefits, Combination of the OASI and SSDI, Dependent of Disabled recipient, Dependent of Deceased recipient.
} 
are typically available only once per panel (thus, whether imputation is needed depends only on this response). 
Table 1: Benefit Programs and Periods Examined, by Survey

A. Aggregate Dollars

\begin{tabular}{lccccc}
\hline \hline & \multicolumn{5}{c}{ Survey and Calendar Years } \\
\cline { 2 - 6 } \multicolumn{1}{c}{ Benefit Program } & \multirow{2}{*}{ PSID } & SIPP & CPS- & ACS & \multirow{2}{*}{ CE Survey } \\
\hline AFDC/TANF & $1970-2004$ & $1983-2004$ & $1975-2004$ & $2000-2004$ & $1979-2004$ \\
FSP & $1973-2004$ & $1983-2005$ & $1979-2006$ & $2004-2005$ & $1979-2006$ \\
OASI & $1970-2003$ & $1983-2005$ & $1967-2006$ & $2000-2006$ & $1979-2006$ \\
SSDI & $1970-2003$ & $1983-2005$ & $1967-2006$ & $2000-2006$ & $1979-2006$ \\
SSI & $1974-2004$ & $1983-2005$ & $1975-2007$ & $2000-2006$ & $1979-2006$ \\
UI & $1976-2004$ & $1983-2005$ & $1987-2007$ & & $1979-2006$ \\
WC & $1976-2004$ & $1983-2005$ & $1987-2006$ & & $1979-2006$ \\
EITC & & & $1991-2006$ & & \\
\hline
\end{tabular}

Note: For the NSLP and WIC program, how to measure dollar information is conceptually unclear and also not available.

B. Average Monthly Participation

\begin{tabular}{|c|c|c|c|c|c|}
\hline \multirow[b]{2}{*}{$\begin{array}{l}\text { Benefit } \\
\text { Program }\end{array}$} & \multicolumn{5}{|c|}{ Survey and Calendar Years } \\
\hline & PSID & SIPP & $\begin{array}{c}\text { CPS- } \\
\text { ADF/ASEC }\end{array}$ & ACS & CE Survey \\
\hline \multirow{2}{*}{ AFDC/TANF } & 1993-2004 & $1983-2005$ & $1987-2007$ & & \\
\hline & $\begin{array}{l}\text { Retrospective \# } \\
\text { of months }\end{array}$ & Monthly & $\begin{array}{l}\text { Retrospective } \\
\# \text { of months }\end{array}$ & & \\
\hline \multirow{2}{*}{ FSP } & $1980-2004$ & $1983-2005$ & 1980-2006 & & \\
\hline & $\begin{array}{l}\text { Retrospective \# } \\
\text { of months }\end{array}$ & Monthly & $\begin{array}{l}\text { Retrospective } \\
\text { \# of months }\end{array}$ & & \\
\hline \multirow[t]{2}{*}{ OASI } & $1974-2003$ & 1983-2005 & $1974-2007$ & 2000-2006 & \\
\hline & At all last year & Monthly & $\begin{array}{c}\text { At all last } \\
\text { year }\end{array}$ & $\begin{array}{l}\text { At all last } \\
12 \text { months }\end{array}$ & \\
\hline \multirow[t]{2}{*}{ SSDI } & $1974-2003$ & $1983-2005$ & $1974-2007$ & $2000-2006$ & \\
\hline & At all last year & Monthly & $\begin{array}{c}\text { At all last } \\
\text { year }\end{array}$ & $\begin{array}{l}\text { At all last } \\
12 \text { months }\end{array}$ & \\
\hline \multirow{3}{*}{ SSI } & 1974-1991 At & $1983-2005$ & $1975-2007$ & & \\
\hline & $\begin{array}{l}\text { all last year } \\
1992-2004\end{array}$ & Monthly & $\begin{array}{c}\text { At all last } \\
\text { year }\end{array}$ & & \\
\hline & $\begin{array}{l}\text { Retrospective \# } \\
\text { of months }\end{array}$ & & & & \\
\hline \multirow[t]{2}{*}{ WIC } & $1998-2004$ & $1983-2005$ & $2000-2007$ & & \\
\hline & At all last year & Monthly & $\begin{array}{l}\text { At all last } \\
\text { year }\end{array}$ & & \\
\hline \multirow{2}{*}{ NSLP } & $1998-2004$ & $1983-2005$ & $1979-2006$ & & \\
\hline & At all last year & $\begin{array}{l}\text { At all last } 4 \\
\text { months }\end{array}$ & $\begin{array}{c}\text { At all last } \\
\text { year }\end{array}$ & & \\
\hline
\end{tabular}

Note: Several of the surveys report combined receipt and dollars for OASI and SSDI. See the Data Appendix for more details. UI, WC and the EITC are not paid on a monthly basis. 
Table 2

Aid to Families with Dependent Children/Temporary Assistance for Needy Families Dollar Reporting Rates

\begin{tabular}{|c|c|c|c|c|c|c|c|c|c|c|c|c|c|c|}
\hline \multirow[b]{2}{*}{ Year } & \multicolumn{2}{|c|}{$\begin{array}{c}\text { Administrative } \\
\text { Total } \\
\text { (in millions of } \\
\text { dollars) } \\
\end{array}$} & \multicolumn{6}{|c|}{ Survey - Weighted Total (in millions of dollars) } & \multicolumn{4}{|c|}{ Reporting Rate } & \multicolumn{2}{|c|}{$\begin{array}{l}\text { Reporting Rate } \\
\text { (with GA) }\end{array}$} \\
\hline & $\begin{array}{l}\text { AFDC/ } \\
\text { TANF }\end{array}$ & $\begin{array}{c}\text { AFDC/ } \\
\text { TANF } \\
+ \text { GA } \\
\end{array}$ & PSID & SIPP & $\begin{array}{l}\text { CPS- } \\
\text { ADF/ } \\
\text { ASEC }\end{array}$ & $\mathrm{ACS}$ & $\begin{array}{c}\text { CE } \\
\text { Survey }\end{array}$ & PSID & SIPP & $\begin{array}{l}\text { CPS- } \\
\text { ADF/ } \\
\text { ASEC }\end{array}$ & ACS & $\begin{array}{c}\text { CE } \\
\text { Survey }\end{array}$ & ACS & $\begin{array}{c}\text { CE } \\
\text { Survey }\end{array}$ \\
\hline 1970 & 4,750 & 7,770 & 4,379 & & & & & 0.922 & & & & & & \\
\hline 1971 & 5,984 & 9,842 & 4,703 & & & & & 0.786 & & & & & & \\
\hline 1972 & 6,747 & 10,018 & 4,413 & & & & & 0.654 & & & & & & \\
\hline 1973 & 7,155 & 10,234 & 4,306 & & & & & 0.602 & & & & & & \\
\hline 1974 & 7,861 & 11,030 & 5,716 & & & & & 0.727 & & & & & & \\
\hline 1975 & 9,016 & 13,009 & 6,035 & & 6,630 & & & 0.669 & & 0.735 & & & & \\
\hline 1976 & 10,004 & 14,123 & 6,644 & & 7,051 & & & 0.664 & & 0.705 & & & & \\
\hline 1977 & 10,417 & 14,284 & 6,522 & & 7,665 & & & 0.626 & & 0.736 & & & & \\
\hline 1978 & 10,631 & 14,225 & 6,938 & & 7,436 & & & 0.653 & & 0.699 & & & & \\
\hline 1979 & 11,003 & 14,231 & 7,116 & & 7,798 & & 9,266 & 0.647 & & 0.709 & & 0.842 & & 0.651 \\
\hline 1980 & 12,114 & 15,432 & 8,516 & & 9,021 & & 8,316 & 0.703 & & 0.745 & & 0.687 & & 0.539 \\
\hline 1981 & 12,770 & 16,208 & 9,196 & & 9,164 & & 8,210 & 0.720 & & 0.718 & & 0.643 & & 0.507 \\
\hline 1982 & 12,973 & 16,414 & 8,907 & & 9,554 & & 8,705 & 0.687 & & 0.736 & & 0.671 & & 0.530 \\
\hline 1983 & 13,727 & 17,453 & 9,803 & 10,830 & 10,262 & & 9,287 & 0.714 & 0.789 & 0.748 & & 0.677 & & 0.532 \\
\hline 1984 & 14,352 & 18,111 & 9,449 & 11,676 & 10,711 & & 9,456 & 0.658 & 0.814 & 0.746 & & 0.659 & & 0.522 \\
\hline 1985 & 14,676 & 18,669 & 8,768 & 11,452 & 11,052 & & 8,952 & 0.597 & 0.780 & 0.753 & & 0.610 & & 0.480 \\
\hline 1986 & 15,437 & 19,535 & 8,940 & 11,477 & 12,096 & & 12,165 & 0.579 & 0.743 & 0.784 & & 0.788 & & 0.623 \\
\hline 1987 & 16,336 & 20,634 & 9,179 & 11,926 & 11,722 & & 12,804 & 0.562 & 0.730 & 0.718 & & 0.784 & & 0.621 \\
\hline 1988 & 16,734 & 21,026 & 10,097 & 11,519 & 11,980 & & 12,123 & 0.603 & 0.688 & 0.716 & & 0.724 & & 0.577 \\
\hline 1989 & 17,486 & 22,054 & 10,098 & 12,359 & 12,167 & & 11,965 & 0.577 & 0.707 & 0.696 & & 0.684 & & 0.543 \\
\hline 1990 & 18,911 & 23,244 & 10,795 & 14,441 & 13,463 & & 13,972 & 0.571 & 0.764 & 0.712 & & 0.739 & & 0.601 \\
\hline 1991 & 20,743 & 25,332 & 12,937 & 15,405 & 14,813 & & 16,241 & 0.624 & 0.743 & 0.714 & & 0.783 & & 0.641 \\
\hline
\end{tabular}


Table 2 (continued)

Aid to Families with Dependent Children/Temporary Assistance for Needy Families Dollar Reporting Rates

\begin{tabular}{|c|c|c|c|c|c|c|c|c|c|c|c|c|c|c|}
\hline \multirow[b]{2}{*}{ Year } & \multicolumn{2}{|c|}{$\begin{array}{c}\text { Administrative } \\
\text { Total } \\
\text { (in millions of } \\
\text { dollars) }\end{array}$} & \multicolumn{6}{|c|}{ Survey - Weighted Total (in millions of dollars) } & \multicolumn{3}{|c|}{ Reporting Rate } & \multicolumn{3}{|c|}{$\begin{array}{l}\text { Reporting Rate } \\
\text { (with GA) }\end{array}$} \\
\hline & $\begin{array}{c}\text { AFDC/ } \\
\text { TANF }\end{array}$ & $\begin{array}{l}\text { AFDC/ } \\
\text { TANF } \\
+ \text { GA }\end{array}$ & PSID & SIPP & $\begin{array}{l}\text { CPS- } \\
\text { ADF/ } \\
\text { ASEC }\end{array}$ & $\mathrm{ACS}$ & $\begin{array}{c}\text { CE } \\
\text { Survey }\end{array}$ & PSID & SIPP & $\begin{array}{l}\text { CPS- } \\
\text { ADF/ } \\
\text { ASEC }\end{array}$ & ACS & $\begin{array}{c}\text { CE } \\
\text { Survey }\end{array}$ & ACS & $\begin{array}{c}\text { CE } \\
\text { Survey }\end{array}$ \\
\hline 1992 & 22,169 & 27,041 & 12,486 & 15,931 & 15,033 & & 18,603 & 0.563 & 0.719 & 0.678 & & 0.839 & & 0.688 \\
\hline 1993 & 22,318 & 27,184 & 11,614 & 18,191 & 16,712 & & 19,103 & 0.520 & 0.815 & 0.749 & & 0.856 & & 0.703 \\
\hline 1994 & 22,509 & 27,121 & 10,255 & 17,853 & 16,165 & & 17,358 & 0.456 & 0.793 & 0.718 & & 0.771 & & 0.640 \\
\hline 1995 & 21,534 & 26,147 & 10,349 & 18,359 & 14,940 & & 15,309 & 0.481 & 0.853 & 0.694 & & 0.711 & & 0.585 \\
\hline 1996 & 19,611 & 23,843 & 10,109 & 15,104 & 13,107 & & 11,851 & 0.515 & 0.770 & 0.668 & & 0.604 & & 0.497 \\
\hline 1997 & 16,742 & 20,758 & & 12,675 & 9,888 & & 9,840 & & 0.757 & 0.591 & & 0.588 & & 0.474 \\
\hline 1998 & 14,282 & 18,476 & 5,555 & 9,692 & 7,797 & & 8,017 & 0.389 & 0.679 & 0.546 & & 0.561 & & 0.434 \\
\hline 1999 & 12,849 & 17,069 & & 7,635 & 6,015 & & 6,217 & & 0.594 & 0.468 & & 0.484 & & 0.364 \\
\hline 2000 & 10,867 & 14,950 & 4,181 & 6,760 & 5,741 & 8,232 & 5,161 & 0.385 & 0.622 & 0.528 & 0.694 & 0.475 & 0.514 & 0.345 \\
\hline 2001 & 9,923 & 13,231 & & 5,812 & 4,892 & 7,983 & 4,905 & & 0.586 & 0.493 & 0.768 & 0.494 & 0.567 & 0.371 \\
\hline 2002 & 9,576 & 13,701 & 3,051 & 5,384 & 4,920 & 8,092 & 4,473 & 0.319 & 0.562 & 0.514 & 0.830 & 0.467 & 0.601 & 0.326 \\
\hline 2003 & 10,211 & 16,686 & 4,164 & 5,514 & 5,493 & 8,763 & 4,779 & 0.408 & 0.540 & 0.538 & 0.886 & 0.468 & 0.577 & 0.286 \\
\hline 2004 & 10,421 & 17,968 & 5,333 & 6,486 & 5,075 & 8,559 & 4,569 & 0.512 & 0.622 & 0.487 & 0.830 & 0.438 & 0.494 & 0.254 \\
\hline 2005 & & & & 6,407 & 5,213 & 8,789 & 5,106 & & & & & & & \\
\hline 2006 & & & & & 4,343 & 8,914 & 4,957 & & & & & & & \\
\hline 2007 & & & & & 3,932 & & & & & & & & & \\
\hline Average & & & & & & & & 0.597 & 0.712 & 0.668 & 0.801 & 0.656 & 0.550 & 0.513 \\
\hline
\end{tabular}

Note: For the ACS, the reporting rate is computed by comparing the survey year total with the average of the current and previous years' administrative totals. 
Table 3

Food Stamp Program Dollar Reporting Rates

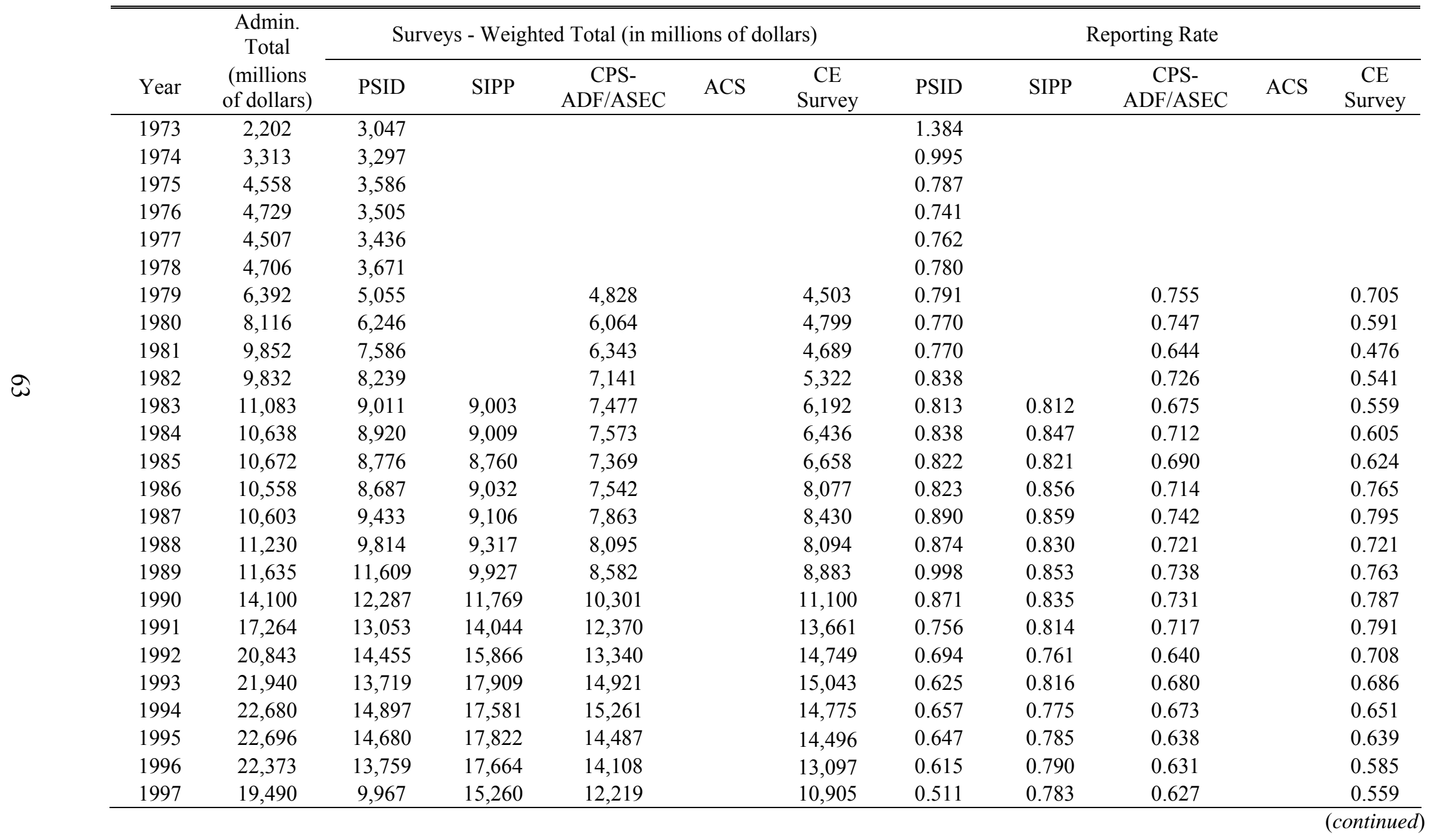


Table 3 (continued)

Food Stamp Program Dollar Reporting Rates

\begin{tabular}{|c|c|c|c|c|c|c|c|c|c|c|c|}
\hline \multirow[b]{2}{*}{ Year } & \multirow{2}{*}{$\begin{array}{c}\text { Admin. } \\
\text { Total } \\
\text { (millions } \\
\text { of dollars) }\end{array}$} & \multicolumn{5}{|c|}{ Surveys - Weighted Total (in millions of dollars) } & \multicolumn{5}{|c|}{ Reporting Rate } \\
\hline & & PSID & SIPP & $\begin{array}{c}\text { CPS- } \\
\text { ADF/ASEC }\end{array}$ & ACS & $\begin{array}{c}\mathrm{CE} \\
\text { Survey }\end{array}$ & PSID & SIPP & $\begin{array}{c}\text { CPS- } \\
\text { ADF/ASEC }\end{array}$ & ACS & $\begin{array}{c}\text { CE } \\
\text { Survey }\end{array}$ \\
\hline 1998 & 16,840 & 9,866 & 13,249 & 10,756 & & 8,895 & 0.586 & 0.787 & 0.639 & & 0.528 \\
\hline 1999 & 15,722 & 10,446 & 12,167 & 9,449 & & 8,537 & 0.664 & 0.774 & 0.601 & & 0.543 \\
\hline 2000 & 14,938 & 10,848 & 12,078 & 8,711 & & 8,252 & 0.726 & 0.809 & 0.583 & & 0.552 \\
\hline 2001 & 15,501 & 8,651 & 13,712 & 9,655 & & 6,922 & 0.558 & 0.885 & 0.623 & & 0.447 \\
\hline 2002 & 14,938 & 10,659 & 15,846 & 11,158 & & 7,765 & 0.714 & 1.061 & 0.747 & & 0.520 \\
\hline 2003 & 22,205 & 20,199 & 17,771 & 12,823 & & 10,003 & 0.910 & 0.800 & 0.577 & & 0.450 \\
\hline 2004 & 25,788 & 21,963 & 20,714 & 14,622 & & 9,682 & 0.852 & 0.803 & 0.567 & & 0.375 \\
\hline 2005 & 29,540 & & 22,572 & 16,132 & 15,472 & 10,998 & & 0.764 & 0.546 & 0.559 & 0.372 \\
\hline 2006 & 29,440 & & & 15,878 & 16,000 & 11,243 & & & 0.539 & 0.543 & 0.382 \\
\hline 2007 & 30,988 & & & & & & & & & & \\
\hline Average & & & & & & & 0.783 & 0.823 & 0.665 & 0.551 & 0.597 \\
\hline
\end{tabular}

Note: For the ACS, the reporting rate is computed by comparing the survey year total with the average of the current and previous years' administrative totals. 
Table 4

Social Security Old Age, Survivors and Disability Insurance (OASDI) Dollar Reporting Rates

\begin{tabular}{|c|c|c|c|c|c|c|c|c|c|c|c|c|}
\hline \multirow[b]{2}{*}{ Year } & \multirow{2}{*}{$\begin{array}{l}\text { Admin. } \\
\text { Total } \\
\text { (millions }\end{array}$} & \multirow{2}{*}{$\begin{array}{c}\text { Admin. } \\
\text { Total (with } \\
\text { Railroad } \\
\text { Retirement) } \\
\text { of dollars) }\end{array}$} & \multicolumn{6}{|c|}{ Surveys - Weighted Total (in millions of dollars) } & \multicolumn{4}{|c|}{ Reporting Rate } \\
\hline & & & PSID & SIPP & $\begin{array}{c}\text { CPS- } \\
\text { ADF/ASEC }\end{array}$ & ACS & CE Survey & PSID & SIPP & $\begin{array}{c}\text { CPS- } \\
\text { ADF/ASEC }\end{array}$ & $\mathrm{ACS}$ & $\begin{array}{c}\text { CE } \\
\text { Survey }\end{array}$ \\
\hline 1967 & 20,506 & 21,591 & & & 19,270 & & & & & 0.893 & & \\
\hline 1968 & 23,880 & 25,196 & & & 21,538 & & & & & 0.855 & & \\
\hline 1969 & 25,611 & 27,158 & & & & & & & & & & \\
\hline 1970 & 30,498 & 32,045 & 24,223 & & 26,593 & & & 0.794 & & 0.830 & & \\
\hline 1971 & 35,548 & 37,095 & 29,277 & & 31,382 & & & 0.824 & & 0.846 & & \\
\hline 1972 & 39,752 & 42,011 & 37,569 & & 36,988 & & & 0.945 & & 0.880 & & \\
\hline 1973 & 49,185 & 52,156 & 38,323 & & 44,511 & & & 0.779 & & 0.853 & & \\
\hline 1974 & 55,925 & 58,896 & 47,884 & & 51,299 & & & 0.856 & & 0.871 & & \\
\hline 1975 & 64,953 & 67,924 & 54,770 & & 57,049 & & & 0.843 & & 0.878 & & \\
\hline 1976 & 73,436 & 76,453 & 63,846 & & 62,774 & & & 0.869 & & 0.855 & & \\
\hline 1977 & 82,049 & 85,478 & 70,157 & & 70,004 & & & 0.855 & & 0.853 & & \\
\hline 1978 & 90,073 & 94,735 & 77,771 & & 78,118 & & & 0.863 & & 0.867 & & \\
\hline 1979 & 101,114 & 105,777 & 87,688 & & 87,375 & & 92,946 & 0.867 & & 0.864 & & 0.879 \\
\hline 1980 & 116,863 & 121,663 & 104,290 & & 103,255 & & 94,073 & 0.892 & & 0.884 & & 0.773 \\
\hline 1981 & 136,739 & 142,058 & 122,729 & & 119,447 & & 95,666 & 0.898 & & 0.874 & & 0.673 \\
\hline 1982 & 151,482 & 157,204 & 135,318 & & 132,178 & & 111,969 & 0.893 & & 0.873 & & 0.712 \\
\hline 1983 & 162,075 & 168,044 & 142,173 & 143,821 & 139,037 & & 132,241 & 0.877 & 0.887 & 0.858 & & 0.787 \\
\hline 1984 & 170,554 & 176,604 & 153,390 & 159,679 & 148,419 & & 152,911 & 0.899 & 0.936 & 0.870 & & 0.866 \\
\hline 1985 & 178,237 & 184,418 & 165,506 & 169,838 & 157,284 & & 147,737 & 0.929 & 0.953 & 0.882 & & 0.801 \\
\hline 1986 & 188,306 & 194,508 & 175,747 & 178,348 & 164,882 & & 172,284 & 0.933 & 0.947 & 0.876 & & 0.886 \\
\hline 1987 & 195,468 & 201,846 & 181,834 & 185,756 & 173,887 & & 186,857 & 0.930 & 0.950 & 0.890 & & 0.926 \\
\hline 1988 & 207,982 & 214,560 & 194,194 & 197,863 & 184,189 & & 196,106 & 0.934 & 0.951 & 0.886 & & 0.914 \\
\hline
\end{tabular}


Table 4 (continued)

Social Security Old Age, Survivors and Disability Insurance (OASDI) Dollar Reporting Rates

\begin{tabular}{|c|c|c|c|c|c|c|c|c|c|c|c|c|}
\hline \multirow[b]{2}{*}{ Year } & \multirow{2}{*}{$\begin{array}{l}\text { Admin. } \\
\text { Total } \\
\text { (millions }\end{array}$} & \multirow{2}{*}{$\begin{array}{c}\text { Admin. } \\
\text { Total (with } \\
\text { Railroad } \\
\text { Retirement) } \\
\text { of dollars) }\end{array}$} & \multicolumn{6}{|c|}{ Surveys - Weighted Total (in millions of dollars) } & \multicolumn{4}{|c|}{ Reporting Rate } \\
\hline & & & PSID & SIPP & $\begin{array}{c}\text { CPS- } \\
\text { ADF/ASEC }\end{array}$ & ACS & CE Survey & PSID & SIPP & $\begin{array}{c}\text { CPS- } \\
\text { ADF/ASEC }\end{array}$ & ACS & $\begin{array}{c}\mathrm{CE} \\
\text { Survey }\end{array}$ \\
\hline 1989 & 221,038 & 227,936 & 221,691 & 210,534 & 197,162 & & 208,473 & 1.003 & 0.952 & 0.892 & & 0.915 \\
\hline 1990 & 237,310 & 244,468 & 233,242 & 228,329 & 209,783 & & 221,739 & 0.983 & 0.962 & 0.884 & & 0.907 \\
\hline 1991 & 256,789 & 264,200 & 243,246 & 243,941 & 221,757 & & 243,525 & 0.947 & 0.950 & 0.864 & & 0.922 \\
\hline 1992 & 273,976 & 281,575 & 254,224 & 251,658 & 235,734 & & 261,749 & 0.928 & 0.919 & 0.860 & & 0.930 \\
\hline 1993 & 289,634 & 297,382 & 261,601 & 262,309 & 248,143 & & 268,894 & 0.903 & 0.906 & 0.857 & & 0.904 \\
\hline 1994 & 303,389 & 311,231 & 273,655 & 270,954 & 274,696 & & 275,323 & 0.902 & 0.893 & 0.905 & & 0.885 \\
\hline 1995 & 316,355 & 324,267 & 294,829 & 285,338 & 287,378 & & 289,999 & 0.932 & 0.902 & 0.908 & & 0.894 \\
\hline 1996 & 330,139 & 338,064 & 308,459 & 292,735 & 298,819 & & 314,163 & 0.934 & 0.887 & 0.905 & & 0.929 \\
\hline 1997 & 344,298 & 352,303 & & 303,966 & 315,494 & & 320,145 & & 0.883 & 0.916 & & 0.909 \\
\hline 1998 & 356,673 & 364,700 & 325,602 & 313,496 & 320,133 & & 328,639 & 0.913 & 0.879 & 0.898 & & 0.901 \\
\hline 1999 & 366,883 & 374,932 & & 323,984 & 333,311 & & 339,417 & & 0.883 & 0.908 & & 0.905 \\
\hline 2000 & 387,687 & 395,809 & 368,864 & 345,768 & 352,480 & 310,442 & 297,242 & 0.951 & 0.892 & 0.909 & 0.806 & 0.751 \\
\hline 2001 & 410,715 & 418,990 & & 366,612 & 375,663 & 336,735 & 357,090 & & 0.893 & 0.915 & 0.827 & 0.852 \\
\hline 2002 & 431,448 & 439,945 & 388,333 & 382,062 & 386,170 & 353,229 & 378,217 & 0.900 & 0.886 & 0.895 & 0.822 & 0.860 \\
\hline 2003 & 447,562 & 456,248 & 329,149 & 405,925 & 405,366 & 368,006 & 395,177 & 0.735 & 0.907 & 0.906 & 0.821 & 0.866 \\
\hline 2004 & 468,926 & 477,748 & & 456,915 & 425,986 & 382,034 & 389,007 & & 0.974 & 0.908 & 0.818 & 0.814 \\
\hline 2005 & 496,041 & 505,044 & & 482,380 & 444,002 & 396,749 & 449,621 & & 0.972 & 0.895 & 0.807 & 0.890 \\
\hline 2006 & 526,541 & 535,818 & & & 470,328 & 421,573 & 423,956 & & & 0.893 & 0.810 & 0.791 \\
\hline 2007 & & & & & 492,700 & & & & & & & \\
\hline Average & & & & & & & & 0.894 & 0.920 & 0.881 & 0.816 & 0.859 \\
\hline
\end{tabular}

Note: The administrative totals include retirement benefits, survivors benefits and benefits paid to special age-72 beneficiaries, lump sum death payments and payments received by disabled workers, their spouse and their children. Survivor's benefits include payments to surviving children, widowed mothers and fathers, widows and widowers and parents. For the CE Survey and the CPS (1968-1975) the reporting rate is calculated using the administrative total that includes Railroad Retirement. For the ACS, the reporting rate is computed by comparing the survey year total with the average of the current and previous years' administrative totals. 
Table 5

Social Security Old Aged and Survivors Insurance (OASI) Dollar Reporting Rates

\begin{tabular}{|c|c|c|c|c|c|c|c|c|c|c|c|c|}
\hline \multirow[b]{2}{*}{ Year } & \multirow{2}{*}{$\begin{array}{l}\text { Admin. } \\
\text { Total } \\
\text { (million }\end{array}$} & \multirow{2}{*}{$\begin{array}{c}\text { Admin. } \\
\text { Total (with } \\
\text { Railroad } \\
\text { Retirement) } \\
\text { of dollars) }\end{array}$} & \multicolumn{6}{|c|}{ Surveys - Weighted Total (in millions of dollars) } & \multicolumn{4}{|c|}{ Reporting Rate } \\
\hline & & & PSID & SIPP & $\begin{array}{c}\text { CPS- } \\
\text { ADF/ASEC }\end{array}$ & ACS & $\begin{array}{c}\text { CE } \\
\text { Survey }\end{array}$ & PSID & SIPP & $\begin{array}{c}\text { CPS- } \\
\text { ADF/ASEC }\end{array}$ & ACS & $\begin{array}{c}\text { CE } \\
\text { Survey }\end{array}$ \\
\hline 1967 & 18,646 & 19,731 & & & 17,085 & & & & & 0.866 & & \\
\hline 1968 & 21,683 & 22,999 & & & 19,238 & & & & & 0.836 & & \\
\hline 1969 & 23,180 & 24,727 & & & & & & & & & & \\
\hline 1970 & 27,569 & 29,116 & 20,431 & & 23,671 & & & 0.741 & & 0.813 & & \\
\hline 1971 & 31,962 & 33,509 & 24,415 & & 27,833 & & & 0.764 & & 0.831 & & \\
\hline 1972 & 35,488 & 37,747 & 31,715 & & 32,531 & & & 0.894 & & 0.862 & & \\
\hline 1973 & 43,740 & 46,711 & 32,525 & & 38,719 & & & 0.744 & & 0.829 & & \\
\hline 1974 & 49,355 & 52,326 & 40,650 & & 44,482 & & & 0.824 & & 0.850 & & \\
\hline 1975 & 56,838 & 59,855 & 45,650 & & 48,960 & & & 0.803 & & 0.861 & & \\
\hline 1976 & 63,833 & 66,849 & 53,660 & & 53,830 & & & 0.841 & & 0.843 & & \\
\hline 1977 & 71,023 & 74,452 & 59,192 & & 59,760 & & & 0.833 & & 0.841 & & \\
\hline 1978 & 78,056 & 82,719 & 64,769 & & 66,870 & & & 0.830 & & 0.857 & & \\
\hline 1979 & 87,959 & 92,622 & 73,850 & & 74,776 & & 79,891 & 0.840 & & 0.850 & & 0.863 \\
\hline 1980 & 102,071 & 106,871 & 89,359 & & 89,122 & & 80,702 & 0.875 & & 0.873 & & 0.755 \\
\hline 1981 & 120,258 & 125,578 & 103,931 & & 103,781 & & 83,295 & 0.864 & & 0.863 & & 0.663 \\
\hline 1982 & 134,876 & 140,598 & 116,768 & & 116,472 & & 98,615 & 0.866 & & 0.864 & & 0.701 \\
\hline 1983 & 145,297 & 151,266 & 124,441 & 129,502 & 123,350 & & 117,602 & 0.856 & 0.891 & 0.849 & & 0.777 \\
\hline 1984 & 153,432 & 159,482 & 136,037 & 143,352 & 131,994 & & 138,546 & 0.887 & 0.934 & 0.860 & & 0.869 \\
\hline 1985 & 160,471 & 166,569 & 147,166 & 152,394 & 140,472 & & 133,008 & 0.917 & 0.950 & 0.875 & & 0.799 \\
\hline 1986 & 169,583 & 175,784 & 158,495 & 159,944 & 147,319 & & 155,644 & 0.935 & 0.943 & 0.869 & & 0.885 \\
\hline 1987 & 176,093 & 182,471 & 163,622 & 167,268 & 154,490 & & 168,666 & 0.929 & 0.950 & 0.877 & & 0.924 \\
\hline 1988 & 187,486 & 194,064 & 177,372 & 178,025 & 164,376 & & 177,220 & 0.946 & 0.950 & 0.877 & & 0.913 \\
\hline
\end{tabular}


Table 5 (continued)

Social Security Old Aged and Survivors Insurance (OASI) Dollar Reporting Rates

\begin{tabular}{|c|c|c|c|c|c|c|c|c|c|c|c|c|}
\hline \multirow[b]{2}{*}{ Year } & $\begin{array}{l}\text { Admin. } \\
\text { Total }\end{array}$ & $\begin{array}{c}\text { Admin. } \\
\text { Total (with } \\
\text { Railroad }\end{array}$ & \multicolumn{6}{|c|}{ Surveys - Weighted Total (in millions of dollars) } & \multicolumn{4}{|c|}{ Reporting Rate } \\
\hline & (millions & of dollars) & PSID & SIPP & $\begin{array}{c}\text { CPS- } \\
\text { ADF/ASEC }\end{array}$ & ACS & $\begin{array}{c}\text { CE } \\
\text { Survey }\end{array}$ & PSID & SIPP & $\begin{array}{c}\text { CPS- } \\
\text { ADF/ASEC }\end{array}$ & ACS & $\begin{array}{c}\text { CE } \\
\text { Survey }\end{array}$ \\
\hline 1989 & 199,408 & 206,306 & 200,506 & 190,082 & 175,522 & & 188,324 & 1.006 & 0.953 & 0.880 & & 0.913 \\
\hline 1990 & 213,825 & 220,982 & 207,648 & 206,833 & 187,052 & & 200,766 & 0.971 & 0.967 & 0.875 & & 0.909 \\
\hline 1991 & 230,571 & 237,983 & 213,370 & 219,058 & 197,351 & & 218,592 & 0.925 & 0.950 & 0.856 & & 0.919 \\
\hline 1992 & 244,487 & 252,087 & 222,736 & 225,840 & 207,877 & & 234,914 & 0.911 & 0.924 & 0.850 & & 0.932 \\
\hline 1993 & 256,799 & 264,548 & 222,887 & 233,770 & 217,526 & & 240,952 & 0.868 & 0.910 & 0.847 & & 0.911 \\
\hline 1994 & 267,650 & 275,492 & 233,663 & 239,679 & 241,010 & & 246,682 & 0.873 & 0.895 & 0.900 & & 0.895 \\
\hline 1995 & 277,857 & 285,716 & 250,496 & 251,111 & 250,835 & & 256,632 & 0.902 & 0.904 & 0.903 & & 0.898 \\
\hline 1996 & 288,557 & 296,483 & 263,592 & 259,750 & 260,612 & & 274,170 & 0.913 & 0.900 & 0.903 & & 0.925 \\
\hline 1997 & 301,319 & 309,323 & & 261,631 & 273,736 & & 278,780 & & 0.868 & 0.908 & & 0.901 \\
\hline 1998 & 311,327 & 319,354 & 281,268 & 261,522 & 278,750 & & 286,308 & 0.903 & 0.840 & 0.895 & & 0.897 \\
\hline 1999 & 318,469 & 326,518 & & 272,399 & 288,344 & & 291,118 & & 0.855 & 0.905 & & 0.892 \\
\hline 2000 & 335,879 & 344,001 & 322,318 & 302,932 & 308,420 & 273,532 & 254,479 & 0.960 & 0.902 & 0.918 & 0.816 & 0.740 \\
\hline 2001 & 354,518 & 362,793 & & 324,550 & 327,070 & 296,445 & 302,642 & & 0.915 & 0.923 & 0.839 & 0.834 \\
\hline 2002 & 369,504 & 378,002 & 332,445 & 337,427 & 335,870 & 310,013 & 325,241 & 0.900 & 0.913 & 0.909 & 0.837 & 0.860 \\
\hline 2003 & 380,612 & 389,298 & 289,711 & 355,405 & 352,088 & 320,748 & 343,873 & 0.761 & 0.934 & 0.925 & 0.836 & 0.883 \\
\hline 2004 & 395,005 & 403,828 & & 394,457 & 365,943 & 332,643 & 333,397 & & 0.999 & 0.926 & 0.839 & 0.826 \\
\hline 2005 & 415,093 & 424,096 & & 413,833 & 377,881 & 343,495 & 382,863 & & 0.997 & 0.910 & 0.830 & 0.903 \\
\hline 2006 & 438,915 & 448,193 & & & 398,559 & 362,620 & 364,938 & & & 0.908 & 0.831 & 0.814 \\
\hline 2007 & & & & & 415,921 & & & & & & & \\
\hline Average & & & & & & & & 0.874 & 0.924 & 0.874 & 0.833 & 0.857 \\
\hline
\end{tabular}

Note: The administrative totals include retirement benefits, survivors benefits and benefits paid to special age-72 beneficiaries and lump sum death payments. Survivor's benefits include payments to surviving children, widowed mothers and fathers, widows and widowers and parents. For the CE Survey and the CPS (1968-1975) the reporting rate is calculated using the administrative total that includes Railroad Retirement. For the ACS, the reporting rate is computed by comparing the survey year total with the average of the current and previous years' administrative totals. 
Table 6

Social Security Disability Insurance (SSDI) Dollar Reporting Rates

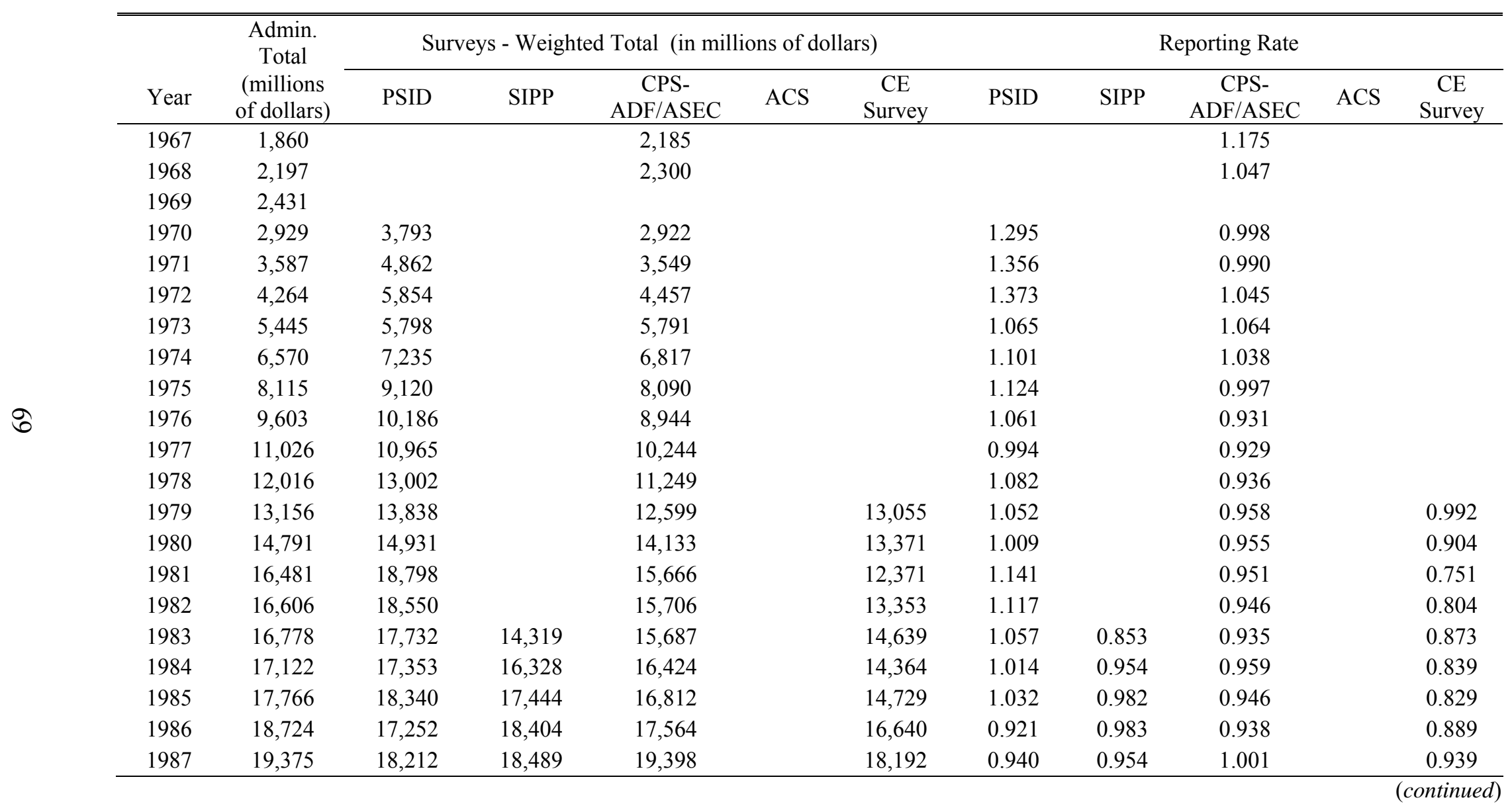


Table 6 (continued)

Social Security Disability Insurance (SSDI) Dollar Reporting Rates

\begin{tabular}{|c|c|c|c|c|c|c|c|c|c|c|c|}
\hline \multirow[b]{2}{*}{ Year } & \multirow{2}{*}{$\begin{array}{c}\text { Admin. } \\
\text { Total } \\
\text { (millions of } \\
\text { dollars) }\end{array}$} & \multicolumn{5}{|c|}{ Surveys - Weighted Total (in millions of dollars) } & \multicolumn{5}{|c|}{ Reporting Rate } \\
\hline & & PSID & SIPP & $\begin{array}{c}\text { CPS- } \\
\text { ADF/ASEC }\end{array}$ & ACS & $\begin{array}{c}\text { CE } \\
\text { Survey }\end{array}$ & PSID & SIPP & $\begin{array}{c}\text { CPS- } \\
\text { ADF/ASEC }\end{array}$ & ACS & $\begin{array}{c}\text { CE } \\
\text { Survey }\end{array}$ \\
\hline 1988 & 20,495 & 16,822 & 19,838 & 19,813 & & 18,886 & 0.821 & 0.968 & 0.967 & & 0.921 \\
\hline 1989 & 21,629 & 21,185 & 20,452 & 21,640 & & 20,150 & 0.979 & 0.946 & 1.000 & & 0.932 \\
\hline 1990 & 23,486 & 25,594 & 21,495 & 22,732 & & 20,973 & 1.090 & 0.915 & 0.968 & & 0.893 \\
\hline 1991 & 26,218 & 29,876 & 24,883 & 24,406 & & 24,933 & 1.140 & 0.949 & 0.931 & & 0.951 \\
\hline 1992 & 29,488 & 31,488 & 25,818 & 27,857 & & 26,835 & 1.068 & 0.876 & 0.945 & & 0.910 \\
\hline 1993 & 32,835 & 38,714 & 28,539 & 30,617 & & 27,942 & 1.179 & 0.869 & 0.932 & & 0.851 \\
\hline 1994 & 35,739 & 39,993 & 31,275 & 33,686 & & 28,641 & 1.119 & 0.875 & 0.943 & & 0.801 \\
\hline 1995 & 38,498 & 44,333 & 34,226 & 36,543 & & 33,366 & 1.152 & 0.889 & 0.949 & & 0.867 \\
\hline 1996 & 41,582 & 44,867 & 32,986 & 38,206 & & 39,993 & 1.079 & 0.793 & 0.919 & & 0.962 \\
\hline 1997 & 42,980 & & 42,334 & 41,759 & & 41,365 & & 0.985 & 0.972 & & 0.962 \\
\hline 1998 & 45,346 & 44,334 & 51,974 & 41,383 & & 42,331 & 0.978 & 1.146 & 0.913 & & 0.933 \\
\hline 1999 & 48,414 & & 51,585 & 44,967 & & 48,299 & & 1.065 & 0.929 & & 0.998 \\
\hline 2000 & 51,808 & 46,547 & 42,836 & 44,059 & 36,911 & 42,763 & 0.898 & 0.827 & 0.850 & 0.737 & 0.825 \\
\hline 2001 & 56,197 & & 42,062 & 48,590 & 40,290 & 54,448 & & 0.748 & 0.865 & 0.746 & 0.969 \\
\hline 2002 & 61,943 & 55,887 & 44,636 & 50,297 & 43,215 & 52,976 & 0.902 & 0.721 & 0.812 & 0.732 & 0.855 \\
\hline 2003 & 66,951 & 39,438 & 50,521 & 53,262 & 47,258 & 51,304 & 0.589 & 0.755 & 0.796 & 0.733 & 0.766 \\
\hline 2004 & 73,920 & & 62,458 & 59,962 & 49,391 & 55,610 & & 0.845 & 0.811 & 0.701 & 0.752 \\
\hline 2005 & 80,948 & & 68,547 & 66,087 & 53,254 & 66,758 & & 0.847 & 0.816 & 0.688 & 0.825 \\
\hline 2006 & 87,625 & & & 71,757 & 58,953 & 59,017 & & & 0.819 & 0.699 & 0.674 \\
\hline 2007 & & & & 76,767 & & & & & & & \\
\hline Average & & & & & & & 1.056 & 0.902 & 0.945 & 0.719 & 0.874 \\
\hline
\end{tabular}

Note: The administrative totals include payments received by the disabled workers, their spouse and their children. For the ACS, the reporting rate is computed by comparing the survey year total with the average of the current and previous years' administrative totals. 
Table 7

Supplemental Security Income Dollar Reporting Rates

\begin{tabular}{|c|c|c|c|c|c|c|c|c|c|c|c|}
\hline \multirow[b]{2}{*}{ Year } & \multirow{2}{*}{$\begin{array}{c}\text { Admin. Total } \\
\text { (in millions of } \\
\text { dollars) }\end{array}$} & \multicolumn{5}{|c|}{ Surveys - Weighted Total (in millions of dollars) } & \multicolumn{5}{|c|}{ Reporting Rate } \\
\hline & & PSID & SIPP & $\begin{array}{c}\text { CPS- } \\
\text { ADF/ASEC }\end{array}$ & ACS & $\begin{array}{c}\text { CE } \\
\text { Survey }\end{array}$ & PSID & SIPP & $\begin{array}{c}\text { CPS- } \\
\text { ADF/ASEC }\end{array}$ & ACS & $\begin{array}{c}\text { CE } \\
\text { Survey }\end{array}$ \\
\hline 1974 & 5,010 & 3,518 & & & & & 0.702 & & & & \\
\hline 1975 & 5,614 & 3,625 & & 3,609 & & & 0.646 & & 0.643 & & \\
\hline 1976 & 5,793 & 3,497 & & 4,057 & & & 0.604 & & 0.700 & & \\
\hline 1977 & 6,022 & 4,406 & & 4,344 & & & 0.732 & & 0.721 & & \\
\hline 1978 & 6,653 & 4,216 & & 4,573 & & & 0.634 & & 0.687 & & \\
\hline 1979 & 6,782 & 5,776 & & 4,967 & & 6,925 & 0.852 & & 0.732 & & 1.021 \\
\hline 1980 & 7,636 & 5,733 & & 6,055 & & 6,471 & 0.751 & & 0.793 & & 0.848 \\
\hline 1981 & 8,236 & 7,205 & & 6,505 & & 4,329 & 0.875 & & 0.790 & & 0.526 \\
\hline 1982 & 8,598 & 6,928 & & 6,597 & & 4,410 & 0.806 & & 0.767 & & 0.513 \\
\hline 1983 & 9,081 & 7,942 & 7,880 & 7,629 & & 6,314 & 0.875 & 0.868 & 0.840 & & 0.695 \\
\hline 1984 & 9,939 & 7,818 & 9,211 & 8,445 & & 6,305 & 0.787 & 0.927 & 0.850 & & 0.634 \\
\hline 1985 & 10,592 & 7,990 & 9,638 & 8,876 & & 5,381 & 0.754 & 0.910 & 0.838 & & 0.508 \\
\hline 1986 & 11,558 & 9,046 & 10,325 & 9,005 & & 6,484 & 0.783 & 0.893 & 0.779 & & 0.561 \\
\hline 1987 & 12,405 & 7,907 & 11,120 & 9,517 & & 6,734 & 0.637 & 0.896 & 0.767 & & 0.543 \\
\hline 1988 & 13,173 & 9,347 & 12,076 & 10,244 & & 8,611 & 0.710 & 0.917 & 0.778 & & 0.654 \\
\hline 1989 & 14,343 & 10,194 & 12,515 & 11,225 & & 8,885 & 0.711 & 0.873 & 0.783 & & 0.619 \\
\hline 1990 & 15,897 & 10,020 & 12,853 & 12,050 & & 9,927 & 0.630 & 0.809 & 0.758 & & 0.624 \\
\hline 1991 & 18,303 & 10,603 & 14,726 & 14,397 & & 11,707 & 0.579 & 0.805 & 0.787 & & 0.640 \\
\hline 1992 & 21,974 & 11,938 & 16,904 & 15,351 & & 13,796 & 0.543 & 0.769 & 0.699 & & 0.628 \\
\hline 1993 & 24,363 & 15,374 & 18,918 & 18,532 & & 13,644 & 0.631 & 0.776 & 0.761 & & 0.560 \\
\hline 1994 & 25,557 & 13,908 & 20,323 & 18,174 & & 15,944 & 0.544 & 0.795 & 0.711 & & 0.624 \\
\hline 1995 & 27,323 & 13,843 & 22,276 & 19,550 & & 17,562 & 0.507 & 0.815 & 0.715 & & 0.643 \\
\hline 1996 & 28,674 & 15,116 & 26,772 & 22,261 & & 19,001 & 0.527 & 0.934 & 0.776 & & 0.663 \\
\hline 1997 & 28,904 & 16,295 & 28,679 & 22,717 & & 17,395 & 0.564 & 0.992 & 0.786 & & 0.602 \\
\hline
\end{tabular}


Table 7 (continued)

Supplemental Security Income Dollar Reporting Rates

\begin{tabular}{|c|c|c|c|c|c|c|c|c|c|c|c|}
\hline \multirow[b]{2}{*}{ Year } & \multirow{2}{*}{$\begin{array}{l}\text { Admin. Total } \\
\text { (in millions of } \\
\text { dollars) }\end{array}$} & \multicolumn{5}{|c|}{ Surveys - Weighted Total (in millions of dollars) } & \multicolumn{5}{|c|}{ Reporting Rate } \\
\hline & & PSID & SIPP & $\begin{array}{c}\text { CPS- } \\
\text { ADF/ASEC }\end{array}$ & $\mathrm{ACS}$ & $\begin{array}{c}\text { CE } \\
\text { Survey }\end{array}$ & PSID & SIPP & $\begin{array}{c}\text { CPS- } \\
\text { ADF/ASEC }\end{array}$ & $\mathrm{ACS}$ & $\begin{array}{c}\text { CE } \\
\text { Survey }\end{array}$ \\
\hline 1998 & 30,085 & 15,984 & 29,138 & 22,309 & & 18,971 & 0.531 & 0.969 & 0.742 & & 0.631 \\
\hline 1999 & 30,907 & 20,719 & 29,805 & 22,583 & & 18,995 & 0.670 & 0.964 & 0.731 & & 0.615 \\
\hline 2000 & 31,562 & 17,252 & 31,501 & 22,468 & 25,099 & 21,209 & 0.547 & 0.998 & 0.712 & 0.804 & 0.672 \\
\hline 2001 & 33,314 & & 33,188 & 25,652 & 25,847 & 28,881 & & 0.996 & 0.770 & 0.797 & 0.867 \\
\hline 2002 & 34,708 & 17,037 & 35,161 & 25,924 & 26,920 & 25,957 & 0.491 & 1.013 & 0.747 & 0.791 & 0.748 \\
\hline 2003 & 36,151 & 18,445 & 37,231 & 28,022 & 28,901 & 22,533 & 0.510 & 1.030 & 0.775 & 0.816 & 0.623 \\
\hline 2004 & 37,504 & 23,857 & 39,901 & 30,634 & 29,537 & 21,749 & 0.636 & 1.064 & 0.817 & 0.802 & 0.580 \\
\hline 2005 & 39,755 & & 43,139 & 31,150 & 32,350 & 26,095 & & 1.085 & 0.784 & 0.837 & 0.656 \\
\hline 2006 & 41,576 & & & 31,977 & 36,599 & 21,808 & & & 0.769 & 0.900 & 0.525 \\
\hline 2007 & 43,466 & & & 33,008 & & & & & 0.759 & & \\
\hline Average & & & & & & & 0.659 & 0.917 & 0.760 & 0.821 & 0.644 \\
\hline
\end{tabular}

Note: For the ACS, the reporting rate is computed by comparing the survey year total with the average of the current and previous years' administrative totals. 


\section{Table 8}

\section{Unemployment Insurance Dollar Reporting Rates}

\begin{tabular}{|c|c|c|c|c|c|c|c|c|c|}
\hline \multirow[b]{2}{*}{ Year } & \multirow{2}{*}{$\begin{array}{l}\text { Admin. } \\
\text { Total } \\
\text { (millions } \\
\text { of dollars) }\end{array}$} & \multicolumn{4}{|c|}{$\begin{array}{l}\text { Survey - Weighted Total } \\
\text { (in millions of dollars) }\end{array}$} & \multicolumn{4}{|c|}{ Reporting Rate } \\
\hline & & PSID & SIPP & $\begin{array}{l}\text { CPS- } \\
\text { ADF/ } \\
\text { ASEC }\end{array}$ & $\begin{array}{c}\text { CE } \\
\text { Survey }\end{array}$ & PSID & SIPP & $\begin{array}{l}\text { CPS- } \\
\text { ADF/ } \\
\text { ASEC }\end{array}$ & $\begin{array}{l}\text { CE } \\
\text { Survey }\end{array}$ \\
\hline 1976 & 11,141 & 8,772 & & & & 0.787 & & & \\
\hline 1977 & 9,989 & 6,046 & & & & 0.605 & & & \\
\hline 1978 & 8,318 & 5,631 & & & & 0.677 & & & \\
\hline 1979 & 8,703 & 5,213 & & & 8,022 & 0.599 & & & 0.922 \\
\hline 1980 & 15,364 & 10,527 & & & 10,191 & 0.685 & & & 0.663 \\
\hline 1981 & 14,392 & 10,388 & & & 9,216 & 0.722 & & & 0.640 \\
\hline 1982 & 24,146 & 20,321 & & & 11,124 & 0.842 & & & 0.461 \\
\hline 1983 & 24,726 & 15,495 & 15,065 & & 14,787 & 0.627 & 0.609 & & 0.598 \\
\hline 1984 & 14,760 & 8,660 & 11,447 & & 11,100 & 0.587 & 0.776 & & 0.752 \\
\hline 1985 & 14,763 & 10,998 & 11,990 & & 8,581 & 0.745 & 0.812 & & 0.581 \\
\hline 1986 & 15,425 & 11,546 & 12,584 & & 9,553 & 0.749 & 0.816 & & 0.619 \\
\hline 1987 & 13,584 & 9,839 & 11,151 & 10,417 & 8,401 & 0.724 & 0.821 & 0.767 & 0.618 \\
\hline 1988 & 12,490 & 10,197 & 9,801 & 9,476 & 8,108 & 0.816 & 0.785 & 0.759 & 0.649 \\
\hline 1989 & 13,529 & 10,263 & 10,170 & 10,310 & 7,624 & 0.759 & 0.752 & 0.762 & 0.564 \\
\hline 1990 & 17,195 & 13,502 & 14,237 & 14,172 & 10,087 & 0.785 & 0.828 & 0.824 & 0.587 \\
\hline 1991 & 25,435 & 18,768 & 22,064 & 21,652 & 16,392 & 0.738 & 0.867 & 0.851 & 0.644 \\
\hline 1992 & 37,239 & 25,352 & 30,858 & 27,786 & 20,021 & 0.681 & 0.829 & 0.746 & 0.538 \\
\hline 1993 & 32,357 & 23,275 & 28,343 & 25,811 & 18,167 & 0.719 & 0.876 & 0.798 & 0.561 \\
\hline 1994 & 21,761 & 18,983 & 18,192 & 20,497 & 15,219 & 0.872 & 0.836 & 0.942 & 0.699 \\
\hline 1995 & 19,909 & 13,804 & 16,080 & 18,808 & 11,773 & 0.693 & 0.808 & 0.945 & 0.591 \\
\hline 1996 & 20,418 & 16,454 & 14,222 & 17,591 & 8,921 & 0.806 & 0.697 & 0.862 & 0.437 \\
\hline 1997 & 18,375 & & 11,687 & 15,856 & 9,092 & & 0.636 & 0.863 & 0.495 \\
\hline 1998 & 18,187 & 19,805 & 10,417 & 15,728 & 8,787 & 1.089 & 0.573 & 0.865 & 0.483 \\
\hline 1999 & 19,027 & & 12,007 & 14,606 & 8,168 & & 0.631 & 0.768 & 0.429 \\
\hline 2000 & 19,218 & 15,384 & 14,713 & 14,469 & 7,937 & 0.801 & 0.766 & 0.753 & 0.413 \\
\hline 2001 & 30,143 & & 19,365 & 24,291 & 11,718 & & 0.642 & 0.806 & 0.389 \\
\hline 2002 & 51,086 & 36,234 & 28,903 & 37,912 & 19,394 & 0.709 & 0.566 & 0.742 & 0.380 \\
\hline 2003 & 50,163 & 21,822 & 31,047 & 36,932 & 21,881 & 0.435 & 0.619 & 0.736 & 0.436 \\
\hline 2004 & 33,512 & 30,978 & 25,405 & 25,058 & 15,907 & 0.924 & 0.758 & 0.748 & 0.475 \\
\hline 2005 & 31,104 & & 27,073 & 22,290 & 13,728 & & 0.870 & 0.717 & 0.441 \\
\hline 2006 & 29,885 & & & 20,650 & 12,425 & & & 0.691 & 0.416 \\
\hline 2007 & 32,213 & & & 21,876 & & & & 0.679 & \\
\hline \multicolumn{2}{|c|}{ Average } & & & & & 0.738 & 0.747 & 0.792 & 0.553 \\
\hline
\end{tabular}


Table 9

Workers' Compensation Dollar Reporting Rates

\begin{tabular}{|c|c|c|c|c|c|c|c|c|c|}
\hline \multirow[b]{2}{*}{ Year } & \multirow{2}{*}{$\begin{array}{c}\text { Admin. } \\
\text { Total } \\
\text { (millions } \\
\text { of dollars) }\end{array}$} & \multicolumn{4}{|c|}{$\begin{array}{l}\text { Survey - Weighted Total } \\
\text { (in millions of dollars) }\end{array}$} & \multicolumn{4}{|c|}{ Reporting Rate } \\
\hline & & PSID & SIPP & $\begin{array}{l}\text { CPS- } \\
\text { ADF/ } \\
\text { ASEC }\end{array}$ & $\begin{array}{c}\text { CE } \\
\text { Survey }\end{array}$ & PSID & SIPP & $\begin{array}{l}\text { CPS- } \\
\text { ADF/ } \\
\text { ASEC }\end{array}$ & $\begin{array}{c}\text { CE } \\
\text { Survey }\end{array}$ \\
\hline 1976 & 5,204 & 1,788 & & & & 0.344 & & & \\
\hline 1977 & 5,950 & 2,343 & & & & 0.394 & & & \\
\hline 1978 & 6,816 & 2,854 & & & & 0.419 & & & \\
\hline 1979 & 8,507 & 2,573 & & & 9,076 & 0.302 & & & 1.067 \\
\hline 1980 & 9,671 & 3,420 & & & 9,770 & 0.354 & & & 1.010 \\
\hline 1981 & 10,623 & 4,081 & & & 8,239 & 0.384 & & & 0.776 \\
\hline 1982 & 11,349 & 3,728 & & & 6,902 & 0.328 & & & 0.608 \\
\hline 1983 & 11,894 & 4,777 & 5,536 & & 10,011 & 0.402 & 0.465 & & 0.842 \\
\hline 1984 & 13,261 & 4,139 & 5,484 & & 10,348 & 0.312 & 0.414 & & 0.780 \\
\hline 1985 & 14,719 & 5,210 & 5,822 & & 8,024 & 0.354 & 0.396 & & 0.545 \\
\hline 1986 & 15,971 & 7,521 & 5,728 & & 9,631 & 0.471 & 0.359 & & 0.603 \\
\hline 1987 & 17,405 & 7,155 & 7,313 & 8,375 & 12,927 & 0.411 & 0.420 & 0.481 & 0.743 \\
\hline 1988 & 19,196 & 7,214 & 7,054 & 10,726 & 13,611 & 0.376 & 0.367 & 0.559 & 0.709 \\
\hline 1989 & 20,892 & 8,893 & 8,582 & 12,822 & 12,103 & 0.426 & 0.411 & 0.614 & 0.579 \\
\hline 1990 & 23,050 & 7,510 & 9,684 & 13,005 & 11,885 & 0.326 & 0.420 & 0.564 & 0.516 \\
\hline 1991 & 25,355 & 9,512 & 9,958 & 14,412 & 11,839 & 0.375 & 0.393 & 0.568 & 0.467 \\
\hline 1992 & 25,996 & 11,141 & 9,989 & 13,660 & 12,168 & 0.429 & 0.384 & 0.525 & 0.468 \\
\hline 1993 & 24,422 & 7,352 & 9,687 & 13,434 & 14,855 & 0.301 & 0.397 & 0.550 & 0.608 \\
\hline 1994 & 26,288 & 9,987 & 9,773 & 13,554 & 15,104 & 0.380 & 0.372 & 0.516 & 0.575 \\
\hline 1995 & 25,389 & 8,447 & 8,465 & 11,752 & 13,235 & 0.333 & 0.333 & 0.463 & 0.521 \\
\hline 1996 & 25,221 & 6,843 & 11,946 & 10,263 & 12,742 & 0.271 & 0.474 & 0.407 & 0.505 \\
\hline 1997 & 24,574 & & 10,949 & 12,417 & 12,675 & & 0.446 & 0.505 & 0.516 \\
\hline 1998 & 25,365 & 9,589 & 10,659 & 11,089 & 10,947 & 0.378 & 0.420 & 0.437 & 0.432 \\
\hline 1999 & 26,258 & & 11,678 & 11,799 & 12,105 & & 0.445 & 0.449 & 0.461 \\
\hline 2000 & 26,766 & 10,597 & 9,807 & 12,944 & 11,750 & 0.396 & 0.366 & 0.484 & 0.439 \\
\hline 2001 & 27,690 & & 9,930 & 12,246 & 9,515 & & 0.359 & 0.442 & 0.344 \\
\hline 2002 & 28,094 & 5,935 & 10,905 & 12,943 & 8,999 & 0.211 & 0.388 & 0.461 & 0.320 \\
\hline 2003 & 29,147 & 5,491 & 11,223 & 13,926 & 9,577 & 0.188 & 0.385 & 0.478 & 0.329 \\
\hline 2004 & 29,719 & 10,202 & 9,859 & 13,658 & 9,683 & 0.343 & 0.332 & 0.460 & 0.326 \\
\hline 2005 & 29,228 & & 11,541 & 15,323 & 11,051 & & 0.395 & 0.524 & 0.378 \\
\hline 2006 & 28,207 & & & 14,870 & 11,787 & & & 0.527 & 0.418 \\
\hline 2007 & & & & 12,820 & & & & & \\
\hline \multicolumn{2}{|c|}{ Average } & & & & & 0.354 & 0.397 & 0.501 & 0.567 \\
\hline
\end{tabular}

Note: The administrative totals refer to only cash payments, obtained by removing the medical portion of the total program cost. 
Table 10

Earned Income Tax Credit Dollar Reporting Rates

\begin{tabular}{|c|c|c|c|}
\hline \multirow[b]{2}{*}{ Year } & \multirow{2}{*}{$\begin{array}{c}\text { Admin. } \\
\text { Total } \\
\text { (in millions of } \\
\text { dollars) } \\
\end{array}$} & $\begin{array}{l}\text { Survey - Weighted Total } \\
\text { (in dollars) }\end{array}$ & Reporting Rate \\
\hline & & CPS-ADF/ASEC & CPS-ADF/ASEC \\
\hline 1991 & 11,105 & $7,114,273,167$ & 0.641 \\
\hline 1992 & 13,028 & $8,557,786,177$ & 0.657 \\
\hline 1993 & 15,537 & $9,838,109,512$ & 0.633 \\
\hline 1994 & 21,105 & $15,657,377,258$ & 0.742 \\
\hline 1995 & 25,956 & $18,745,177,769$ & 0.722 \\
\hline 1996 & 28,825 & $21,759,768,835$ & 0.755 \\
\hline 1997 & 30,389 & $21,853,593,976$ & 0.719 \\
\hline 1998 & 32,340 & $22,746,758,857$ & 0.703 \\
\hline 1999 & 31,901 & $22,925,582,818$ & 0.719 \\
\hline 2000 & 32,296 & $22,114,667,940$ & 0.685 \\
\hline 2001 & 33,376 & $23,249,556,083$ & 0.697 \\
\hline 2002 & 35,784 & $25,758,259,544$ & 0.720 \\
\hline 2003 & 34,412 & $25,280,285,195$ & 0.735 \\
\hline 2004 & 33,490 & $26,180,929,642$ & 0.782 \\
\hline 2005 & 34,961 & $28,419,265,886$ & 0.813 \\
\hline 2006 & 36,693 & $30,332,485,115$ & 0.827 \\
\hline Average & & & 0.722 \\
\hline
\end{tabular}


Table 11

AFDC/TANF Average Monthly Participation

\begin{tabular}{|c|c|c|c|c|c|c|c|}
\hline \multirow[b]{2}{*}{ Year } & \multirow{2}{*}{$\begin{array}{l}\text { Administrative } \\
\text { Average } \\
\text { Monthly } \\
\text { Participation } \\
\text { (Families) }\end{array}$} & \multicolumn{3}{|c|}{$\begin{array}{l}\text { Surveys - Average Monthly Participation } \\
\text { (family level) }\end{array}$} & \multicolumn{3}{|c|}{ Reporting Rate } \\
\hline & & \multirow[t]{2}{*}{ PSID } & SIPP & $\begin{array}{c}\text { CPS- } \\
\text { ADF/ASEC }\end{array}$ & PSID & SIPP & $\begin{array}{c}\text { CPS- } \\
\text { ADF/ASEC }\end{array}$ \\
\hline 1980 & $3,692,608$ & & & & & & \\
\hline 1981 & $3,812,123$ & & & & & & \\
\hline 1982 & $3,522,001$ & & & & & & \\
\hline 1983 & $3,667,080$ & & $2,851,592$ & & & 0.778 & \\
\hline 1984 & $3,695,574$ & & $3,040,356$ & & & 0.823 & \\
\hline 1985 & $3,683,941$ & & $2,900,857$ & & & 0.787 & \\
\hline 1986 & $3,746,240$ & & $2,801,266$ & & & 0.748 & \\
\hline 1987 & $3,759,011$ & & $2,871,043$ & $3,025,954$ & & 0.764 & 0.805 \\
\hline 1988 & $3,732,307$ & & $2,795,287$ & $2,968,807$ & & 0.749 & 0.795 \\
\hline 1989 & $3,781,426$ & & $2,902,077$ & $2,816,732$ & & 0.767 & 0.745 \\
\hline 1990 & $4,039,016$ & & $3,209,590$ & $3,120,412$ & & 0.795 & 0.773 \\
\hline 1991 & $4,478,428$ & & $3,436,155$ & $3,419,110$ & & 0.767 & 0.763 \\
\hline 1992 & $4,809,566$ & & $3,579,069$ & $3,468,416$ & & 0.744 & 0.721 \\
\hline 1993 & $4,990,435$ & $3,099,655$ & $4,020,104$ & $3,713,955$ & 0.621 & 0.806 & 0.744 \\
\hline 1994 & $5,011,151$ & $2,840,407$ & $3,966,091$ & $3,451,463$ & 0.567 & 0.791 & 0.689 \\
\hline 1995 & $4,770,300$ & $2,603,520$ & $3,942,927$ & $3,124,368$ & 0.546 & 0.827 & 0.655 \\
\hline 1996 & $4,415,233$ & $2,347,537$ & $3,510,786$ & $2,957,559$ & 0.532 & 0.795 & 0.670 \\
\hline 1997 & $3,724,214$ & & $3,001,523$ & $2,275,387$ & & 0.806 & 0.611 \\
\hline 1998 & $3,041,589$ & $1,217,162$ & $2,376,098$ & $1,824,069$ & 0.400 & 0.781 & 0.600 \\
\hline 1999 & $2,547,606$ & & $1,866,543$ & $1,401,124$ & & 0.733 & 0.550 \\
\hline 2000 & $2,203,417$ & $1,117,209$ & $1,656,865$ & $1,283,230$ & 0.507 & 0.752 & 0.582 \\
\hline 2001 & $2,093,124$ & & $1,519,928$ & $1,173,244$ & & 0.726 & 0.561 \\
\hline 2002 & $2,040,879$ & 708,284 & $1,337,550$ & $1,089,399$ & 0.347 & 0.655 & 0.534 \\
\hline 2003 & $2,014,886$ & $1,369,355$ & $1,397,108$ & $1,290,115$ & 0.680 & 0.693 & 0.640 \\
\hline 2004 & $1,971,090$ & $1,130,092$ & $1,632,136$ & $1,117,250$ & 0.573 & 0.828 & 0.567 \\
\hline 2005 & $1,887,309$ & & $1,527,558$ & $1,189,858$ & & 0.809 & 0.630 \\
\hline 2006 & $1,774,635$ & & & 935,072 & & & 0.527 \\
\hline 2007 & $1,662,727$ & & & 875,565 & & & 0.527 \\
\hline \multirow{2}{*}{\multicolumn{5}{|c|}{$\begin{array}{l}\text { Average } \\
\text { Average Dollars Renorting Rate for Comnarable Years }\end{array}$}} & 0.530 & 0.771 & 0.652 \\
\hline & \multicolumn{4}{|c|}{ Average Dollars Reporting Rate for Comparable Years } & 0.443 & 0.712 & 0.624 \\
\hline
\end{tabular}


Table 12

Food Stamp Program Average Monthly Participation

\begin{tabular}{|c|c|c|c|c|c|c|c|}
\hline \multirow[b]{2}{*}{ Year } & \multirow{2}{*}{$\begin{array}{l}\text { Administrative } \\
\text { Average } \\
\text { Monthly } \\
\text { Participation } \\
\text { (Households) }\end{array}$} & \multicolumn{3}{|c|}{$\begin{array}{c}\text { Surveys - Average Monthly } \\
\text { Participation }\end{array}$} & \multicolumn{3}{|c|}{ Reporting rate } \\
\hline & & PSID & SIPP & $\begin{array}{c}\text { CPS- } \\
\text { ADF/ASEC }\end{array}$ & PSID & SIPP & $\begin{array}{c}\text { CPS- } \\
\text { ADF/ASEC }\end{array}$ \\
\hline 1980 & $7,763,714$ & $5,659,991$ & & $5,130,682$ & 0.729 & & 0.661 \\
\hline 1981 & $8,231,565$ & $5,986,317$ & & $5,273,484$ & 0.727 & & 0.641 \\
\hline 1982 & $7,817,518$ & $6,341,138$ & & $5,351,906$ & 0.811 & & 0.685 \\
\hline 1983 & $7,839,288$ & $6,414,963$ & $6,561,402$ & $5,560,356$ & 0.818 & 0.837 & 0.709 \\
\hline 1984 & $7,515,342$ & $5,921,546$ & $6,656,248$ & $5,533,007$ & 0.788 & 0.886 & 0.736 \\
\hline 1985 & $7,291,303$ & $5,742,227$ & $6,228,872$ & $5,314,065$ & 0.788 & 0.854 & 0.729 \\
\hline 1986 & $7,202,921$ & $6,063,710$ & $6,272,349$ & $5,239,128$ & 0.842 & 0.871 & 0.727 \\
\hline 1987 & $7,084,390$ & $6,082,936$ & $6,242,591$ & $5,183,350$ & 0.859 & 0.881 & 0.732 \\
\hline 1988 & $7,092,014$ & $6,039,197$ & $6,133,158$ & $5,249,217$ & 0.852 & 0.865 & 0.740 \\
\hline 1989 & $7,337,547$ & $6,261,035$ & $6,164,276$ & $5,159,889$ & 0.853 & 0.840 & 0.703 \\
\hline 1990 & $7,999,990$ & $6,200,845$ & $6,582,906$ & $5,697,878$ & 0.775 & 0.823 & 0.712 \\
\hline 1991 & $9,208,275$ & $6,238,023$ & $7,263,082$ & $6,294,527$ & 0.677 & 0.789 & 0.684 \\
\hline 1992 & $10,282,358$ & $6,982,771$ & $7,891,822$ & $6,816,542$ & 0.679 & 0.768 & 0.663 \\
\hline 1993 & $10,902,288$ & $7,598,139$ & $8,733,851$ & $7,329,268$ & 0.697 & 0.801 & 0.672 \\
\hline 1994 & $11,093,566$ & $7,796,566$ & $8,561,080$ & $7,420,375$ & 0.703 & 0.772 & 0.669 \\
\hline 1995 & $10,791,655$ & $7,273,270$ & $8,474,133$ & $7,071,615$ & 0.674 & 0.785 & 0.655 \\
\hline 1996 & $10,395,150$ & $6,912,900$ & $8,751,572$ & $6,896,048$ & 0.665 & 0.842 & 0.663 \\
\hline 1997 & $9,087,686$ & $5,179,876$ & $8,001,126$ & $6,111,001$ & 0.570 & 0.880 & 0.672 \\
\hline 1998 & $8,068,051$ & $4,884,314$ & $7,075,561$ & $5,374,420$ & 0.605 & 0.877 & 0.666 \\
\hline 1999 & $7,568,908$ & $4,504,903$ & $6,564,475$ & $4,780,595$ & 0.595 & 0.867 & 0.632 \\
\hline 2000 & $7,326,583$ & $4,441,331$ & $6,304,656$ & $4,606,152$ & 0.606 & 0.861 & 0.629 \\
\hline 2001 & $7,595,058$ & $4,622,812$ & $6,827,110$ & $4,823,717$ & 0.609 & 0.899 & 0.635 \\
\hline 2002 & $8,402,369$ & $5,017,984$ & $7,393,731$ & $5,149,868$ & 0.597 & 0.880 & 0.613 \\
\hline 2003 & $9,447,575$ & $7,502,129$ & $8,007,800$ & $5,704,880$ & 0.794 & 0.848 & 0.604 \\
\hline 2004 & $10,566,039$ & $8,464,400$ & $8,914,594$ & $6,002,098$ & 0.801 & 0.844 & 0.568 \\
\hline 2005 & $11,485,609$ & & $9,525,628$ & $6,484,700$ & & 0.829 & 0.565 \\
\hline 2006 & $11,592,557$ & & & $6,147,814$ & & & 0.530 \\
\hline 2007 & $11,927,826$ & & & & & & \\
\hline \multirow{2}{*}{\multicolumn{5}{|c|}{$\begin{array}{l}\text { Average } \\
\text { Average Dollars Reporting Rate for Comparable Years }\end{array}$}} & 0.725 & 0.843 & 0.663 \\
\hline & \multicolumn{4}{|c|}{ Average Dollars Reporting Rate for Comparable Years } & 0.753 & 0.823 & 0.662 \\
\hline
\end{tabular}


Table 13

OASI Average Monthly Participation

\begin{tabular}{|c|c|c|c|c|c|c|c|c|c|}
\hline \multirow[b]{2}{*}{ Year } & \multirow{2}{*}{$\begin{array}{c}\text { Admin } \\
\text { Average } \\
\text { Monthly } \\
\text { Participation } \\
\text { (thousands) }\end{array}$} & \multicolumn{4}{|c|}{ Survey Aggregates (thousands) } & \multicolumn{4}{|c|}{ Reporting Rate } \\
\hline & & PSID & SIPP & $\begin{array}{l}\text { CPS- } \\
\text { ADF/ } \\
\text { ASEC }\end{array}$ & $\mathrm{ACS}$ & PSID & SIPP & $\begin{array}{l}\text { CPS- } \\
\text { ADF/ } \\
\text { ASEC }\end{array}$ & ACS \\
\hline 1974 & 25,007 & 18,360 & & 19,874 & & 0.734 & & 0.795 & \\
\hline 1975 & 26,033 & 18,739 & & 20,286 & & 0.720 & & 0.779 & \\
\hline 1976 & 26,781 & 19,562 & & 20,716 & & 0.730 & & 0.774 & \\
\hline 1977 & 27,525 & 20,380 & & 21,638 & & 0.740 & & 0.786 & \\
\hline 1978 & 28,185 & 21,136 & & 22,780 & & 0.750 & & 0.808 & \\
\hline 1979 & 28,743 & 21,607 & & 23,787 & & 0.752 & & 0.828 & \\
\hline 1980 & 29,351 & 23,050 & & 24,929 & & 0.785 & & 0.849 & \\
\hline 1981 & 29,946 & 23,914 & & 25,722 & & 0.799 & & 0.859 & \\
\hline 1982 & 30,417 & 24,315 & & 25,912 & & 0.799 & & 0.852 & \\
\hline 1983 & 30,781 & 26,007 & 27,254 & 26,354 & & 0.845 & 0.885 & 0.856 & \\
\hline 1984 & 31,174 & 26,967 & 29,024 & 26,732 & & 0.865 & 0.931 & 0.858 & \\
\hline 1985 & 31,295 & 27,803 & 29,360 & 27,265 & & 0.888 & 0.938 & 0.871 & \\
\hline 1986 & 31,809 & 28,910 & 29,853 & 27,353 & & 0.909 & 0.939 & 0.860 & \\
\hline 1987 & 32,287 & 28,969 & 30,522 & 28,403 & & 0.897 & 0.945 & 0.880 & \\
\hline 1988 & 32,691 & 29,861 & 30,946 & 28,878 & & 0.913 & 0.947 & 0.883 & \\
\hline 1989 & 33,110 & 32,925 & 31,436 & 29,264 & & 0.994 & 0.949 & 0.884 & \\
\hline 1990 & 33,598 & 31,735 & 32,234 & 29,622 & & 0.945 & 0.959 & 0.882 & \\
\hline 1991 & 34,107 & 31,133 & 32,682 & 29,711 & & 0.913 & 0.958 & 0.871 & \\
\hline 1992 & 34,610 & 30,259 & 32,540 & 30,544 & & 0.874 & 0.940 & 0.883 & \\
\hline 1993 & 35,043 & & 32,740 & 29,834 & & & 0.934 & 0.851 & \\
\hline 1994 & 35,369 & & 32,523 & 30,433 & & & 0.920 & 0.860 & \\
\hline 1995 & 35,566 & & 32,871 & 30,829 & & & 0.924 & 0.867 & \\
\hline 1996 & 35,740 & & 33,668 & 30,121 & & & 0.942 & 0.843 & \\
\hline 1997 & 35,878 & & 32,889 & 29,645 & & & 0.917 & 0.826 & \\
\hline 1998 & 35,995 & & 32,038 & 30,028 & & & 0.890 & 0.834 & \\
\hline 1999 & 36,103 & & 32,559 & 30,088 & & & 0.902 & 0.833 & \\
\hline 2000 & 36,499 & & 34,651 & 30,708 & 29,091 & & 0.949 & 0.841 & 0.801 \\
\hline 2001 & 36,914 & & 36,390 & 31,535 & 30,299 & & 0.986 & 0.854 & 0.825 \\
\hline 2002 & 37,137 & & 36,485 & 31,229 & 30,352 & & 0.982 & 0.841 & 0.820 \\
\hline 2003 & 37,359 & 31,747 & 36,785 & 31,871 & 30,886 & 0.850 & 0.985 & 0.853 & 0.829 \\
\hline 2004 & 37,598 & & 36,763 & 31,689 & 30,943 & & 0.978 & 0.843 & 0.826 \\
\hline 2005 & 37,943 & & 36,823 & 31,423 & 30,958 & & 0.970 & 0.828 & 0.820 \\
\hline 2006 & 38,299 & & & 31,259 & 31,531 & & & 0.816 & 0.827 \\
\hline 2007 & 39,291 & & & 31,566 & & & & 0.803 & \\
\hline \multicolumn{6}{|c|}{ Average } & 0.835 & 0.942 & 0.843 & 0.821 \\
\hline \multicolumn{6}{|c|}{ Average Dollars Reporting Rate for Comparable Years } & 0.881 & 0.926 & 0.880 & 0.833 \\
\hline
\end{tabular}

Note: For the ACS, the reporting rate is computed by comparing the survey year total with the average of the current and previous years' administrative totals. 
Table 14

SSDI Average Monthly Participation

\begin{tabular}{|c|c|c|c|c|c|c|c|c|c|}
\hline \multirow[b]{2}{*}{ Year } & \multirow{2}{*}{$\begin{array}{c}\text { Admin } \\
\text { Average } \\
\text { Monthly } \\
\text { Participation } \\
\text { (thousands) }\end{array}$} & \multicolumn{4}{|c|}{ Survey Aggregates (thousands) } & \multicolumn{4}{|c|}{ Reporting rates } \\
\hline & & PSID & SIPP & $\begin{array}{l}\text { CPS- } \\
\text { ADF/ } \\
\text { ASEC }\end{array}$ & ACS & PSID & SIPP & $\begin{array}{l}\text { CPS- } \\
\text { ADF/ } \\
\text { ASEC }\end{array}$ & ACS \\
\hline 1974 & 3,535 & 2,814 & & 3,066 & & 0.796 & & 0.867 & \\
\hline 1975 & 3,943 & 3,010 & & 3,389 & & 0.764 & & 0.860 & \\
\hline 1976 & 4,279 & 3,170 & & 3,453 & & 0.741 & & 0.807 & \\
\hline 1977 & 4,510 & 3,332 & & 3,645 & & 0.739 & & 0.808 & \\
\hline 1978 & 4,619 & 3,481 & & 3,782 & & 0.754 & & 0.819 & \\
\hline 1979 & 4,579 & 3,626 & & 4,076 & & 0.792 & & 0.890 & \\
\hline 1980 & 4,484 & 3,419 & & 3,974 & & 0.763 & & 0.886 & \\
\hline 1981 & 4,332 & 3,716 & & 3,924 & & 0.858 & & 0.906 & \\
\hline 1982 & 3,994 & 3,430 & & 3,721 & & 0.859 & & 0.932 & \\
\hline 1983 & 3,686 & 3,787 & 3,342 & 3,599 & & 1.027 & 0.907 & 0.976 & \\
\hline 1984 & 3,612 & 3,684 & 3,664 & 3,648 & & 1.020 & 1.014 & 1.010 & \\
\hline 1985 & 3,619 & 3,613 & 3,725 & 3,511 & & 0.998 & 1.029 & 0.970 & \\
\hline 1986 & 3,701 & 3,215 & 3,800 & 3,557 & & 0.869 & 1.027 & 0.961 & \\
\hline 1987 & 3,770 & 3,623 & 3,820 & 3,831 & & 0.961 & 1.013 & 1.016 & \\
\hline 1988 & 3,809 & 3,668 & 3,905 & 3,758 & & 0.963 & 1.025 & 0.987 & \\
\hline 1989 & 3,851 & 4,109 & 3,978 & 3,882 & & 1.067 & 1.033 & 1.008 & \\
\hline 1990 & 3,947 & 4,228 & 4,121 & 3,954 & & 1.071 & 1.044 & 1.002 & \\
\hline 1991 & 4,131 & 4,907 & 4,804 & 3,935 & & 1.188 & 1.163 & 0.953 & \\
\hline 1992 & 4,428 & 4,329 & 4,923 & 4,383 & & 0.978 & 1.112 & 0.990 & \\
\hline 1993 & 4,779 & & 4,988 & 4,484 & & & 1.044 & 0.938 & \\
\hline 1994 & 5,098 & & 4,837 & 4,688 & & & 0.949 & 0.919 & \\
\hline 1995 & 5,374 & & 5,035 & 4,970 & & & 0.937 & 0.925 & \\
\hline 1996 & 5,603 & & 5,075 & 5,024 & & & 0.906 & 0.897 & \\
\hline 1997 & 5,742 & & 6,138 & 5,006 & & & 1.069 & 0.872 & \\
\hline 1998 & 5,865 & & 7,379 & 4,921 & & & 1.258 & 0.839 & \\
\hline 1999 & 6,051 & & 7,146 & 5,114 & & & 1.181 & 0.845 & \\
\hline 2000 & 6,210 & & 5,868 & 4,866 & 4,530 & & 0.945 & 0.784 & 0.739 \\
\hline 2001 & 6,395 & & 5,581 & 5,207 & 4,697 & & 0.873 & 0.814 & 0.745 \\
\hline 2002 & 6,655 & & 5,696 & 5,260 & 4,769 & & 0.856 & 0.790 & 0.731 \\
\hline 2003 & 6,981 & 6,662 & 6,159 & 5,491 & 5,067 & 0.954 & 0.882 & 0.787 & 0.743 \\
\hline 2004 & 7,332 & & 6,863 & 5,812 & 5,137 & & 0.936 & 0.793 & 0.718 \\
\hline 2005 & 7,683 & & 7,199 & 6,049 & 5,425 & & 0.937 & 0.787 & 0.723 \\
\hline 2006 & 8,004 & & & 6,050 & 5,784 & & & 0.756 & 0.737 \\
\hline 2007 & 8,461 & & & 6,387 & & & & 0.755 & \\
\hline \multicolumn{6}{|c|}{ Average } & 0.908 & 1.006 & 0.887 & 0.734 \\
\hline \multicolumn{6}{|c|}{ Average Dollars Reporting Rate for Comparable Years } & 1.017 & 0.907 & 0.926 & 0.719 \\
\hline
\end{tabular}

Note: For the ACS, the reporting rate is computed by comparing the survey year total with the average of the current and previous years' administrative totals. 
Table 15

SSI Average Monthly Participation

\begin{tabular}{|c|c|c|c|c|c|c|c|c|c|}
\hline \multirow[b]{2}{*}{ Year } & \multirow{2}{*}{$\begin{array}{c}\text { Admin } \\
\text { Average } \\
\text { Monthly } \\
\text { Participation } \\
\text { (thousands) }\end{array}$} & \multicolumn{4}{|c|}{ Survey Aggregates (thousands) } & \multicolumn{4}{|c|}{ Reporting rates } \\
\hline & & PSID & SIPP & $\begin{array}{l}\text { CPS- } \\
\text { ADF/ } \\
\text { ASEC }\end{array}$ & ACS & PSID & SIPP & $\begin{array}{l}\text { CPS- } \\
\text { ADF/ } \\
\text { ASEC }\end{array}$ & ACS \\
\hline 1974 & 3,475 & 3,103 & & & & 0.893 & & & \\
\hline 1975 & 4,005 & 2,718 & & 2,888 & & 0.679 & & 0.721 & \\
\hline 1976 & 4,128 & 2,388 & & 2,911 & & 0.578 & & 0.705 & \\
\hline 1977 & 4,093 & 2,648 & & 2,908 & & 0.647 & & 0.710 & \\
\hline 1978 & 4,084 & 2,556 & & 2,898 & & 0.626 & & 0.710 & \\
\hline 1979 & 4,044 & 2,777 & & 2,868 & & 0.687 & & 0.709 & \\
\hline 1980 & 4,010 & 2,579 & & 3,082 & & 0.643 & & 0.769 & \\
\hline 1981 & 3,945 & 2,935 & & 2,986 & & 0.744 & & 0.757 & \\
\hline 1982 & 3,808 & 2,736 & & 2,760 & & 0.718 & & 0.725 & \\
\hline 1983 & 3,755 & 2,837 & 3,061 & 2,972 & & 0.755 & 0.815 & 0.791 & \\
\hline 1984 & 3,844 & 2,457 & 3,498 & 3,081 & & 0.639 & 0.910 & 0.802 & \\
\hline 1985 & 3,960 & 2,484 & 3,582 & 3,074 & & 0.627 & 0.904 & 0.776 & \\
\hline 1986 & 4,081 & 2,644 & 3,684 & 3,078 & & 0.648 & 0.903 & 0.754 & \\
\hline 1987 & 4,204 & 2,471 & 3,797 & 3,057 & & 0.588 & 0.903 & 0.727 & \\
\hline 1988 & 4,297 & 2,857 & 3,985 & 3,271 & & 0.665 & 0.927 & 0.761 & \\
\hline 1989 & 4,400 & 3,071 & 4,075 & 3,434 & & 0.698 & 0.926 & 0.781 & \\
\hline 1990 & 4,565 & 2,759 & 3,912 & 3,438 & & 0.604 & 0.857 & 0.753 & \\
\hline 1991 & 4,817 & 2,703 & 4,199 & 3,695 & & 0.561 & 0.872 & 0.767 & \\
\hline 1992 & 5,179 & 2,883 & 4,573 & 3,870 & & 0.557 & 0.883 & 0.747 & \\
\hline 1993 & 5,592 & 3,540 & 4,874 & 4,117 & & 0.633 & 0.872 & 0.736 & \\
\hline 1994 & 5,941 & 3,282 & 5,124 & 3,979 & & 0.553 & 0.862 & 0.670 & \\
\hline 1995 & 6,185 & 3,360 & 5,271 & 4,073 & & 0.543 & 0.852 & 0.659 & \\
\hline 1996 & 6,328 & 3,003 & 5,971 & 4,164 & & 0.475 & 0.944 & 0.658 & \\
\hline 1997 & 6,323 & & 6,429 & 3,851 & & & 1.017 & 0.609 & \\
\hline 1998 & 6,310 & 3,154 & 6,451 & 3,966 & & 0.500 & 1.022 & 0.628 & \\
\hline 1999 & 6,346 & & 6,406 & 3,970 & & & 1.009 & 0.626 & \\
\hline 2000 & 6,363 & 3,012 & 6,346 & 3,682 & 3,516 & 0.473 & 0.997 & 0.579 & 0.553 \\
\hline 2001 & 6,427 & & 6,330 & 3,931 & 3,491 & & 0.985 & 0.612 & 0.546 \\
\hline 2002 & 6,477 & 2,838 & 6,669 & 3,724 & 3,462 & 0.438 & 1.030 & 0.575 & 0.537 \\
\hline 2003 & 6,537 & & 6,804 & 4,049 & 3,740 & & 1.041 & 0.619 & 0.575 \\
\hline 2004 & 6,633 & 3,511 & 6,569 & 4,090 & 3,631 & 0.529 & 0.990 & 0.617 & 0.551 \\
\hline 2005 & 6,793 & & 6,917 & 3,904 & 3,773 & & 1.018 & 0.575 & 0.562 \\
\hline 2006 & 6,912 & & & 3,737 & 4,152 & & & 0.541 & 0.606 \\
\hline 2007 & 7,030 & & & 3,773 & & & & 0.537 & \\
\hline \multicolumn{6}{|c|}{ Average } & 0.619 & 0.937 & 0.688 & 0.561 \\
\hline \multicolumn{6}{|c|}{ Average Dollars Reporting Rate for Comparable Years } & 0.659 & 0.917 & 0.760 & 0.821 \\
\hline
\end{tabular}

Note: For the ACS, the reporting rate is computed by comparing the survey year total with the average of the current and previous years' administrative totals. 
Table 16

National School Lunch Program (NSLP) - Average Monthly Participation (in thousands)

\begin{tabular}{|c|c|c|c|c|c|c|c|c|c|c|c|c|c|}
\hline \multirow[b]{2}{*}{ Year } & \multicolumn{3}{|c|}{$\begin{array}{c}\text { Administrative } \\
\text { Average Monthly Participation }\end{array}$} & \multicolumn{5}{|c|}{ Survey- Average Monthly Participation } & \multicolumn{5}{|c|}{ Reporting Rates } \\
\hline & Free & Reduced & $\begin{array}{l}\text { Free or } \\
\text { Reduced } \\
\text { Price }\end{array}$ & PSID & $\begin{array}{l}\text { SIPP } \\
\text { (Free) }\end{array}$ & $\begin{array}{c}\text { SIPP } \\
\text { (Reduced } \\
\text { Price) }\end{array}$ & $\begin{array}{c}\text { SIPP } \\
\text { (Free or } \\
\text { Reduced } \\
\text { Price) } \\
\end{array}$ & $\begin{array}{l}\text { CPS- } \\
\text { ADF/ } \\
\text { ASEC }\end{array}$ & PSID & $\begin{array}{l}\text { SIPP } \\
\text { (Free) }\end{array}$ & $\begin{array}{c}\text { SIPP } \\
\text { (Reduced } \\
\text { Price) }\end{array}$ & $\begin{array}{c}\text { SIPP } \\
\text { (Free or } \\
\text { Reduced } \\
\text { Price) } \\
\end{array}$ & $\begin{array}{l}\text { CPS- } \\
\text { ADF/ } \\
\text { ASEC }\end{array}$ \\
\hline 1979 & 10,000 & 1,767 & 11,767 & & & & & 5,704 & & & & & 0.485 \\
\hline 1980 & 10,200 & 1,900 & 12,100 & & & & & 6,212 & & & & & 0.513 \\
\hline 1981 & 10,333 & 1,800 & 12,133 & & & & & 5,963 & & & & & 0.491 \\
\hline 1982 & 9,967 & 1,567 & 11,533 & & & & & 6,241 & & & & & 0.541 \\
\hline 1983 & 10,300 & 1,500 & 11,800 & & 10,444 & 2,353 & 12,796 & 6,186 & & 1.014 & 1.569 & 1.084 & 0.524 \\
\hline 1984 & 10,167 & 1,533 & 11,700 & & 9,648 & 2,343 & 11,991 & 6,163 & & 0.949 & 1.528 & 1.025 & 0.527 \\
\hline 1985 & 9,933 & 1,600 & 11,533 & & 9,560 & 2,576 & 12,136 & 6,340 & & 0.962 & 1.610 & 1.052 & 0.550 \\
\hline 1986 & 10,000 & 1,600 & 11,600 & & 10,103 & 2,791 & 12,894 & 6,382 & & 1.010 & 1.744 & 1.112 & 0.550 \\
\hline 1987 & 9,933 & 1,600 & 11,533 & & 10,479 & 2,633 & 13,112 & 6,273 & & 1.055 & 1.645 & 1.137 & 0.544 \\
\hline 1988 & 9,767 & 1,600 & 11,367 & & 10,496 & 2,574 & 13,070 & 5,869 & & 1.075 & 1.609 & 1.150 & 0.516 \\
\hline 1989 & 9,704 & 1,609 & 11,313 & & 10,019 & 2,446 & 12,465 & 6,253 & & 1.032 & 1.520 & 1.102 & 0.553 \\
\hline 1990 & 9,980 & 1,696 & 11,675 & & 10,292 & 2,278 & 12,570 & 6,419 & & 1.031 & 1.343 & 1.077 & 0.550 \\
\hline 1991 & 10,590 & 1,742 & 12,331 & & 11,196 & 2,544 & 13,741 & 7,186 & & 1.057 & 1.461 & 1.114 & 0.583 \\
\hline 1992 & 11,400 & 1,734 & 13,133 & & 12,164 & 2,665 & 14,829 & 7,505 & & 1.067 & 1.537 & 1.129 & 0.571 \\
\hline 1993 & 11,874 & 1,762 & 13,637 & & 13,158 & 2,713 & 15,871 & 8,515 & & 1.108 & 1.539 & 1.164 & 0.624 \\
\hline 1994 & 12,272 & 1,836 & 14,108 & & 13,791 & 2,860 & 16,651 & 9,033 & & 1.124 & 1.558 & 1.180 & 0.640 \\
\hline 1995 & 12,469 & 1,910 & 14,379 & & 14,677 & 2,939 & 17,616 & 9,374 & & 1.177 & 1.539 & 1.225 & 0.652 \\
\hline 1996 & 12,774 & 2,025 & 14,799 & & 13,793 & 2,724 & 16,517 & 9,497 & & 1.080 & 1.345 & 1.116 & 0.642 \\
\hline 1997 & 12,969 & 2,126 & 15,095 & & 13,592 & 2,905 & 16,497 & 8,508 & & 1.048 & 1.366 & 1.093 & 0.564 \\
\hline 1998 & 13,031 & 2,255 & 15,286 & 11,333 & 13,623 & 3,048 & 16,671 & 9,292 & 0.741 & 1.045 & 1.352 & 1.091 & 0.608 \\
\hline 1999 & 12,956 & 2,391 & 15,347 & & 13,586 & 3,248 & 16,834 & 8,129 & & 1.049 & 1.358 & 1.097 & 0.530 \\
\hline 2000 & 12,951 & 2,497 & 15,448 & 10,736 & 14,587 & 3,016 & 17,603 & 7,934 & 0.695 & 1.126 & 1.208 & 1.139 & 0.514 \\
\hline 2001 & 13,047 & 2,591 & 15,638 & & 14,607 & 3,282 & 17,889 & 8,076 & & 1.120 & 1.266 & 1.144 & 0.516 \\
\hline
\end{tabular}


Table 16 (continued)

National School Lunch Program (NSLP) - Average Monthly Participation (in thousands)

\begin{tabular}{|c|c|c|c|c|c|c|c|c|c|c|c|c|c|}
\hline \multirow[b]{2}{*}{ Year } & \multicolumn{3}{|c|}{$\begin{array}{c}\text { Administrative } \\
\text { Average Monthly Participation }\end{array}$} & \multicolumn{5}{|c|}{ Survey- Average Monthly Participation } & \multicolumn{5}{|c|}{ Reporting Rates } \\
\hline & Free & Reduced & $\begin{array}{l}\text { Free or } \\
\text { Reduced } \\
\text { Price }\end{array}$ & PSID & $\begin{array}{l}\text { SIPP } \\
\text { (Free) }\end{array}$ & $\begin{array}{c}\text { SIPP } \\
\text { (Reduced } \\
\text { Price) }\end{array}$ & $\begin{array}{c}\text { SIPP } \\
\text { (Free or } \\
\text { Reduced } \\
\text { Price) } \\
\end{array}$ & $\begin{array}{l}\text { CPS- } \\
\text { ADF/ } \\
\text { ASEC }\end{array}$ & PSID & $\begin{array}{l}\text { SIPP } \\
\text { (Free) }\end{array}$ & $\begin{array}{c}\text { SIPP } \\
\text { (Reduced } \\
\text { Price) }\end{array}$ & $\begin{array}{c}\text { SIPP } \\
\text { (Free or } \\
\text { Reduced } \\
\text { Price) } \\
\end{array}$ & $\begin{array}{l}\text { CPS- } \\
\text { ADF/ } \\
\text { ASEC }\end{array}$ \\
\hline 2002 & 13,433 & 2,633 & 16,067 & 11,645 & 15,026 & 3,294 & 18,320 & 8,901 & 0.725 & 1.119 & 1.251 & 1.140 & 0.554 \\
\hline 2003 & 13,833 & 2,733 & 16,567 & & 14,781 & 3,421 & 18,202 & 8,858 & & 1.069 & 1.252 & 1.099 & 0.535 \\
\hline 2004 & 14,267 & 2,833 & 17,100 & 12,155 & 15,707 & 3,923 & 19,630 & 8,628 & 0.711 & 1.101 & 1.385 & 1.148 & 0.505 \\
\hline 2005 & 14,667 & 2,900 & 17,567 & & 15,879 & 3,884 & 19,763 & 8,503 & & 1.083 & 1.339 & 1.125 & 0.484 \\
\hline 2006 & 14,833 & 2,933 & 17,767 & & & & & 8,288 & & & & & 0.466 \\
\hline 2007 & & & & & & & & 8,380 & & & & & \\
\hline Average & & & & & & & & & 0.718 & 1.065 & 1.449 & 1.119 & 0.548 \\
\hline
\end{tabular}


Table 17

Women, Infants and Children (WIC) - Average Monthly Participation

\begin{tabular}{|c|c|c|c|c|c|c|c|c|c|c|}
\hline \multirow[b]{2}{*}{ Year } & \multicolumn{4}{|c|}{ Average Monthly Participation } & \multicolumn{3}{|c|}{ Surveys } & \multicolumn{3}{|c|}{ Reporting Rates } \\
\hline & Women & Infants & Children & Total & PSID & SIPP & $\begin{array}{c}\text { CPS- } \\
\text { ADF/ASEC }\end{array}$ & PSID & SIPP & $\begin{array}{c}\text { CPS- } \\
\text { ADF/ASEC }\end{array}$ \\
\hline 1983 & 578,010 & 762,100 & $1,341,762$ & $2,681,873$ & & $2,548,915$ & & & 0.950 & \\
\hline 1984 & 656,534 & 834,477 & $1,575,325$ & $3,066,336$ & & $2,857,268$ & & & 0.932 & \\
\hline 1985 & 678,098 & 891,376 & $1,625,838$ & $3,195,311$ & & $2,741,860$ & & & 0.858 & \\
\hline 1986 & 717,986 & 963,642 & $1,653,688$ & $3,335,315$ & & $2,438,474$ & & & 0.731 & \\
\hline 1987 & 758,672 & $1,030,236$ & $1,651,786$ & $3,440,693$ & & $2,269,432$ & & & 0.660 & \\
\hline 1989 & 986,097 & $1,299,690$ & $1,985,077$ & $4,270,865$ & & $2,371,682$ & & & 0.555 & \\
\hline 1990 & $1,040,887$ & $1,444,443$ & $2,065,124$ & $4,550,454$ & & $2,694,798$ & & & 0.592 & \\
\hline 1991 & $1,154,320$ & $1,602,121$ & $2,295,770$ & $5,052,210$ & & $3,176,805$ & & & 0.629 & \\
\hline 1992 & $1,252,709$ & $1,696,693$ & $2,555,337$ & $5,504,738$ & & $3,469,799$ & & & 0.630 & \\
\hline 1993 & $1,404,240$ & $1,757,864$ & $2,909,770$ & $6,071,873$ & & $3,924,523$ & & & 0.646 & \\
\hline 1994 & $1,524,576$ & $1,796,083$ & $3,298,240$ & $6,618,898$ & & $3,997,409$ & & & 0.604 & \\
\hline 1995 & $1,589,327$ & $1,816,872$ & $3,541,696$ & $6,947,895$ & & $4,073,833$ & & & 0.586 & \\
\hline 1997 & $1,708,688$ & $1,868,648$ & $3,807,929$ & $7,385,265$ & & $3,892,830$ & & & 0.527 & \\
\hline 1998 & $1,744,294$ & $1,893,036$ & $3,741,169$ & $7,378,499$ & $6,911,033$ & $3,794,967$ & & 0.937 & 0.514 & \\
\hline 1999 & $1,737,284$ & $1,891,698$ & $3,629,042$ & $7,258,024$ & & $3,727,767$ & & & 0.514 & \\
\hline 2000 & $1,760,347$ & $1,899,835$ & $3,551,309$ & $7,211,492$ & $6,384,731$ & $3,649,744$ & $4,595,053$ & 0.885 & 0.506 & 0.637 \\
\hline 2001 & $1,788,958$ & $1,925,665$ & $3,648,665$ & $7,363,287$ & & $4,132,639$ & $4,806,973$ & & 0.561 & 0.653 \\
\hline 2002 & $1,818,691$ & $1,931,632$ & $3,763,862$ & $7,514,184$ & $6,453,758$ & $4,274,605$ & $4,861,428$ & 0.859 & 0.569 & 0.647 \\
\hline 2003 & $1,874,606$ & $1,959,486$ & $3,850,275$ & $7,684,367$ & & $4,132,526$ & $5,075,717$ & & 0.538 & 0.661 \\
\hline 2004 & $1,944,911$ & $2,028,188$ & $3,991,965$ & $7,965,064$ & $8,150,696$ & $4,470,050$ & $5,105,831$ & 1.023 & 0.561 & 0.641 \\
\hline 2005 & $1,975,405$ & $2,053,280$ & $4,001,781$ & $8,030,466$ & & $4,671,507$ & $4,825,039$ & & 0.582 & 0.601 \\
\hline 2006 & $2,043,836$ & $2,093,967$ & $3,987,749$ & $8,125,552$ & & & $4,951,229$ & & & 0.609 \\
\hline 2007 & $2,110,410$ & $2,185,447$ & $4,080,116$ & $8,375,973$ & & & $4,843,223$ & & & 0.578 \\
\hline \multirow{2}{*}{\multicolumn{5}{|c|}{$\begin{array}{l}\text { Average } \\
\text { Average I }\end{array}$}} & & & & 0.926 & 0.626 & 0.628 \\
\hline & & & & & & & & & 0.717 & \\
\hline
\end{tabular}




\section{Table 18 - Reporting Rates Regression Estimates}

\begin{tabular}{|c|c|c|c|c|c|c|}
\hline \multirow{2}{*}{$\begin{array}{l}\text { Indicator Variables } \\
\text { for: }\end{array}$} & \multicolumn{3}{|c|}{ Dollars } & \multicolumn{3}{|c|}{ Months } \\
\hline & (1) & (2) & (3) & (4) & $(5)$ & (6) \\
\hline \multicolumn{7}{|l|}{ Program } \\
\hline AFDC/TANF & $\begin{array}{l}-0.318 \\
(0.038)\end{array}$ & $\begin{array}{l}-0.318 \\
(0.039)\end{array}$ & $\begin{array}{l}-0.313 \\
(0.047)\end{array}$ & $\begin{array}{l}-0.254 \\
(0.022)\end{array}$ & $\begin{array}{l}-0.255 \\
(0.024)\end{array}$ & $\begin{array}{l}-0.221 \\
(0.031)\end{array}$ \\
\hline FSP & $\begin{array}{l}-0.223 \\
(0.045)\end{array}$ & $\begin{array}{l}-0.223 \\
(0.045)\end{array}$ & $\begin{array}{l}-0.148 \\
(0.065)\end{array}$ & $\begin{array}{l}-0.191 \\
(0.025)\end{array}$ & $\begin{array}{l}-0.192 \\
(0.026)\end{array}$ & $\begin{array}{l}-0.139 \\
(0.039)\end{array}$ \\
\hline OASI & $\begin{array}{l}-0.059 \\
(0.037)\end{array}$ & $\begin{array}{l}-0.059 \\
(0.037)\end{array}$ & $\begin{array}{c}0.093 \\
(0.044)\end{array}$ & $\begin{array}{l}-0.045 \\
(0.014)\end{array}$ & $\begin{array}{l}-0.045 \\
(0.014)\end{array}$ & $\begin{array}{c}0.061 \\
(0.020)\end{array}$ \\
\hline SSI & $\begin{array}{l}-0.186 \\
(0.048)\end{array}$ & $\begin{array}{l}-0.186 \\
(0.048)\end{array}$ & $\begin{array}{l}-0.008 \\
(0.060)\end{array}$ & $\begin{array}{l}-0.187 \\
(0.037)\end{array}$ & $\begin{array}{l}-0.187 \\
(0.037)\end{array}$ & $\begin{array}{l}-0.138 \\
(0.066)\end{array}$ \\
\hline UI & $\begin{array}{l}-0.227 \\
(0.048)\end{array}$ & $\begin{array}{l}-0.228 \\
(0.048)\end{array}$ & $\begin{array}{l}-0.153 \\
(0.062)\end{array}$ & & & \\
\hline $\mathrm{WC}$ & $\begin{array}{l}-0.470 \\
(0.074)\end{array}$ & $\begin{array}{l}-0.470 \\
(0.074)\end{array}$ & $\begin{array}{l}-0.402 \\
(0.062)\end{array}$ & & & \\
\hline WIC & & & & $\begin{array}{l}-0.300 \\
(0.082)\end{array}$ & $\begin{array}{l}-0.297 \\
(0.084)\end{array}$ & $\begin{array}{l}-0.186 \\
(0.101)\end{array}$ \\
\hline
\end{tabular}

Survey

$\begin{array}{lllllll}\text { PSID } & -0.071 & -0.066 & -0.122 & -0.131 & 0.007 & -0.120 \\ & (0.042) & (0.055) & (0.061) & (0.044) & (0.074) & (0.092) \\ \text { CPS } & -0.043 & -0.022 & -0.058 & -0.118 & -0.069 & -0.168 \\ & (0.035) & (0.051) & (0.044) & (0.029) & (0.049) & (0.057) \\ \text { ACS } & -0.065 & & -0.107 & -0.196 & & -0.211 \\ & (0.067) & & (0.049) & (0.056) & & (0.061) \\ \text { CE Survey } & -0.120 & -0.102 & -0.196 & & & \\ & (0.043) & (0.058) & (0.052) & & & \end{array}$

Specification

$\begin{array}{lcccccc}\text { Year Dummies } & \text { Yes } & \text { Yes } & \text { Yes } & \text { Yes } & \text { Yes } & \text { Yes } \\ \begin{array}{l}\text { Coefficients } \\ \text { above for }\end{array} & & & & \\ \begin{array}{l}\text { Survey*Post } \\ 2000\end{array} & & \text { Yes } & & \text { Yes } & \end{array}$

Only 2000-2007

Data

Yes

Yes

Notes: This table reports the estimated coefficients in a regression of reporting rates on indicator variables for programs, surveys and years. In column 2, we further add a set of surveys and post year 2000 interactions, and the coefficients for these interactions are reported instead. In column 3, the regression is based on 2000-2007 data only. Standard errors, clustered by survey and program combinations, are in parentheses. The omitted program indicator is SSDI and the omitted survey indicator is for the SIPP. In these regressions we exclude the NSLP. For AFDC/TANF in the ACS and CE Survey we use the reporting rates that incorporate General Assistance. 
Table 19

CPS-ADF/ASEC Share of Dollars Imputed

A. Recipiency Imputed

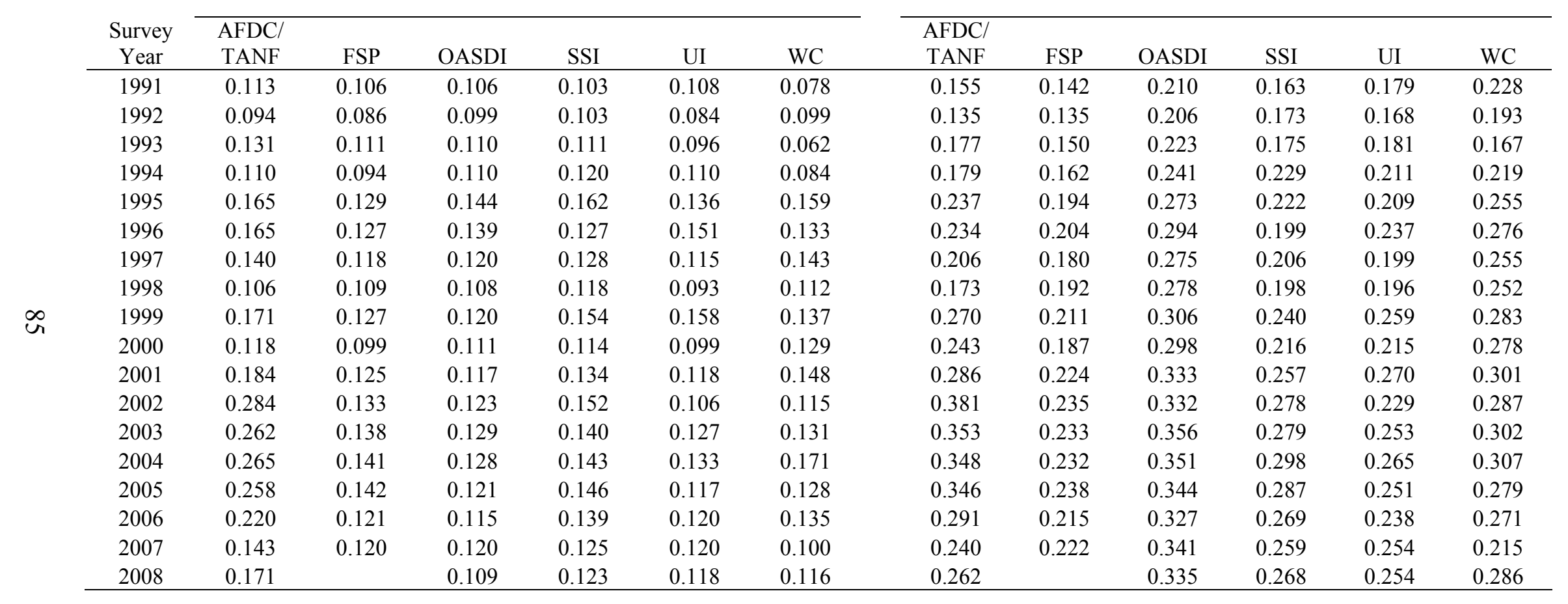

Notes: Panel A shows the share of total dollars reported attributable to those whose recipiency is imputed. Panel B shows the share of

total dollars reported that are imputed. Food Stamps data for 2008 are currently unavailable.

B. All Imputations 
Table 20

CPS-ADF/ASEC Share of Months Imputed

\begin{tabular}{|c|c|c|c|c|c|c|}
\hline \multirow{3}{*}{$\begin{array}{c}\text { Survey } \\
\text { Year }\end{array}$} & \multicolumn{2}{|c|}{ A. Recipiency Imputed } & \multicolumn{4}{|c|}{ B. All Imputations } \\
\hline & AFDC/ & & $\mathrm{AFDC} /$ & & & \\
\hline & TANF & FSP & TANF & FSP & OASDI & SSI \\
\hline 1991 & 0.115 & 0.115 & 0.134 & 0.126 & 0.107 & 0.104 \\
\hline 1992 & 0.104 & 0.092 & 0.117 & 0.113 & 0.099 & 0.102 \\
\hline 1993 & 0.123 & 0.118 & 0.144 & 0.146 & 0.109 & 0.115 \\
\hline 1994 & 0.108 & 0.101 & 0.115 & 0.108 & 0.108 & 0.115 \\
\hline 1995 & 0.151 & 0.140 & 0.218 & 0.194 & 0.146 & 0.156 \\
\hline 1996 & 0.154 & 0.139 & 0.214 & 0.203 & 0.141 & 0.127 \\
\hline 1997 & 0.139 & 0.124 & 0.209 & 0.178 & 0.124 & 0.135 \\
\hline 1998 & 0.117 & 0.112 & 0.173 & 0.184 & 0.108 & 0.120 \\
\hline 1999 & 0.174 & 0.139 & 0.285 & 0.210 & 0.118 & 0.150 \\
\hline 2000 & 0.120 & 0.107 & 0.238 & 0.185 & 0.111 & 0.119 \\
\hline 2001 & 0.206 & 0.128 & 0.301 & 0.207 & 0.116 & 0.128 \\
\hline 2002 & 0.282 & 0.142 & 0.379 & 0.227 & 0.121 & 0.147 \\
\hline 2003 & 0.263 & 0.136 & 0.356 & 0.228 & 0.130 & 0.143 \\
\hline 2004 & 0.266 & 0.140 & 0.362 & 0.229 & 0.127 & 0.143 \\
\hline 2005 & 0.281 & 0.142 & 0.398 & 0.229 & 0.125 & 0.144 \\
\hline 2006 & 0.238 & 0.123 & 0.329 & 0.211 & 0.116 & 0.133 \\
\hline 2007 & 0.166 & 0.123 & 0.257 & 0.210 & 0.120 & 0.120 \\
\hline 2008 & 0.174 & 0.118 & 0.270 & 0.201 & 0.109 & 0.122 \\
\hline
\end{tabular}

Notes: Panel A shows the share of months for those who recipiency is imputed. Panel B shows the overall average monthly participation imputation rates. 
Table 21

SIPP Share of Dollars Imputed

A. Recipiency Imputed

B. All Imputation

\begin{tabular}{|c|c|c|c|c|c|c|c|c|c|c|c|c|}
\hline $\begin{array}{c}\text { Survey } \\
\text { Year }\end{array}$ & $\begin{array}{l}\text { AFDC/ } \\
\text { TANF }\end{array}$ & FSP & OASDI & SSI & UI & WC & $\begin{array}{c}\text { AFDC/ } \\
\text { TANF }\end{array}$ & FSP & OASDI & SSI & UI & WC \\
\hline 1991 & 0.097 & 0.095 & 0.056 & 0.088 & 0.177 & 0.097 & 0.140 & 0.145 & 0.291 & 0.158 & 0.255 & 0.212 \\
\hline 1993 & 0.101 & 0.091 & 0.058 & 0.092 & 0.187 & 0.095 & 0.175 & 0.156 & 0.327 & 0.170 & 0.276 & 0.229 \\
\hline 1994 & 0.108 & 0.099 & 0.070 & 0.102 & 0.220 & 0.128 & 0.191 & 0.175 & 0.364 & 0.193 & 0.326 & 0.280 \\
\hline 1995 & 0.109 & 0.095 & 0.067 & 0.106 & 0.203 & 0.136 & 0.187 & 0.168 & 0.354 & 0.194 & 0.310 & 0.292 \\
\hline 1996 & 0.146 & 0.128 & 0.080 & 0.103 & 0.183 & 0.368 & 0.269 & 0.192 & 0.291 & 0.194 & 0.268 & 0.407 \\
\hline 1999 & 0.216 & 0.206 & 0.130 & 0.158 & 0.242 & 0.494 & 0.312 & 0.277 & 0.360 & 0.251 & 0.374 & 0.571 \\
\hline 2000 & 0.181 & 0.132 & 0.075 & 0.103 & 0.206 & 0.361 & 0.273 & 0.188 & 0.319 & 0.197 & 0.301 & 0.428 \\
\hline 2001 & 0.148 & 0.146 & 0.097 & 0.126 & 0.227 & 0.385 & 0.264 & 0.214 & 0.376 & 0.254 & 0.341 & 0.494 \\
\hline 2002 & 0.179 & 0.176 & 0.131 & 0.161 & 0.213 & 0.412 & 0.260 & 0.257 & 0.428 & 0.284 & 0.338 & 0.518 \\
\hline 2003 & 0.186 & 0.181 & 0.146 & 0.172 & 0.209 & 0.364 & 0.284 & 0.264 & 0.436 & 0.287 & 0.358 & 0.480 \\
\hline 2004 & 0.126 & 0.104 & 0.116 & 0.209 & 0.274 & 0.133 & 0.403 & 0.358 & 0.807 & 0.492 & 0.441 & 0.462 \\
\hline
\end{tabular}

Notes: Panel A shows the share of total dollars reported attributable to those whose recipiency is imputed. Panel B shows the share of total dollars reported that are imputed. 
Table 22

SIPP Share of Months Imputed

\begin{tabular}{ccccc}
\hline \hline Calendar Year & AFDC/TANF & FSP & OASDI & SSI \\
\hline 1990 & 0.096 & 0.088 & 0.029 & 0.074 \\
1991 & 0.101 & 0.095 & 0.036 & 0.083 \\
1992 & 0.105 & 0.091 & 0.036 & 0.080 \\
1993 & 0.107 & 0.095 & 0.039 & 0.082 \\
1994 & 0.114 & 0.098 & 0.049 & 0.095 \\
1995 & 0.115 & 0.098 & 0.046 & 0.099 \\
1996 & 0.152 & 0.136 & 0.058 & 0.095 \\
1997 & 0.262 & 0.188 & 0.098 & 0.137 \\
1998 & 0.240 & 0.180 & 0.109 & 0.142 \\
1999 & 0.210 & 0.192 & 0.106 & 0.151 \\
2000 & 0.158 & 0.124 & 0.060 & 0.101 \\
2001 & 0.170 & 0.141 & 0.075 & 0.124 \\
2002 & 0.195 & 0.178 & 0.101 & 0.155 \\
2003 & 0.210 & 0.176 & 0.109 & 0.169 \\
2004 & 0.145 & 0.102 & 0.079 & 0.210 \\
\hline
\end{tabular}


Table 23

ACS Dollars Imputation Rates, by Year and Program

\begin{tabular}{ccccc}
\hline \hline Survey Year & TANF & FSP & OASDI & SSI \\
\hline 2000 & 0.166 & & 0.215 & 0.217 \\
2001 & 0.171 & & 0.208 & 0.169 \\
2002 & 0.179 & & 0.185 & 0.167 \\
2003 & 0.173 & & 0.185 & 0.166 \\
2004 & 0.145 & & 0.156 & 0.145 \\
2005 & 0.139 & 0.172 & 0.145 & 0.141 \\
2006 & 0.217 & 0.164 & 0.173 & 0.175
\end{tabular}

Note: The table above shows the dollars imputation rates in the ACS, obtained by dividing the weighted total imputed benefit amounts in each year by the unconditional weighted total in that year. 
Table 24

Reporting Rates from Microdata and Aggregates, and Reporting Conditional on True Receipt

\begin{tabular}{|c|c|c|c|}
\hline \multirow[b]{2}{*}{ Study/Program } & \multicolumn{2}{|c|}{ Microdata } & \multirow[b]{2}{*}{$\begin{array}{c}\text { Aggregate Data } \\
\text { Reporting Rate } \\
(3)\end{array}$} \\
\hline & $\begin{array}{l}\text { Reporting Rate } \\
\text { Conditional on } \\
\text { True Receipt } \\
\text { (1) }\end{array}$ & $\begin{array}{c}\text { Unconditional } \\
\text { Reporting Rate } \\
(2) \\
\end{array}$ & \\
\hline \multicolumn{4}{|c|}{ Marquis and Moore (1990) - 1984 SIPP } \\
\hline AFDC & 0.51 & 0.61 & 0.82 \\
\hline FSP & 0.77 & 0.87 & 0.89 \\
\hline OASDI & 0.95 & 1.01 & 0.94 \\
\hline SSI & 0.77 & 0.88 & 0.91 \\
\hline UI & 0.61 & 0.80 & 0.78 \\
\hline WC & 0.45 & 0.82 & 0.41 \\
\hline \multicolumn{4}{|c|}{ Huynh, Rupp and Sears (2002) - SIPP } \\
\hline \multicolumn{4}{|c|}{ OASDI } \\
\hline Jan 1993 & 0.96 & 1.02 & 0.95 \\
\hline Aug 1995 & 0.95 & 1.02 & 0.93 \\
\hline Mar 1996 & 0.94 & 0.99 & 0.94 \\
\hline Oct 1998 & 0.95 & 1.00 & 0.94 \\
\hline \multicolumn{4}{|l|}{ SSI } \\
\hline Jan 1993 & 0.83 & 1.04 & 0.87 \\
\hline Aug 1995 & 0.86 & 1.12 & 0.85 \\
\hline Mar 1996 & 0.83 & 0.96 & 0.94 \\
\hline Oct 1998 & 0.83 & 0.98 & 1.02 \\
\hline \multicolumn{4}{|c|}{ Sears and Rupp (2003) - SIPP } \\
\hline \multicolumn{4}{|c|}{ OASDI } \\
\hline Mar 1996 & 0.96 & 1.00 & 0.94 \\
\hline Jan 2001 & 0.95 & 0.99 & 0.97 \\
\hline \multicolumn{4}{|l|}{ SSI } \\
\hline Mar 1996 & 0.86 & 1.00 & 0.94 \\
\hline Jan 2001 & 0.81 & 0.99 & 0.99 \\
\hline \multicolumn{4}{|c|}{ Taeuber et al. (2004) - ACS } \\
\hline \multicolumn{4}{|l|}{ FSP } \\
\hline 2001 & 0.53 & 0.58 & 0.57 \\
\hline $20012^{\text {nd }}$ method & 0.62 & & \\
\hline
\end{tabular}

Note: The time periods and geography do not match exactly. For UI and WC, the rates in column 3 come from the dollars reporting rates reported in this paper. We also assume OASDI participation is the sum of OASI and SSDI participation. 
Table 25

\section{Adjusted Trends in the Number of Single Mothers with Neither Work or Welfare, CPS and SIPP Data}

A. SIPP

\begin{tabular}{lccc}
\hline \hline Calendar Year & $\begin{array}{c}\text { Observed Fraction of } \\
\text { Disconnected Single Mothers } \\
\text { in Blank and Kovak (2008) }\end{array}$ & $\begin{array}{c}\text { Adjustment } \\
\text { Factor }\end{array}$ & $\begin{array}{c}\text { Adjusted Fraction of } \\
\text { Disconnected Single } \\
\text { Mothers }\end{array}$ \\
\cline { 2 - 4 } & $(1)$ & $(2)$ & $(3)=(1)-(2)$ \\
\hline 1990 & 0.188 & 0.091 & 0.097 \\
1996 & 0.170 & 0.071 & 0.099 \\
2001 & 0.232 & 0.035 & 0.197 \\
\hline
\end{tabular}

B. CPS

\begin{tabular}{lccc}
\hline \hline Calendar Year & $\begin{array}{c}\text { Observed Fraction of } \\
\text { Disconnected Single Mothers } \\
\text { in Blank and Kovak (2008) }\end{array}$ & $\begin{array}{c}\text { Adjustment } \\
\text { Factor }\end{array}$ & $\begin{array}{c}\text { Adjusted Fraction of } \\
\text { Disconnected Single } \\
\text { Mothers }\end{array}$ \\
\cline { 2 - 4 } & $(1)$ & $(2)$ & $(3)=(1)-(2)$ \\
\hline 1990 & 0.099 & 0.079 & 0.020 \\
1995 & 0.117 & 0.111 & 0.006 \\
2000 & 0.146 & 0.052 & 0.094 \\
2005 & 0.200 & 0.040 & 0.160 \\
\hline
\end{tabular}

Notes: The sample is based on families headed by a single mother ages 18-54, with at least one child ages $0-18$, and with family income equal or less than $200 \%$ of the poverty level (for the SIPP, we annualize the monthly income reported prior to comparing to the poverty level). For the CPS, disconnected single mothers are those with: 1) zero earnings in the past calendar year, 2) zero AFDC/TANF receipts in the past calendar year, and 3) those who reported not working in the past calendar year for reasons other than going to school. For the SIPP, disconnected single mothers are those with: 1) zero earnings in the month, 2) zero AFDC/TANF receipts in the month, and 3) those who are not in school in the month. Column 1 numbers are obtained from Table 2 of Blank and Kovak (2008). The adjustment factors in columns 2 are equal to $\mathrm{k}(1-\mathrm{y}) / \mathrm{y}$ where $\mathrm{k}$ is the observed probability of not working and receiving welfare (among low-income single mothers) and $\mathrm{y}$ is the AFDC/TANF month reporting rate of the corresponding year. 


\section{Appendix Table 1 \\ Summary of PSID Benefit Variable Information}

\begin{tabular}{|c|c|c|c|c|c|c|c|c|}
\hline $\begin{array}{c}\text { Benefit } \\
\text { Year }\end{array}$ & $\begin{array}{c}\text { Survey } \\
\text { Year }\end{array}$ & SSI & OASI & SSDI & UI & WC & FSP & AFDC/TANF \\
\hline 1967 & 1968 & & \multicolumn{2}{|c|}{ H only (a) } & \multicolumn{2}{|c|}{ H only (a) } & All & All \\
\hline 1968 & 1969 & & \multicolumn{2}{|c|}{ H only (a) } & \multicolumn{2}{|c|}{ H only (a) } & All & $\mathrm{H}$ \\
\hline 1969 & 1970 & & \multicolumn{2}{|c|}{ H only } & \multicolumn{2}{|c|}{ H only } & All & $\mathrm{H}$ \\
\hline 1970 & 1971 & & \multicolumn{2}{|c|}{$(\mathrm{H}+\mathrm{W})$ only } & \multicolumn{2}{|c|}{$\mathrm{H}$ only } & All & $(\mathrm{H}+\mathrm{W})$ \\
\hline 1971 & 1972 & & \multicolumn{2}{|c|}{$(\mathrm{H}+\mathrm{W})$ only } & \multicolumn{2}{|c|}{$\mathrm{H}$ only } & All & $(\mathrm{H}+\mathrm{W})$ \\
\hline 1972 & 1973 & & \multicolumn{2}{|c|}{$(\mathrm{H}+\mathrm{W})$ only } & \multicolumn{2}{|c|}{ H only } & & $(\mathrm{H}+\mathrm{W})$ \\
\hline 1973 & 1974 & & \multicolumn{2}{|c|}{$(\mathrm{H}+\mathrm{W})$ only } & \multicolumn{2}{|c|}{ H only } & All & $(\mathrm{H}+\mathrm{W})$ \\
\hline 1974 & 1975 & $(\mathrm{H}+\mathrm{W})+\mathrm{O}$ & \multicolumn{2}{|c|}{$(\mathrm{H}+\mathrm{W})+\mathrm{O}$} & \multicolumn{2}{|c|}{$\mathrm{H}+(\mathrm{W}+\mathrm{O})$} & All & $(\mathrm{H}+\mathrm{W})+\mathrm{O}$ \\
\hline 1975 & 1976 & $(\mathrm{H}+\mathrm{W})+\mathrm{O}$ & \multicolumn{2}{|c|}{$(\mathrm{H}+\mathrm{W})+\mathrm{O}$} & \multicolumn{2}{|c|}{$\mathrm{H}+(\mathrm{W}+\mathrm{O})$} & All & $(\mathrm{H}+\mathrm{W})+\mathrm{O}$ \\
\hline 1976 & 1977 & $(\mathrm{H}+\mathrm{W})+\mathrm{O}$ & \multicolumn{2}{|c|}{$(\mathrm{H}+\mathrm{W})+\mathrm{O}$} & $\mathrm{H}+(\mathrm{W}+\mathrm{O})$ & $\mathrm{H}+(\mathrm{W}+\mathrm{O})$ & All & $(\mathrm{H}+\mathrm{W})+\mathrm{O}$ \\
\hline 1977 & 1978 & $(\mathrm{H}+\mathrm{W})+\mathrm{O}$ & \multicolumn{2}{|c|}{$(\mathrm{H}+\mathrm{W})+\mathrm{O}$} & $\mathrm{H}+(\mathrm{W}+\mathrm{O})$ & $\mathrm{H}+(\mathrm{W}+\mathrm{O})$ & All & $(\mathrm{H}+\mathrm{W})+\mathrm{O}$ \\
\hline 1978 & 1979 & $(\mathrm{H}+\mathrm{W})+\mathrm{O}$ & \multicolumn{2}{|c|}{$(\mathrm{H}+\mathrm{W})+\mathrm{O}$} & $\mathrm{H}+(\mathrm{W}+\mathrm{O})$ & $\mathrm{H}+(\mathrm{W}+\mathrm{O})$ & All & $(\mathrm{H}+\mathrm{W})+\mathrm{O}$ \\
\hline 1979 & 1980 & $(\mathrm{H}+\mathrm{W})+\mathrm{O}$ & \multicolumn{2}{|c|}{$(\mathrm{H}+\mathrm{W})+\mathrm{O}$} & $\mathrm{H}+(\mathrm{W}+\mathrm{O})$ & $\mathrm{H}+(\mathrm{W}+\mathrm{O})$ & All & $(\mathrm{H}+\mathrm{W})+\mathrm{O}$ \\
\hline 1980 & 1981 & $(\mathrm{H}+\mathrm{W})+\mathrm{O}$ & \multicolumn{2}{|c|}{$(\mathrm{H}+\mathrm{W})+\mathrm{O}$} & $\mathrm{H}+(\mathrm{W}+\mathrm{O})$ & $\mathrm{H}+(\mathrm{W}+\mathrm{O})$ & All & $(\mathrm{H}+\mathrm{W})+\mathrm{O}$ \\
\hline 1981 & 1982 & $(\mathrm{H}+\mathrm{W})+\mathrm{O}$ & \multicolumn{2}{|c|}{$(\mathrm{H}+\mathrm{W})+\mathrm{O}$} & $\mathrm{H}+(\mathrm{W}+\mathrm{O})$ & $\mathrm{H}+(\mathrm{W}+\mathrm{O})$ & All & $(\mathrm{H}+\mathrm{W})+\mathrm{O}$ \\
\hline 1982 & 1983 & $(\mathrm{H}+\mathrm{W})+\mathrm{O}$ & \multicolumn{2}{|c|}{$(\mathrm{H}+\mathrm{W})+\mathrm{O}$} & $\mathrm{H}+(\mathrm{W}+\mathrm{O})$ & $\mathrm{H}+(\mathrm{W}+\mathrm{O})$ & All & $(\mathrm{H}+\mathrm{W})+\mathrm{O}$ \\
\hline 1983 & 1984 & $(\mathrm{H}+\mathrm{W})+\mathrm{O}$ & $\mathrm{H}+\mathrm{W}+\mathrm{O}(\mathrm{b})$ & $\mathrm{H}+\mathrm{W}+\mathrm{O}(\mathrm{b})$ & $\mathrm{H}+(\mathrm{W}+\mathrm{O})$ & $\mathrm{H}+(\mathrm{W}+\mathrm{O})$ & All & $(\mathrm{H}+\mathrm{W})+\mathrm{O}$ \\
\hline 1984 & 1985 & $(\mathrm{H}+\mathrm{W})+\mathrm{O}$ & $\mathrm{H}+\mathrm{W}+\mathrm{O}(\mathrm{b})$ & $\mathrm{H}+\mathrm{W}+\mathrm{O}(\mathrm{b})$ & $\mathrm{H}+(\mathrm{W}+\mathrm{O})$ & $\mathrm{H}+(\mathrm{W}+\mathrm{O})$ & All & $(\mathrm{H}+\mathrm{W})+\mathrm{O}$ \\
\hline 1985 & 1986 & $\mathrm{H}+\mathrm{W}+\mathrm{O}$ & $\mathrm{H}+\mathrm{W}+\mathrm{O}(\mathrm{b})$ & $\mathrm{H}+\mathrm{W}+\mathrm{O}(\mathrm{b})$ & $\mathrm{H}+\mathrm{W}+\mathrm{O}$ & $\mathrm{H}+\mathrm{W}+\mathrm{O}$ & All & $\mathrm{H}+\mathrm{W}+\mathrm{O}$ \\
\hline 1986 & 1987 & $\mathrm{H}+\mathrm{W}+\mathrm{O}$ & $\mathrm{H}+\mathrm{W}+\mathrm{O}(\mathrm{b})$ & $\mathrm{H}+\mathrm{W}+\mathrm{O}(\mathrm{b})$ & $\mathrm{H}+\mathrm{W}+\mathrm{O}$ & $\mathrm{H}+\mathrm{W}+\mathrm{O}$ & All & $\mathrm{H}+\mathrm{W}+\mathrm{O}$ \\
\hline 1987 & 1988 & $\mathrm{H}+\mathrm{W}+\mathrm{O}$ & $\mathrm{H}+\mathrm{W}+\mathrm{O}(\mathrm{b})$ & $\mathrm{H}+\mathrm{W}+\mathrm{O}(\mathrm{b})$ & $\mathrm{H}+\mathrm{W}+\mathrm{O}$ & $\mathrm{H}+\mathrm{W}+\mathrm{O}$ & All & $\mathrm{H}+\mathrm{W}+\mathrm{O}$ \\
\hline 1988 & 1989 & $\mathrm{H}+\mathrm{W}+\mathrm{O}$ & $\mathrm{H}+\mathrm{W}+\mathrm{O}(\mathrm{b})$ & $\mathrm{H}+\mathrm{W}+\mathrm{O}(\mathrm{b})$ & $\mathrm{H}+\mathrm{W}+\mathrm{O}$ & $\mathrm{H}+\mathrm{W}+\mathrm{O}$ & All & $\mathrm{H}+\mathrm{W}+\mathrm{O}$ \\
\hline 1989 & 1990 & $\mathrm{H}+\mathrm{W}+\mathrm{O}$ & $\mathrm{H}+\mathrm{W}+\mathrm{O}(\mathrm{b})$ & $\mathrm{H}+\mathrm{W}+\mathrm{O}(\mathrm{b})$ & $\mathrm{H}+\mathrm{W}+\mathrm{O}$ & $\mathrm{H}+\mathrm{W}+\mathrm{O}$ & All & $\mathrm{H}+\mathrm{W}+\mathrm{O}$ \\
\hline 1990 & 1991 & $\mathrm{H}+\mathrm{W}+\mathrm{O}$ & $\mathrm{H}+\mathrm{W}+\mathrm{O}(\mathrm{b})$ & $\mathrm{H}+\mathrm{W}+\mathrm{O}(\mathrm{b})$ & $\mathrm{H}+\mathrm{W}+\mathrm{O}$ & $\mathrm{H}+\mathrm{W}+\mathrm{O}$ & All & $\mathrm{H}+\mathrm{W}+\mathrm{O}$ \\
\hline 1991 & 1992 & $\mathrm{H}+\mathrm{W}+\mathrm{O}$ & $\mathrm{H}+\mathrm{W}+\mathrm{O}(\mathrm{b})$ & $\mathrm{H}+\mathrm{W}+\mathrm{O}(\mathrm{b})$ & $\mathrm{H}+\mathrm{W}+\mathrm{O}$ & $\mathrm{H}+\mathrm{W}+\mathrm{O}$ & All & $\mathrm{H}+\mathrm{W}+\mathrm{O}$ \\
\hline 1992 & 1993 & $\mathrm{H}+\mathrm{W}+\mathrm{O}$ & $\mathrm{H}+\mathrm{W}+\mathrm{O}(\mathrm{d})$ & $\mathrm{H}+\mathrm{W}+\mathrm{O}(\mathrm{d})$ & $\mathrm{H}+\mathrm{W}+\mathrm{O}$ & $\mathrm{H}+\mathrm{W}+\mathrm{O}$ & All & $\mathrm{H}+\mathrm{W}+\mathrm{O}$ \\
\hline 1993 & 1994 & $\mathrm{H}+\mathrm{W}$ & & & $\mathrm{H}+\mathrm{W}$ & $\mathrm{H}+\mathrm{W}$ & All & $\mathrm{H}+\mathrm{W}$ \\
\hline 1994 & 1995 & $\mathrm{H}+\mathrm{W}$ & & & $\mathrm{H}+\mathrm{W}$ & $\mathrm{H}+\mathrm{W}$ & All & $\mathrm{H}+\mathrm{W}$ \\
\hline 1995 & 1996 & $\mathrm{H}+\mathrm{W}$ & & & $\mathrm{H}+\mathrm{W}$ & $\mathrm{H}+\mathrm{W}$ & All & $\mathrm{H}+\mathrm{W}$ \\
\hline 1996 & 1997 & $\mathrm{H}+\mathrm{W}$ & & & $\mathrm{H}+\mathrm{W}$ & $\mathrm{H}+\mathrm{W}$ & All & $\mathrm{H}+\mathrm{W}$ \\
\hline 1997 & 1999 & All & & & & & All & \\
\hline 1998 & 1999 & $\mathrm{H}+\mathrm{W}(\mathrm{e})$ & & & $\mathrm{H}+\mathrm{W}$ & $\mathrm{H}+\mathrm{W}$ & All & $\mathrm{H}+\mathrm{W}$ \\
\hline 1999 & 2001 & All & & & & & All & \\
\hline 2000 & 2001 & $\mathrm{H}+\mathrm{W}(\mathrm{e})$ & & & $\mathrm{H}+\mathrm{W}$ & $\mathrm{H}+\mathrm{W}$ & All & $\mathrm{H}+\mathrm{W}$ \\
\hline 2001 & 2003 & & & & & & All & \\
\hline 2002 & 2003 & $\mathrm{H}+\mathrm{W}$ & & & $\mathrm{H}+\mathrm{W}$ & $\mathrm{H}+\mathrm{W}$ & All & $\mathrm{H}+\mathrm{W}$ \\
\hline 2003 & 2005 & All & $\mathrm{H}+\mathrm{W}$ & $\mathrm{O}(\mathrm{g})$ & All & All & All & All \\
\hline 2004 & $2005(\mathrm{~g})$ & $\mathrm{H}+\mathrm{W}$ & & & $\mathrm{H}+\mathrm{W}$ & $\mathrm{H}+\mathrm{W}$ & All & $\mathrm{H}+\mathrm{W}$ \\
\hline
\end{tabular}

Note: $\mathrm{H}$ - head, $\mathrm{W}$ - spouse, $\mathrm{O}$ - other family members, All - family, $\mathrm{H}+\mathrm{W}$ - head and spouse reported separately, $(\mathrm{H}+\mathrm{W})$ - head and spouse amounts combined, $(\mathrm{W}+\mathrm{O})$ - spouse amount and other family members amount combined, $\mathrm{H}+\mathrm{W}+\mathrm{O}$ - head, spouse and all other family members reported separately (other family members amount combined as one). (a) These variables are reported in bracketed form; we take the midpoint of the interval in each case. (b) Amount of Social security income is recorded for each individual in the family. The type of social security (Disability, Retirement, Survivors, More than one of the above) is also recorded. (d) Amount of Social security income is recorded separately for the Head and Spouse. But for other family members, only the combined amount is available. The type of social security (Disability, Retirement, Survivors, More than one of the above) is also recorded only for the Head and the spouse. (e) SSI is reported also for the second year before the survey year and is for the whole family. (f) Based on the preliminary data release, the table here reflects only what is currently made available to the public, extra variables may be available in future data releases. (g) Each family is asked to nominate two types of social security received and each family member is asked about whether he received social security. 
Appendix Table 2

Summary of CPS Annual Demographic File/Annual Social and Economic Supplement Benefit Variable Information

\begin{tabular}{|c|c|c|c|c|c|c|c|}
\hline Survey Year & SSI & OASI & UI & WC & FSP & AFDC/TANF & EITC \\
\hline 1968 & & Y (b) & & & $\mathrm{N}$ & $\mathrm{Y}(\mathrm{d})$ & \\
\hline 1969 & & Y (b) & & & $\mathrm{N}$ & $Y(d)$ & \\
\hline 1970 & & & & & & & \\
\hline 1971 & & Y (b) & & & $\mathrm{N}$ & $Y(d)$ & \\
\hline 1972 & & Y (b) & & & $\mathrm{N}$ & $Y(d)$ & \\
\hline 1973 & & $Y(b)$ & & & $\mathrm{N}$ & $Y(d)$ & \\
\hline 1974 & & $Y(b)$ & & & $\mathrm{N}$ & $Y(d)$ & \\
\hline 1975 & & $Y(b)$ & & & $\mathrm{N}$ & $Y(d)$ & \\
\hline 1976 & $\mathrm{Y}(\mathrm{e})$ & $\mathrm{Y}(\mathrm{h}, \mathrm{i})$ & & & $\mathrm{N}$ & $Y(f)$ & \\
\hline 1977 & Y (e) & Y(h,i) & & & $\mathrm{N}$ & $Y(f)$ & \\
\hline 1978 & Y (e) & $\mathrm{Y}(\mathrm{h}, \mathrm{i})$ & & & $\mathrm{N}$ & $Y(f)$ & \\
\hline 1979 & $\mathrm{Y}(\mathrm{e})$ & $\mathrm{Y}(\mathrm{h}, \mathrm{i})$ & & & $\mathrm{N}$ & $Y(f)$ & \\
\hline 1980 & Y (e) & $\mathrm{Y}(\mathrm{h}, \mathrm{i})$ & & & $\mathrm{Y}(\mathrm{k})$ & $Y(f)$ & \\
\hline 1981 & $\mathrm{Y}(\mathrm{e})$ & $Y(h, i)$ & & & $Y(k)$ & $Y(f)$ & \\
\hline 1982 & Y (e) & $\mathrm{Y}(\mathrm{h}, \mathrm{i})$ & & & $Y(k)$ & $Y(f)$ & \\
\hline 1983 & $\mathrm{Y}(\mathrm{e})$ & $\mathrm{Y}(\mathrm{h})$ & & & $\mathrm{Y}(\mathrm{k})$ & $Y(f)$ & \\
\hline 1984 & Y (e) & $\mathrm{Y}(\mathrm{h})$ & & & $Y(k)$ & $Y(f)$ & \\
\hline 1985 & Y (e) & $\mathrm{Y}(\mathrm{h})$ & & & $Y(k)$ & $Y(f)$ & \\
\hline 1986 & Y (e) & $\mathrm{Y}(\mathrm{h})$ & & & $Y(k)$ & $Y(f)$ & \\
\hline 1987 & $\mathrm{Y}(\mathrm{e})$ & $\mathrm{Y}(\mathrm{h})$ & & & $Y(k)$ & $Y(f)$ & \\
\hline 1988 & Y (e) & $\mathrm{Y}$ & $\mathrm{Y}(\mathrm{n})$ & Y & $Y(k)$ & $Y(f)$ & \\
\hline 1989 & Y (e) & $\mathrm{Y}$ & $\mathrm{Y}(\mathrm{n})$ & Y & $Y(k)$ & $Y(f)$ & \\
\hline 1990 & $\mathrm{Y}(\mathrm{e})$ & Y & $Y(n)$ & Y & $Y(k)$ & $Y(f)$ & \\
\hline 1991 & Y (e) & Y & $Y(n)$ & Y & $Y(k)$ & $Y(f)$ & \\
\hline 1992 & Y (e) & Y & $Y(n)$ & Y & $Y(k)$ & $Y(f)$ & Y \\
\hline 1993 & Y (e) & Y & $\mathrm{Y}(\mathrm{n})$ & Y & $Y(k)$ & $Y(f)$ & Y \\
\hline 1994 & $\mathrm{Y}(\mathrm{e})$ & Y & $Y(n)$ & Y & $Y(k)$ & $Y(f)$ & Y \\
\hline 1995 & Y (e) & Y & $Y(n)$ & Y & $Y(k)$ & $Y(f)$ & Y \\
\hline 1996 & Y (e) & Y & $Y(n)$ & Y & $Y(k)$ & $Y(f)$ & Y \\
\hline 1997 & Y (e) & Y & $\mathrm{Y}(\mathrm{n})$ & Y & $Y(k)$ & $Y(f)$ & Y \\
\hline 1998 & Y (e) & Y & $Y(n)$ & Y & $Y(k)$ & $Y(f)$ & $\mathrm{Y}$ \\
\hline 1999 & Y (e) & Y & $Y(n)$ & Y & $Y(k)$ & $Y(f)$ & Y \\
\hline 2000 & Y (e) & Y & $Y(n)$ & Y & $Y(k)$ & $Y(f)$ & Y \\
\hline 2001 & Y (e) & Y & $Y(n)$ & Y & $Y(k)$ & $Y(f)$ & Y \\
\hline 2002 & $\mathrm{Y}(\mathrm{e})$ & Y & $Y(n)$ & Y & $Y(k)$ & $Y(f)$ & Y \\
\hline 2003 & Y (e) & Y & $Y(n)$ & Y & $Y(k)$ & $Y(f)$ & Y \\
\hline 2004 & $\mathrm{Y}(\mathrm{e})$ & Y & $Y(n)$ & Y & $Y(k)$ & $Y(f)$ & $\mathrm{Y}$ \\
\hline 2005 & $\mathrm{Y}(\mathrm{e})$ & Y & $Y(n)$ & Y & $Y(k)$ & $Y(f)$ & $\mathrm{Y}$ \\
\hline 2006 & $\mathrm{Y}(\mathrm{e})$ & Y & $Y(n)$ & Y & $Y(k)$ & $Y(f)$ & $\mathrm{Y}$ \\
\hline 2007 & Y (e) & Y & $Y(n)$ & Y & $Y(k)$ & $Y(f)$ & Y \\
\hline 2008 & Y (e) & Y & $\mathrm{Y}(\mathrm{n})$ & Y & $\mathrm{N}(\mathrm{m})$ & $Y(f)$ & $\mathrm{N}(\mathrm{m})$ \\
\hline
\end{tabular}

(a) Also includes Veterans benefits, government employee pensions.

(b) Also includes railroad retirement benefits.

(d) Old age assistance, AFDC and aid to the blind or disabled are combined; no variable for type of benefit.

(e) Federal and state payments are included

(f) AFDC and general assistance are combined; they can be partially separated (except when both benefit type variables $=1$ ).

(g) Includes Veterans benefits.

(h) Also includes railroad retirement benefits; they can be partially separated (except when both benefit type variables=1)

(i) The variable is called "income from US government", the position of this variable though is the same as other years' social security.

(k) Available at the household level only.

(m) Data withheld by the Census Bureau.

(n) May include union or strike benefit payments. The amount of unemployment compensation was asked after asking whether the individual received unemployment benefits, supplemental benefits or union and strike benefit payments. 


\section{Appendix Table 3: Comparison of Household Survey Characteristics}

\begin{tabular}{|c|c|c|c|c|c|}
\hline & ACS & CE Survey (Interview) & CPS-ADF/ASEC & PSID & SIPP \\
\hline Years of Operation & 1999-Present & 1980-present & 1947-present & 1968-present & 1983-present \\
\hline Interview Mandatory? & Yes & No & No & No & No \\
\hline $\begin{array}{l}\text { Type of Survey and } \\
\text { Frequency }\end{array}$ & Cross-Sectional, Annual & $\begin{array}{l}\text { Quarterly interviews for } \\
12 \text { months }\end{array}$ & 2 year panel, Annual & $\begin{array}{l}\text { Panel, annual until } \\
\text { 1997, bi-annual after }\end{array}$ & $\begin{array}{l}2-5 \text { year panels, } \\
\text { interviews every } 4 \\
\text { months }\end{array}$ \\
\hline Recall Period & Last 12 months & Last 12 months & Last calendar year & $\begin{array}{l}\text { Last calendar year or } \\
\text { last two calendar years }\end{array}$ & Last 4 months \\
\hline Target Population & $\begin{array}{l}\text { 1999-2005: Civilian non- } \\
\text { institutionalized } \\
\text { 2006-present: Group } \\
\text { quarters are included. }\end{array}$ & $\begin{array}{l}\text { Civilian non- } \\
\text { institutionalized }\end{array}$ & $\begin{array}{l}\text { Civilian non- } \\
\text { institutionalized* }\end{array}$ & $\begin{array}{l}\text { Civilian non- } \\
\text { institutionalized }\end{array}$ & $\begin{array}{l}\text { Civilian non- } \\
\text { institutionalized }\end{array}$ \\
\hline $\begin{array}{l}\text { Months in which } \\
\text { Interviews are } \\
\text { Conducted }\end{array}$ & Throughout the year & Throughout the year & $\begin{array}{l}\text { March } \\
\text { (February-April } \\
\text { beginning in 2002) }\end{array}$ & March - August & Throughout the year \\
\hline Interview Mode & $\begin{array}{l}\text { Mailed Questionnaire, } \\
\text { Telephone and Personal } \\
\text { Visits }\end{array}$ & Personal Visits & $\begin{array}{l}\text { Personal visits, } \\
\text { Telephone }\end{array}$ & $\begin{array}{l}\text { Personal visits until } \\
1972, \text { Telephone }\end{array}$ & $\begin{array}{l}\text { Mostly personal visits in } \\
\text { the } 1984-1993 \text { panels. } \\
\text { Personal visits and phone } \\
\text { in } 1996-2004 \text { panels. }\end{array}$ \\
\hline $\begin{array}{l}\text { Computer Aided } \\
\text { Interviewing }\end{array}$ & Yes & $\begin{array}{l}\text { Yes (beginning in } \\
2003 \text { ) }\end{array}$ & $\begin{array}{l}\text { Yes (beginning in } \\
1994 \text { ) }\end{array}$ & Yes (beginning in 1993) & $\begin{array}{l}\text { Yes (beginning in the } \\
1996 \text { panel) }\end{array}$ \\
\hline Sample Size & $\begin{array}{l}\text { Over } 3 \text { million addresses } \\
\text { surveyed when fully } \\
\text { implemented in } 2005\end{array}$ & $\begin{array}{l}\text { About } 7,800 \text { consumer } \\
\text { units are interviewed } \\
\text { each quarter }\end{array}$ & $\begin{array}{l}\text { Over } 97,000 \\
\text { households in the } \\
2008 \text { survey }\end{array}$ & $\begin{array}{l}\text { Over } 67,000 \text { individuals } \\
\text { interviewed at least } \\
\text { once }\end{array}$ & $\begin{array}{l}20,897 \text { households (1984 } \\
\text { Panel) - 40,188 } \\
\text { households (1996 Panel) }\end{array}$ \\
\hline $\begin{array}{l}\text { Average Time per } \\
\text { Interview }\end{array}$ & & About 65 minutes & & About 30 minutes & $\begin{array}{l}\text { About } 20 \text { minutes } \\
\text { (median) }\end{array}$ \\
\hline $\begin{array}{l}\text { Imputation of Income } \\
\text { Data }\end{array}$ & Yes & $\begin{array}{l}\text { Yes (beginning in } \\
2004 \text { ) }\end{array}$ & Yes & Some & Yes \\
\hline $\begin{array}{l}\text { Household Head or } \\
\text { Householder Provides } \\
\text { Information for All } \\
\text { Family Members? }\end{array}$ & Yes & Yes & Yes & $\begin{array}{l}\text { Yes (except in the } 1976 \\
\text { and } 1985 \text { surveys when } \\
\text { wives were also } \\
\text { interviewed) }\end{array}$ & $\begin{array}{l}\text { Interviewers attempt } \\
\text { interviews with each } \\
\text { family member } 15 \text { years } \\
\text { of age and above }\end{array}$ \\
\hline $\begin{array}{l}\text { Monetary Compensation } \\
\text { for Participation }\end{array}$ & No & No & No & Yes & No \\
\hline
\end{tabular}

*Military personnel living with at least one other civilian adult are also included. 